CHEMUTAI SEGO

CIRCUITARIA E ASSINATURA NEUROQUIMICA DAS PROJEÇÕES ENTRE A

HABENULA LATERAL, O NÚCLEO TEGMENTAL ROSTROMEDIAL E O NÚCLEO

DORSAL DA RAFE

Dissertação apresentada ao Programa de Pós-Graduação em Ciências Morfofuncionais do Instituto de Ciências Biomédicas da Universidade de São Paulo, para obtenção do Título de Mestre em Ciências.

São Paulo

2013 


\section{CHEMUTAI SEGO}

\section{CIRCUITARIA E ASSINATURA NEUROQUIMICA DAS PROJEÇÕES ENTRE A}

HABENULA LATERAL, O NÚCLEO TEGMENTAL ROSTROMEDIAL E O NÚCLEO DORSAL DA RAFE

Dissertação apresentada ao Programa de Pós-Graduação em Ciências Morfofuncionais do Instituto de Ciências Biomédicas da Universidade de São Paulo, para obtenção do Título de Mestre em Ciências.

Área de concentração: Ciências Morfofuncionais

Orientador: Prof. Dr. Jackson Cioni Bittencourt

Versão original 
DADOS DE CATALOGAÇÃO NA PUBLICAÇÃO (CIP)

Serviço de Biblioteca e Informação Biomédica do

Instituto de Ciências Biomédicas da Universidade de São Paulo

Cำ reprodução total

\section{Sego, Chemutai}

Circuitaria e assinatura neuroquímica das projeções entre a habenula lateral, o núcleo tegmental rostromedial e o núcleo dorsal da rafe / Chemutai Sego. -- São Paulo, 2013.

Orientador: Prof. Dr. Jackson Cioni Bittencourt.

Dissertação (Mestrado) - Universidade de São Paulo. Instituto de Ciências Biomédicas. Departamento de Anatomia. Área de concentração: Ciências Morfofuncionais. Linha de pesquisa: Neuroanatomia

Versão do título para o inglês: Circuitry and neurochemical signature of projections between the lateral habenula, the rostromedial tegmental nucleus and the dorsal raphe nucleus.

1. Medicina 2. Anatomia 3. Neuroanatomia I. Bittencourt Prof. Dr. Jackson Cioni II. Universidade de São Paulo. Instituto de Ciências Biomédicas. Programa de Pós-Graduação em Ciências Morfofuncionais III. Título. 


\section{UNIVERSIDADE DE SÃO PAULO \\ INSTITUTO DE CIÊNCIAS BIOMÉDICAS}

Candidato(a): $\quad$ Chemutai Sego.

Título da Dissertação: Circuitaria e assinatura neuroquímica das projeções entre a habenula lateral, o núcleo tegmental rostromedial e o núcleo dorsal da rafe.

Orientador(a): $\quad$ Prof. Dr. Jackson Cioni Bittencourt.

A Comissão Julgadora dos trabalhos de Defesa da Dissertação de Mestrado, em sessão pública realizada a ................................................, considerou
( ) Aprovado(a)
( ) Reprovado(a)

Examinador(a): Assinatura:

Nome:

Instituição:

Examinador(a): Assinatura:

Nome:

Instituição:

Presidente: Assinatura:

Nome:

Instituição: 


\begin{tabular}{|c|c|}
\hline & 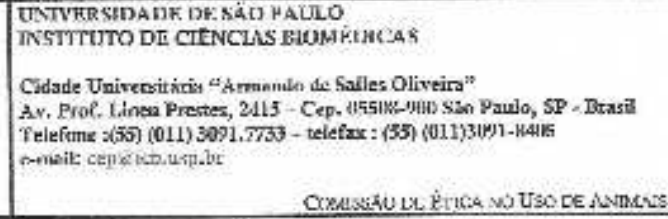 \\
\hline
\end{tabular}

DeCl. CEUA-019/ICB/USP

\author{
DECLARACÃO
}

Em adendo ao Ccrtificadi 070/10/CEUA, datado de 01.07.10? c por solicitayão do Prof. Dr. Jackson Cioni Bíttencourt, responsável pela linha de Posquisa, autorizo a inclusaio da Chemutal Srgo ao Projeto de Pesiluisa

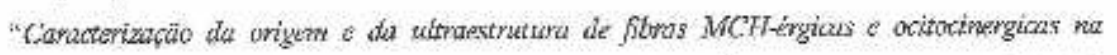

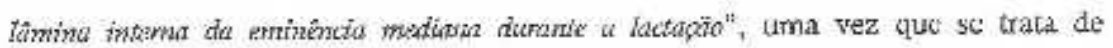
utilizaço di mesma espccie animal e de metudos experimentais similares ao refcrido urtilicado.

São Paulo, 02 de maio de 2011.

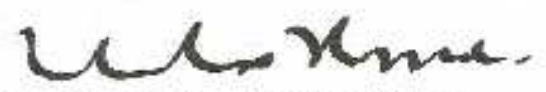

Proi, Dr. Wothan Tavares de Lima Courdcriador da CEUA

ICB/USP 


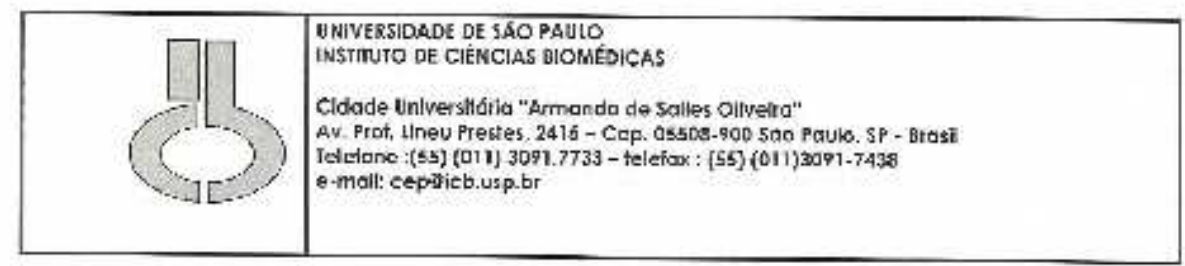

SOLICITACËO PARA INCLUSAO DE ALUMD EM PROTOCOLO APROVADO - CEUA

$\| m a S$,

Prol. Da. Wothon avcres aelima

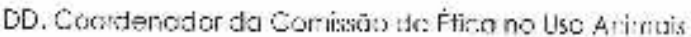

ICBIUS?

Frexodo Senhor.

So icito es merticas necossárias à Comissōo de Ético no Uso de Animais do ICR/LS? puro que scjo inclido o aluno "CHEMUIAI SEGo" ao prolucole do oxpermentocōo animal n'105/08/CEEA comerte do projeto intilucudo "Efeltos do treinamento líslco Intensa e da restrlção alimentar sobre a açăo da leptina medlada pelo hormónio concentrador de melanina no eixo reprodutor de ralos" aprovacto em $19 / 11 / 2008$, sob minho esponscabilidade.

Deciura que nòo nouve alteracāo de melocologia experimental nem dos tócnicos descritos inicialmente quardo da apovaço do retendo proccclo de expormentaça animal. Cstarris centes e de acordo crom as regras acocodcs pela CEJA. Consultamos os "links' ind coddus ne protocolo e corruumetemo nos a proceder con arme as infomaçoes ocul tornecicas, Estarnos cientes de que cas regus adotadas. pela CEUA estōo do acardo com u legislaço naciona e irteracionol vigente.

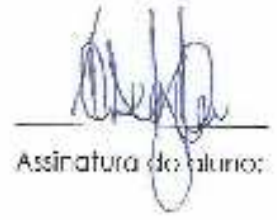

Sé Fuslo. 22\%04/2011

Prof. 2 _

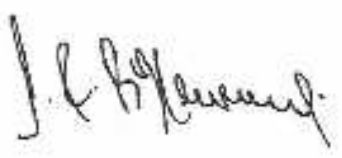

Coorenacor do Lirhu de Pesquisa 
À Cherop 


\section{AGRADECIMENTOS}

Kimaiyo, Pauline e Chepchirchir

Dra. Ana Maria Itezerote, M.D., PhD

Prof. Dr. Jackson Cioni Bittencourt

Prof. Dr. Martin Andreas Metzger

Prof $^{a}$ Dra. Sara-Joyce Shammah-Lagnado

Prof. Dr. José Donato Jr.

A Fundação de Apoio a Pesquisa Do Estado De São Paulo - FAPESP (2011/03292-7) 


\section{RESUMO}

SEGO, C. Circuitaria e assinatura neuroquímica das projeções entre a habenula lateral, o núcleo tegmental rostromedial e o núcleo dorsal da rafe. 2013. $93 \mathrm{f}$. Dissertação (Mestrado em Ciências Morfofuncionais) - Instituto de Ciências Biomédicas, Universidade de São Paulo, São Paulo, 2013.

A habênula lateral (LHb) é uma estrutura epitalâmica diferenciada em uma divisão medial (LHbM) e lateral (LHbL). A LHb recebe robustas aferências principalmente de estruturas do prosencéfalo basal e as suas eferências são, na sua maioria, formadas por projeções descendentes glutamatérgicas para estruturas mesopontinas. O principal alvo da LHb no tegmento mesopontino é um núcleo GABAérgico denominada núcleo tegmental rostromedial (RMTg), atualmente conhecido como o principal mediador da potente influência inibitória exercida pela LHb sobre neurônios dopaminérgicos da área tegmental ventral e substância negra. Interessantemente, o núcleo dorsal da rafe (DR) também recebe projeções de ambos a LHb e o RMTg, e a estimulação elétrica da LHb provoca uma inibição profunda porém transitória em neurônios do DR. Realizamos injeções da leucoaglutinina Phaseolus vulgaris, um traçador anterógrado, em diferentes divisões da LHb e no RMTg. Confirmamos nossos achados através de rastreamento neuronal retrógrado. Investigamos um possível fenótipo GABAérgico dos neurônios do RMTg que projetam para o DR através da combinação de técnicas de rastreamento retrógrado e com hibridização in situ para a enzima GAD-67. Encontramos projeções diretas da LHb para o DR de caráter somente modesto, emergindo da LHbM e direcionadas principalmente para a parte caudal do DR. Em contraste, as projeções do RMTg para o DR foram robustas, emergiam de neurônios enriquecidos em mRNA da GAD-67 e foram focalmente direcionadas para uma subdivisão central do DR que em seguida caracterizamos como pobre em serotonina e rica em neurônios presumidamente glutamatérgicos. Em suma, nossos achados implicam que o RMTg seja um importante intermediário inibitório entre a LHb e o DR.

Palavras-chave: Habenula. Rafe. Serotonina. Tegmento mesopontino. Aversão. 


\begin{abstract}
SEGO, C. Circuitry and neurochemical signature of projections between the lateral habenula, the rostromedial tegmental nucleus and the dorsal raphe nucleus. 2013. 93 p. Masters thesis (Morpho-functional Sciences) - Instituto de Ciências Biomédicas, Universidade de São Paulo, São Paulo, 2013.

The lateral habenula ( $\mathrm{LHb})$ is an epithalamic structure divided into medial (LHbM) and lateral (LHbL) divisions. The LHb receives robust afferents mainly from structures in the basal prosencephalon and emits mainly glutamatergic projections to pontomesencephalic structures. The main target of $\mathrm{LHb}$ projections to the mesopontine tegmentum is the mostly GABAergic rostromedial tegmental nucleus (RMTg), now known to be a major mediator of the LHb's potent inhibitory influence on dopamine-containing neurons of the ventral tegmental area and the substantia nigra. Interestingly, the dorsal raphe nucleus (DR) receives projections from both the $\mathrm{LHb}$ and the RMTg, and LHb stimulation is known to provoke a profound, though transitory inhibition on DR neurons. We therefore re-examined sections from animals that received Phaseolus vulgaris leucoagglutinin injections aimed at different divisions of the $\mathrm{LHb}$ and the RMT, and confirmed our findings through retrograde tracing techniques. We investigated a possible GABAergic phenotype of DR-projecting RMTg neurons by combining retrograde neuronal tracing techniques with in situ hybridization for GAD-67 mRNA. We found only modest direct projections from the $\mathrm{LHb}$ to the DR emerging from the LHbM and directed mainly to the caudal part of the DR. In contrast, RMTg projections to the DR were robust, emerged from neurons enriched in GAD-67 mRNA and were focally directed to a central subdivision of the DR which we characterized as serotonin-poor and rich in presumptive glutamatergic neurons. In conclusion, our findings point to an important role for the RMTg as an inhibitory node between the LHb and the DR.
\end{abstract}

Keywords: Habenula. Raphe. Serotonin. Mesopontine tegmentum. Aversion. 


\section{LISTA DE FIGURAS}

Figura 1 - Fotomicrografia e ilustração semi-esquemática de nível rostrocaudal intermediário pelos complexos habenulares.

Figura 2 - Fotomicrografias de cortes coronais pelo com subdivisões ilustradas (dados obtidos em literatura, e nossos achados).

Figura 3 - Fotomicrografias mostrando locais de injeção de PHA-L em diferentes divisões da $\mathrm{LHb}$ e a marcação retrógrada resultante no DR.....

Figura 4 - llustrações semi-esquemáticas mostrando a distribuição de axônios anterógradamente marcados no DR e VLPAG após injeções de PHA-L em diferentes subdivisões da LHb

Figura 5 - Fotomicrografias de sítios de injeção de CTb e FG representativos no $\mathrm{DR}$ e no $\mathrm{RMTg}$, e marcação retrógrada resultante na LHb.

Figura 6 - llustrações semi-esquemáticas mostrando a distribuição de neurônios retrogradamente marcados na LHb, resultantes de injeções no DR

Figura 7 - Fotomicrografias de sítios de injeção de CTb no DR e marcação retrógrada resultante no RMTg

Figura 8 - llustrações semi-esquemáticas de um sítio de injeção de CTb no DRDCe e a marcação retrógrada resultante.

Figura 9 - Fotomicrografias de cortes coronais pelo tegmento mesopontino ventral duplamente marcados para mRNA da GAD-67 e CTb injetado no DR.

Figura 10 - Fotomicrografias de cortes coronais mostrando uma injeção de PHA-L no RMTg e a marcação anterógrada resultante no DR.

Figura 11 - llustrações semi-esquemáticas mostrando a distribuição de axônios anterógradamente marcados no DR após uma injeção de PHA-L no RMTg.

Figura 12 - Fotomicrografias de cortes coronais marcados para 5-HT no DR mostrando marcação anterógrada após a injeção de PHA-L no RMTg 
e na LHbM

Figura 13 - Fotomicrografias de cortes coronais marcados para VGLUT3 no DR mostrando marcação anterógrada após a injeção de PHA-L no $\mathrm{RMTg}$

Figura 14 - Gráfico de barras divididas mostrando a frequência relativa de neurônios VGLUT3-/5-HT+, VGLUT3+/5HT- e VGLUT3+/5HT+ nas subdivisões do DR

Figura 15 - Box plot mostrando medidas de posição e dispersão dos diâmetros médio de corpos celulares VGLUT3+/5HT- e VGLUT3+/5HT+ em subdivisões do DR.

Figura 16 - llustração esquemática resumindo os principais achados do presente estudo. 


\section{LISTA DE TABELAS}

Tabela 1 - Relação de casos preparados para estudo, mostrando os respectivos locais de injeção de traçadores neuronais......

Tabela 2 - Relação de anticorpos primários utilizados, as respectivas espécies de origem, e as diluições determinadas.

Tabela 3 - Relação de anticorpos secundários utilizados, as respectivas espécies de origem, e as diluições determinadas.

Tabela 4 - Distribuição de neurônios retrógradamente marcados na LHb após a injeção dos traçadores no DR.

Tabela 5 - Composição de populações neuronais VGLUT3+/5-HT+, VGLUT3+/5-HT- ou VGLUT3-/5-HT+ no DR.

Tabela 6 - Medidas-resumo dos diâmetros médio dos neurônios VGLUT3+/5HT- e VGLUT3+/5HT+ no DR 


\section{LISTA DE ABREVIATURAS E SIGLAS}

\begin{tabular}{|c|c|}
\hline $4 \mathrm{~V}$ & quarto ventrículo \\
\hline $5-\mathrm{HT}$ & serotonina \\
\hline $\mathrm{Aq}$ & aqueduto \\
\hline BNST & núcleo intersticial da estria terminal \\
\hline $\mathrm{CeA}$ & núcleo central da amígdala \\
\hline DBB & banda diagonal de Brocá \\
\hline DR & núcleo dorsal da rafe \\
\hline DRC & núcleo dorsal da rafe, parte caudal \\
\hline DRD & núcleo dorsal da rafe, parte dorsal \\
\hline DRDC & DRD, core \\
\hline DRDCe & DRD, parte central \\
\hline DRDSh & DRD, shell \\
\hline $\mathrm{DRL}$ & núcleo dorsal da rafe, asas laterais \\
\hline DRR & núcleo dorsal da rafe, parte rostral \\
\hline DRV & núcleo dorsal da rafe, parte ventral \\
\hline DTgP & núcleo tegmental dorsal, parte pericentral \\
\hline EPn & núcleo entopeduncular \\
\hline $\mathrm{fr}$ & fascículo retroflexo \\
\hline GABA & ácido Y-amino-butírico \\
\hline GPi & Globo pálido, parte interna \\
\hline
\end{tabular}




\begin{tabular}{|c|c|}
\hline IP & núcleo interpeduncular \\
\hline is Rt & formação reticular ístmica \\
\hline LC & lócus cerúleos \\
\hline LDTg & núcleo tegmental laterodorsal \\
\hline $\mathrm{LH}$ & área hipotalâmica lateral \\
\hline $\mathrm{LHb}$ & complexo habenular lateral \\
\hline LHbL & LHb, divisão lateral \\
\hline LHbLMc & subnúcleo magnocelular da LHbM \\
\hline LHbM & LHb, divisão medial \\
\hline LHbMC & subnúcleo central da LHbM \\
\hline LHbMPc & subnúcleo parvocelular da LHbM \\
\hline LPAG & área cinzenta periaquedutal, parte lateral \\
\hline LPO & área hipotalâmica pré-óptica, parte lateral \\
\hline Me5 & núcleo mesocefálico trigeminal \\
\hline $\mathrm{ml}$ & lemnisco medial \\
\hline mlf & fascículo longitudinal medial \\
\hline $\mathrm{MnR}$ & núcleo mediano da rafe \\
\hline MPO & área hipotalâmica pré-óptica, parte medial \\
\hline mPFC & córtex pré-frontal, parte medial \\
\hline PDR & núcleo posterodorsal da rafe \\
\hline PMnR & núcleo paramediano da rafe \\
\hline
\end{tabular}




$\begin{array}{ll}\text { Pn } & \text { núcleos pontinos } \\ \text { PTg } & \text { núcleo tegmental pedúnculopontino } \\ \text { PVP } & \text { núcleo talâmico paraventricular, parte posterior } \\ \text { RLi } & \text { núcleo rostral linear da rafe } \\ \text { RMTg } & \text { núcleo tegmental rostromedial } \\ \text { RRF } & \text { campo retrorubral } \\ \text { Sm } & \text { estria medular do tálamo } \\ \text { SNC } & \text { substância negra, parte compacta } \\ \text { VLPAG } & \text { área cinzenta periaquedutal, parte ventrolateral } \\ \text { VP } & \text { pálido ventral } \\ \text { VTA } & \text { área tegmental ventral } \\ \text { xScp } & \text { decussação do pedúnculo cerebelar superior }\end{array}$




\section{SUMÁRIO}

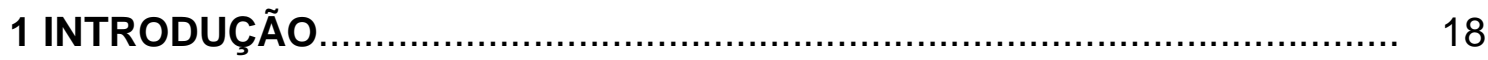

1.10 complexo habenular lateral.................................................. 18

1.1.1 Anatomia e neuroquímica do complexo habenular lateral............... 18

1.1.2 Conectividade do complexo habenular lateral.............................. 20

1.1.2.1 Conexões aferentes do complexo habenular lateral........................... 20

1.1.2.2 Conexões eferentes do complexo habenular lateral........................... 21

1.1.3 Estudos funcionais envolvendo o complexo habenular lateral........ 22

1.20 núcleo tegmental rostromedial.............................................. 23

1.2.1 Anatomia e neuroquímica do núcleo tegmental rostromedial........... 24

1.2.2 Conectividade do núcleo tegmental rostromedial.............................. 25

1.2.2.1 Conexões aferentes do núcleo tegmental rostromedial........................ 25

1.2.2.2 Conexões eferentes do núcleo tegmental rostromedial....................... 26

1.2.3 Estudos funcionais envolvendo o núcleo tegmental rostromedial... 26

1.30 núcleo dorsal da rafe................................................................. 27

1.3.1 Anatomia e fenótipos neuroquímicos encontrados no núcleo dorsal da rafe

1.3.2 Conectividade do núcleo dorsal da rafe.......................................... 28

1.3.2.1 Conexões aferentes do núcleo dorsal da rafe................................... 28

1.3.2.2 Conexões eferentes do núcleo dorsal da rafe................................... 29

1.3.3 Estudos funcionais envolvendo o núcleo dorsal da rafe................ 30

1.3.4 Interações entre o complexo habenular lateral e o núcleo dorsal da rafe.

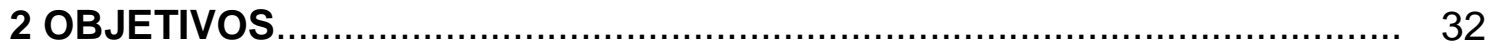

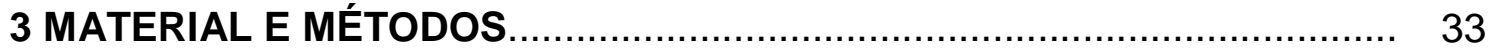

3.1 Animais e intervenções cirúrgicas............................................... 33

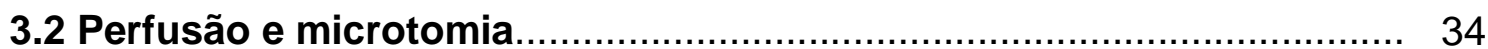

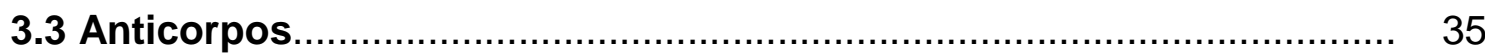


3.4 Marcações de imunoperoxidase ........................................................ 36

3.5 Dupla-Marcação de Imunofluorescência........................................... 37

3.6 Hibridação in situ com imunoistoquimica para traçador retrógrado.

3.7 Análise e registro dos dados........................................................... 39

3.7.1 Aquisição e processamento de imagens............................................. 39

3.7.2 Contagens e medidas de neurônios na LHb e no DR............................ 40

4 RESULTADOS

4.1 Experimentos de rastreamento neuronal anterógrado: projeções da LHb para o DR.

4.2 Experimentos de rastreamento neuronal retrógrado: projeções da LHb para o DR.

4.3 Experimentos de rastreamento retrógrado: projeções do RMTg e outras estruturas pontomesencefálicas para o DR

4.4 Combinação de rastreamento retrógrado do DR com hibridização in situ para GAD-67

4.5 Experimentos de rastreamento neuronal anterógrado: projeções do RMTg para o DR.

4.6 Marcação por dupla-imunofluorescência para PHA-L e 5-HT ou VGLUT3.

5 DISCUSSÃO.

5.1 Considerações metodológicas.

5.2 Topografia das projeções da LHb para o DR.

5.3 Projeções do RMTg e outras estruturas mesopontinas para o DR...... 67

5.4 Fenótipo de neurotransmissores de neurônios no DR nas respectivas regiões alvo da LHb e RMTg.

5.5 Considerações funcionais gerais. 74 REFERÊNCIAS.

ANEXO Confirmação da submissão de artigo ao Journal of Comparative Neurology. 



\section{INTRODUÇÃO}

O conceito de um sistema diencefálico dorsal de condução (SDDC) foi inicialmente formulado por Nauta (1958) ao descrever das vias de projeção do hipocampo e áreas telencefálicas relacionadas para o mesencéfalo no gato. Esta via foi então identificado em todas as espécies vertebradas (CONCHA; WILSON, 2001), sendo evolucionariamente altamente conservado. O SDDC é uma de duas grandes vias paralelas que conectam bilateralmente o telencéfalo basal com o mesencéfalo $\mathrm{e}$ rombencéfalo. A outra grande via é composta pelos componentes descendentes do fascículo tele cefálico medial, e transita ventralmente pela área hipotalâmica lateral (GEISLER, 2008; NAUTA, 1958; STEPHENSON-JONES, 2012; SUTHERLAND, 1982). O SDDC tem de cada lado três componentes: estrias medulares medial e lateral, compostas principalmente por fibras vindas do telencéfalo; os núcleos habenulares bilateralmente pareados, beirando o terceiro ventrículo; e o fascículo retroflexo, composto principalmente por fibras dos núcleos habenulares.

As aves e os mamíferos possuem complexos habenulares medial ( $\mathrm{MHb}$ ) e lateral (LHb) bilateralmente (CONCHA; WILSON, 2001). Os complexos habenulares são inseridos em duas vias de condução essencialmente paralelas, tendo aferências e eferências quase que mutuamente exclusivas (para revisão, veja STEPHENSONJONES, 2012). A MHb se destaca pela morfologia distintiva em preparações com nitrato de prata (RAMON Y CAJAL, 1911) e em cortes histológicos corados pelo método de Nissl (Fig. 1). O presente estudo é focado LHb, portanto as considerações em seguida se limitarão a esta estrutura.

\subsection{0 complexo habenular lateral}

\subsubsection{Anatomia e neuroquímica do complexo habenular lateral}

A LHb historicamente foi dividida em duas partes, medial e lateral, de acordo com suas conexões aferentes (HERKENHAM; NAUTA, 1979). Segundo esta concepção, a parte medial, aferentada por estruturas relacionadas ao cerne límbico, 
teria uma função 'límbica', enquanto a parte lateral, associada principalmente ao núcleo entopeduncular (EPn), teria uma função 'motora' (HERKENHAM; NAUTA, 1979). Estudos mais recentes da cito- e mieloarquitetura, realizados em cortes semifinos com o auxílio de microscopia eletrônica (ANDRES et al., 1999), e marcações imunoistoquimicas em cortes convencionais (GEISLER; ANDRES; VEH, 2003) identificaram dez subnúcleos na LHb. Os cinco subnúcleos da divisão medial (LHbM) possuem em comum pequenas células, a neurópila clara, e uma quantidade relativamente pequena de fibras mielinizadas. A divisão lateral (LHbL) possui cinco subnúcleos com células grandes e uma quantidade grande de fibras mielinizadas (ANDRES et al., 1999). As fibras de ambas as divisões contribuem para a raiz lateral do fascículo retroflexo.

A maioria dos neurônios da LHb expressa mRNA do transportador vesicular do glutamato do tipo 2 (AIZAWA et al., 2012; BRINSCHWITZ et al., 2010), que sabidamente confere o potencial de transmissão glutamatérgica (FREMEAU et al., 2001). Uma importante exceção é o subnúcleo oval da LHbL, em que se concentram a grande maioria dos neurônios que expressam mRNA da isoforma de 67kDa da descarboxilase do glutamato (GAD-67; BRINSCHWITZ et al., 2010), enzima limitante na síntese do neurotransmissor GABA.

Figura 1 - Fotomicrografia de corte coronal corado pelo método de Nissl e ilustração semi-esquemática de corte coronal num nível rostrocaudal intermediário pelos complexos habenulares à direita.

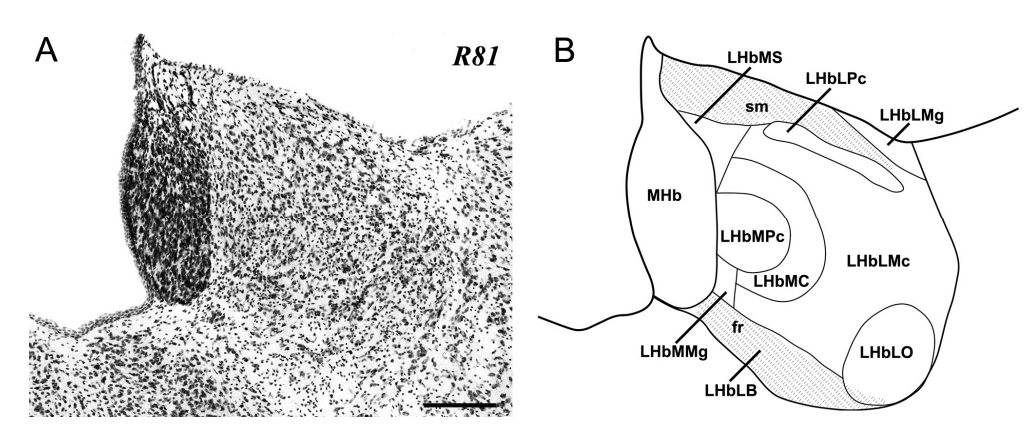




\subsubsection{Conectividade da $\mathrm{LHb}$}

\subsubsection{Conexões aferentes do complexo habenular lateral}

De forma geral, as principais aferências da $\mathrm{LHb}$ rato se originam no EPn (homólogo do segmento interno do globo pálido, GPi, em primatas), da área hipotalâmica lateral (LH), da área pré-óptica lateral (LPO) e do pálido ventral (PV) (HERKENHAM; NAUTA, 1977; KOWSKI et al., 2008; PARENT et al., 1981a, 2001; RAJAKUMAR; ELISEVICH; FLUMERFELT, 1993). No rato, o GPi é de longe a principal aferência da LHb, com virtualmente todos os neurônios contribuindo para estas projeções. Já no gato, a LH e a LPO são as principais aferências da LHb. Em primatas, há uma segregação espacial de neurônios do GPi de acordo com seus alvos. Neurônios que se projetam para a LHb ocupam posições rostral e periférica no GPi, regiões recebem aferências preferencialmente do estríado ventral (PARENT; LEVESQUE; PARENT, 2001; RAJAKUMAR; ELISEVICH; FLUMERFELT, 1993). As aferências da LHb nos primatas são nitidamente organizadas em um contínuo de células que se estende do PV pela LPO, LH e GPi (HERKENHAM; NAUTA, 1977). Projeções menores para a $\mathrm{LHb}$ se originam do córtex pré-frontal medial (mPFC) (GREATREX; PHILLIPSON, 1982), da banda diagonal de Brocá DBB), do shell do núcleo accúmbens (NAc) e do núcleo intersticial da estria terminal (BNST) (HERKENHAM; NAUTA, 1977; PARENT; GRAVEL; BOUCHER, 1981a; STEPHENSON-JONES, 2012).

Conforme mencionado acima, o padrão de aferenciação foi usado para dividir a LHb em partes medial e lateral. A LHbM recebe aferências preferencialmente da DBB, do BNST e da parte ventromedial do VP. A LH e o GPi, por outro lado, se projetam preferencialmente para a LHbL. Por fim, a LPO envia projeções topográficas para ambas as divisões da LHb (para revisões, veja GEISLER, 2008; HIKOSAKA et al., 2008; LECOURTIER; KELLY, 2007).

A $\mathrm{LHb}$ recebe um pequeno contingente de aferências ascendentes do mesencéfalo e rombencéfalo via o fascículo retroflexo (HERKENHAM; NAUTA, 1977). As principais são: axônios dopaminérgicos dos núcleos interfascicular e 
paranigral da área tegmental ventral (VTA) (PHILLIPSON; PYCOCK, 1982; SKAGERBERG; LINDVALL; BJÖRKLUND, 1984), serotonérgicos dos núcleos dorsal (DR) e mediano da rafe (MnR) (VERTES, 1991), colinérgicos do núcleo tegmental laterodorsal (LDT) (CORNWALL; COOPER; PHILLIPSON, 1990) e noradrenérgicos do lócus cerúleos (LC) (GOTTESFELD, 1983).

\subsubsection{Conexões eferentes do complexo habenular lateral}

A LHb dá origem a projeções caudais que atingem estruturas monoaminérgicas e colinérgicas do mesencéfalo e rombencéfalo (ARAKI; MCGEER; KIMURA, 1988; HERKENHAM; NAUTA, 1979). Entre estes os principais alvos de projeção da LHb são a substância negra (SN) e a VTA (ARAKI; MCGEER; KIMURA, 1988), os núcleos tegmentais laterodorsal e pedúnculopontino (PTg) (SEMBA; FIBIGER, 1992) e os núcleos dorsal (DR) e mediano da rafe (BEHZADI et al., 1990; KALÉN; KARLSON; WIKLUND, 1985).

A LHb emite poucas projeções para o prosencéfalo. Projeções modestas para a LH, LPO e o septo ventrolateral se originam na parte medial da LHb e a maior parte se dirige rostralmente pela estria medular (HERKENHAM; NAUTA, 1979). O restante segue pelo fascículo retroflexo e então ascende pelo fascículo prosencefálico medial.

Alguns dos estudos hodológicos clássicos da LHb mostraram uma área no tegmento mesopontino ventral, adjacente à decussação do pedúnculo cerebelar superior (xscp), como alvo de projeções maciças da LHb (ARAKI; MCGEER; KIMURA, 1988; HERKENHAM; NAUTA, 1979; KIM, 2009), ou como fonte notável de projeções para a VTA e SN (FERREIRA et al., 2008). Esta área foi recentemente descrita como o principal campo terminal da projeção habenulo-mesopontina e caracterizada (JHOU et al., 2009a; KAUFLING et al., 2009) sendo então denominada o núcleo tegmental rostromedial (RMTg) por Jhou et al. (2009a). 


\subsubsection{Estudos funcionais envolvendo o complexo habenular lateral}

A LHb é envolvida em diversas funções fisiológicas, entre estas o sono, a resposta a diferentes estressores, o comportamento maternal e reprodutivo e a ritmicidade circadiana, bem como em funções cognitivas como a memória de referências espaciais (para revisões, veja GEISLER, 2008; HIKOSAKA, 2010; STEPHENSON-JONES, 2012). No entanto, a LHb tem atraído interesse na última década devido ao seu envolvimento em estados de estresse patológicos (para revisões, veja HIKOSAKA, 2010; LECOURTIER; KELLY, 2007).

Especificamente, a LHb é criticamente implicada na sinalização de diversos tipos de eventos aversivos. A estimulação nociva periférica induz a expressão de cFos em neurônios da LHb (GAO; HOFFMAN; BENABID, 1996; NAGAO et al., 1993; STAMATAKIS; STUBER, 2012). Outros estressores físicos como a imobilização (CHASTRETTE; PFAFF; GIBBS, 1991) a hipóxia crônica intermitente (SICA et al., 2000) e choques incontroláveis (AMAT et al., 2001) também induzem a expressão de c-Fos principalmente na parte medial da LHb. Em humanos, a participação da LHb na sinalização e punidores foi constatada através de neuroimagem em sujeitos saudáveis executando tarefas operantes (ULLSPERGER; VON CRAMON, 2003).

Estas funções da LHb foram então investigadas sistematicamente pelo grupo de Hikosaka (2007, 2009, 2010a, b, c, 2011). Numa série de estudos eletrofisiológicos realizados em macacos executando tarefas pavlovianas, o grupo mostrou que neurônios da LHb são excitados logo após a apresentação de punidores, a omissão de reforçadores esperados, e a apresentação dos estímulos condicionados a estes eventos. Do contrário, os mesmos neurônios foram inibidos pela apresentação contingente de reforçadores e pelos estímulos condicionados que os precedem.

Estudos de modelos animais também apontam para um papel chave da $\mathrm{LHb}$ na eclosão de distúrbios do tipo depressivo. A LHb possui nível significantemente elevado de atividade metabólica em ratos recém-nascidos com predisposição genética para apresentar comportamentos do tipo desamparo (SHUMAKE; EDWARDS; GONZALEZ-LIMA, 2003). Importantemente, um elegante estudo que 
combinou lesões extensas da LHb com um protocolo comportamental usado para induzir o desamparo aprendido (para revisão, veja MAIER; WATKINS, 2005) mostrou que a projeção LHb-DRC é necessária para a manifestação das sequelas comportamentais (AMAT et al., 2001). Ademais, uma vez instalado o desamparo aprendido, lesões (THORNTON; EVANS; HARRIS, 1985; YANG et al., 2008) ou a estimulação cerebral profunda (MENG et a., 2011) da LHb foram suficientes para reverter estas sequelas.

Por fim, estudos translacionais têm sustentado estes achados pré-clínicos. Em pacientes portadores da depressão maior submetidos a um protocolo experimental de depleção dietética do triptofano com o intuito de induzir recaídas (SMITH; FAIRBURN; COHEN, 1997), o uso de tomografia por emissão de pósitrons mostrou um aumento significante na atividade neural da LHb, positivamente correlacionada com a severidade dos sintomas depressivos induzidos (MORRIS et al., 1999). Interessantemente, houve co-variação negativa significante entre a atividade na LHb e no DR. Consequentemente, a LHb já é um dos alvos da estimulação cerebral profunda para o tratamento da depressão maior refratária (SARTORIUS et al., 2007). O envolvimento da LHb na sinalização de erros pode contribuir para a fisiopatologia das psicoses como a esquizofrenia, em que sujeitos apresentam defeitos na incorporação de erros informativos para guiar a seleção de ações e a solução de problemas (SHEPARD, 2006), e portanto persistem em comportamentos mal adaptativas (LECOURTIER; KELLY, 2005).

\subsection{0 núcleo tegmental rostromedial}

Conforme foi mencionado acima, o principal campo terminal das projeções da $\mathrm{LHb}$ para o tronco encefálico é um núcleo no tegmento mesopontino ventral até recentemente considerada parte da VTA. Foi identificada como um agrupamento de neurônios de caráter GABAérgico que projeta para a VTA/SN (FERREIRA et al., 2008; JHOU, 2005) e acumula seletivamente a variante $\triangle$ FosB do gene fos após a administração aguda de psicoestimulantes (PERROTTI et al., 2005), e choques elétricos na pata (JHOU, 2005). Pela localização adjacente ao polo posterior da VTA, 
foi considerada uma parte da VTA e denominada 'cauda da VTA' (KAUFLING et al., 2009) e 'cauda posterior da VTA' (FERREIRA et al., 2008), até a sua caracterização pelo grupo de JHOU (2009a, b), que o denominou "núcleo tegmental rostromedial" (JHOU et al., 2009a, b).

\subsubsection{Anatomia e neuroquímica do núcleo tegmental rostromedial}

Neurônios que acumulam variantes do gene fos após a administração de psicoestimulantes (KAUFLING et al., 2010; PERROTTI et al., 2005) ou choques elétricos na pata (JHOU, 2005) se encontram num agregado com formato arredondado na extremidade caudal e ventral da VTA propriamente dita, dorsolateral ao IP rostral, mergulhados nas fibras da xscp. Em níveis mais caudais, este agregado adquire o formato de uma lentilha e ocupa posições gradualmente mais dorsais e laterais, acompanhando a dorsalização das fibras da xscp. Em cortes histológicos corados pelo método de Nissl, esta região não apresenta nenhuma característica distinta do tegmento adjacente. No entanto, os neurônios apresentam forte imunomarcação pela GAD-67, e expressam fortemente a mRNA da GAD-67 (JHOU et al., 2009a; KAUFLING et al., 2009). Outros marcadores que delineiam a estrutura são o receptor $\mu$-opióide e a somatostatina (JHOU et al., 2009a).

Neurônios fos-imunorreativos se encontram em densidades decrescentes na medida em que se afastam do agregado central, bem como os neurônios retrógradamente marcados após a injeção de traçadores na VTA/SNC (GONÇALVES; SEGO; METZGER, 2012; JHOU et al., 2009a; KAUFLING et al., 2009). Outras estruturas tegmentais como o LDT e o PTg possuem esta característica de partes 'compacta' e 'dissipata' (CORNWALL; COOPER; PHILLIPSON, 1990) e receberam o status de núcleo devido à fidelidade e a seletividade de imunorreatividade para determinados marcadores e a organização de suas conexões (veja GAHR, 1997).

Assim, por consenso, os critérios que definem o RMTg como núcleo são: aferências robustas da LHb, projeção maciça para a VTA/SNC, o fenótipo GABAérgico dos neurônios e o acúmulo de variantes do gene fos após a 
administração de psicoestimulantes e choques elétricos (para revisão, veja BARROT; BOURDY, 2012).

\subsubsection{Conectividade do núcleo tegmental rostromedial}

\subsubsection{Conexões aferentes do núcleo tegmental rostromedial}

Bem como no caso da VTA propriamente dita, a maioria das aferências para o RMTg vem de neurônios que formalmente fazem parte de diversas estruturas, porém ocupam uma coluna paramediana contínua que se estende do córtex pré-frontal até o tronco encefálico (JHOU et al., 2009a; KAUFLING et al., 2009). Desta forma, o RMTg recebe aferências de grande parte das estruturas telencefálicas e diencefálicas que projetam para a VTA (para revisão, veja GEISLER, 2008). Áreas corticais que se projetam para o RMTg incluem o córtex frontal associativo, o córtex pré-límbico, o córtex peduncular dorsal e o córtex cingulado anterior. Outras áreas telencefálicas que aferentam o RMTg são a região septal, o estriado-pálido ventral (e não o dorsal) e partes da amígdala estendida. O RMTg recebe projeções importantes de diversas regiões hipotalâmicas, a saber, o LH, LPO, a zona incerta, área préóptica medial, núcleos mamilares e supra-mamilares. A LHb é sua única aferência epitalâmica.

O RMTg também recebe projeções importantes de outras estruturas do tronco encefálico. Estas vêm da própria VTA e da SN, das camadas profundas do colículo superior, da área periaquedutal cinzenta (PAG), do PTg e do DR e MnR. No entanto, o fenótipo neuroquímico destas projeções permanece desconhecido exceto no caso do DR onde, segundo Kaufling et al. (2009), 99\% dos neurônios que projetam para o RMTg não são imunomarcados para a hidroxilase do triptófano (TPH), a enzima limitante na síntese da serotonina (5-HT). 


\subsubsection{Conexões eferentes do núcleo tegmental rostromedial}

As projeções do RMTg para o telencéfalo são muito mais restritas do que suas aferências, sendo direcionadas principalmente para o estriado-pálido dorsal e a parte rostral do NAc. Alguns axônios do RMTg com arborizações modestas se encontram na substancia innominata e no BNST, partes da amigdala estendida, no PV e num contínuo que se estende da LH, pelo LPO até o hipotálamo posterior (JHOU et al., 2009a; para revisão, veja BARROT; BOURDY, 2012).

De longe a maior parte das projeções do RMTg aparentemente é direcionada para os principais agrupamentos dopaminérgicos (VTA/SNC), serotonérgicos (DR/MnR), colinérgicos (PTg/LDT) e noradrenérgicos (LC) (JHOU et al., 2009a; LAVEZZI; PARSLEY; ZAHM, 2012) do tronco encefálico.

\subsubsection{Estudos funcionais envolvendo o núcleo tegmental rostromedial}

Neurônios do RMTg, bem como os da LHb, são ativados por processos aversivos do tipo punição e extinção (HONG et al., 2011; JHOU, 2005; JHOU et al., 2009b; STAMATAKIS; STUBER, 2012). Por outro lado, são também ativados por psicoestimulantes como anfetaminas e cocaína, considerados reforçadores (JHOU et al., 2009b; KAUFLING et al., 2010; PERROTTI et al., 2005).

As quantificações realizadas nestes estudos mostram que 80 a $85 \%$ dos neurônios fos-imunorreativos após a administração de choques elétricos na pata se projetam para a VTA e/ou expressam mRNA da GAD-67 (JHOU et al., 2009b) e que dos neurônios que se projetam para a VTA, 66\% são GAD-67 imunorreativas (KAUFLING et al., 2010). As quantificações de Lavezzi, Parsely e Zahm (2012) mostram que cerca de $50 \%$ dos neurônios do RMTg que projetam para o DR acumulam c-Fos após a administração aguda da metanfetamina. Assim, os psicoestimulantes podem, através do RMTg, modular potentemente a atividade neuronal tanto na VTA quanto no DR.

Outras drogas com potencial de abuso também afetam a atividade eletrofisiológica de neurônios do RMTg, e consequentemente dos neurônios 
dopaminérgicos da VTA. Enquanto o agonista canabinóide WIN55212-2 (LECCA et al., 2011) e a morfina (JALABERT et al., 2011; LECCA et al., 2011; MATSUI; WILLIAMS, 2011) suprimem as taxas de disparo destes neurônios, a nicotina (LECCA et al., 2011) provoca uma excitação robusta. Resta verificar se estes psicofármacos também modulam a neurotransmissão do RMTg para o DR.

\subsection{0 núcleo dorsal da rafe}

Entre 60 e 75\% da 5-HT no encéfalo se encontra nos nove principais núcleos serotonérgicos (para revisão, veja HÖRNUNG, 2003). Outras populações de neurônios serotonérgicos ocupam a formação reticular lateral e medial (STEINBUSCH, 1981; WIKLUND; LÉGER; PERSSON, 1981). No rato, 50\% dos neurônios serotonérgicos do encéfalo se encontram no DR, (DESCARRIES et al., 1982), enquanto que em humanos esta proporção chega a 60\% (BAKER et al., 1991).

\subsubsection{Anatomia e neuroquímica do núcleo dorsal da rafe}

O DR é inserido na área cinzenta central do mesencéfalo e da ponte rostral, ventral ao aqueduto cerebral e do quarto ventrículo, (BAKER et al., 1991; DAHLSTROEM; FUXE, 1964; DESCARRIES et al., 1982). Critérios citoarquitetônicos foram utilizados para definir as seguintes divisões do DR pelo eixo rostro-caudal: a parte rostral (DRR), a parte intermediaria e a parte caudal (DRC). A parte intermediaria é por sua vez subdividida nas seguintes partes: a ventral (DRV) na linha média da porção mais ventral da área cinzenta central; a interfascicular também na linha média, entre os núcleos trocleares e os fascículos longitudinais mediais; a dorsal (DRD), abarcando o aqueduto cerebral; e as asas laterais (DRL) (para revisão, veja HORNUNG, 2003).

A visão tradicional 5-HT-centrada do DR (veja JACOBS; FORNAL, 1991) deu lugar ao reconhecimento de uma grande heterogeneidade neuroquímica, com uma abundância de neurônios não-serotonérgicos e neurônios não exclusivamente 
serotonérgicos. O DRD especificamente foi recentemente reexaminado através das técnicas de dupla-imunofluorescência e de hibridização in situ de mRNA para o transportador vesicular do glutamato tipo 3 (VGLUT3) e a enzima TPH (HIOKI et al., 2010). Os resultados deste estudo levaram a uma subdivisão do DRD em duas partes: uma periférica denominada 'shell' (DRDSh, veja Fig. 2), que apresenta 75\% de neurônios que expressam mRNA do VGLUT3 e não da TPH; e uma dorsomedial denominada 'core' (DRDC), onde neurônios que expressam mRNA da TPH são preferencialmente distribuídos (HIOKI et al., 2010).

O DR possui populações de neurônios imunorreativos para o fator liberador da corticotrofina (CRF), a substancia $P$ e a hidroxilase da tirosina, enzima limitante na síntese da dopamina (BAKER et al., 1992; CHARARA; PARENT, 1998; COMMONS, 2009; HIOKI et al., 2010; THOMAS et al., 2003). Estas populações são distribuídas preferencialmente em diferentes subdivisões do DR, sugerindo uma compartimentalização funcional (para revisão, veja HALE; LOWRY, 2011; HALE; SHEKHAR; LOWRY, 2012).

\subsubsection{Conectividade do núcleo dorsal da rafe}

\subsubsection{Conexões aferentes do núcleo dorsal da rafe}

Embora nenhuma aferência seja exclusiva para qualquer uma das subdivisões do DR, quase todas apresentam relativa especificidade na localização dos campos terminais no DR (AMAT et al., 2005; GONÇALVES et al., 2009; LEE et al., 2003; PEYRON et al., 1998).

O DRD e o DRC compartilham a maioria de suas aferências, a saber, o BNST, $\mathrm{CeA}, \mathrm{LHb}$ e as divisões infra- e pré-límbicas do mPFC, todas estas estruturas implicadas no controle de comportamentos do tipo ansioso (SINGEWALD; SALCHNER; SHARP, 2003). A LHb especificamente é considerada por vários autores como a principal fonte de aferências para o DR (BEHZADI et al., 1990; LEE et al., 2003; PEYRON et al., 1998). No entanto, o grosso das projeções da LHb para 
o DR é direcionado para o DRC e para a parte dorsomedial do DR, posteriormente denominada por Hioki et al. (2010) o DRD (LEE et al., 2003).

A região do DRL/VLPAG recebe aferências rombencefálicas de áreas associadas ao controle autonômico, como PBN e NTS, bem como aferências prosencéfalicas de áreas implicadas no controle autonômico e afetivo como o BNST, CeA, MPO, LH e mPFC (para revisão, veja HALE; SHEKHAR; LOWRY, 2012).

Entre estas, as aferências sabidamente excitatórias incluem a LHb, IP, mPFC, córtex cingulado, LDT e algumas divisões hipotalâmicas (BEHZADI et al., 1990; LEE, 2003). As aferências GABAérgicas para o DR foram investigadas por Gervsoni et al. (2000), empregando uma combinação de rastreamento neuronal retrógrado a partir do DR com imunoistoquimica para GAD-67. Neste estudo, o maior número de neurônios CTb+/GAD-67+ foi encontrado na $\mathrm{LH}$ seguida pelo $\mathrm{LPO}$, a $\mathrm{PH}$ e a parte reticulada da SN (SNR). Gervasoni et al. (2000) ilustraram entre seus desenhos esquemáticos uma agrupamento de neurônios CTb+/GAD-67+ que ocupa uma posição no tegmento mesencéfalico ventral, dorsolateral ao IP (veja Fig. 8C), e que pode representar a estrutura hoje conhecida como RMTg.

\subsubsection{Conexões eferentes do núcleo dorsal da rafe}

O DR e o MnR juntos são as principais fontes de 5-HT para o prosencéfalo (STEINBUSCH, 1981; VERTES, 1991), embora também se projetem para o tronco encefálico (VERTES; KOCSIS, 1994).

As projeções do DRD e DRC são direcionadas reciprocamente para o mPFC, os núcleos amigdalóides basolateral e central, o BNST, NAc, DH e PAG dorsolateral. Já as eferências da região DRL/VLPAG são direcionadas principalmente para a parte dorsolateral da PAG, a medula rostral ventrolateral e para a $\mathrm{LH}$, áreas envolvidas em comportamentos ativos de defesa (para revisão, veja HALE; SHEKHAR; LOWRY, 2012). 


\subsubsection{Estudos funcionais envolvendo o núcleo dorsal da rafe}

O agonista GABA-A muscimol (LIU; IKEMOTO, 2007) e o antagonista GABAB baclofen (SHIN; IKEMOTO, 2010) são auto-administrados dentro do DR, e facilmente induzem a preferência espacial condicionada, ambos os paradigmas sendo modelos da fase consumatória do comportamento de dependência química. Consistente com estes dados comportamentais, cerca de $50 \%$ de neurônios do RMTg que projetam para o DR expressam c-Fos logo após a administração de psicoestimulantes (LAVEZZI; PARSLEY; ZAHM, 2012). Assim, aferências GABAérgicas para o DR, possivelmente do RMTg, provavelmente contribuem para processos de aprendizagem por reforçamento positivo (para revisão, veja CUNNINGHAM, 1996).

Por outro lado, o DR também tem sido implicado em processos aversivos. Neurônios do DR são fasicamente ativados logo após choques nocivos (SCHWEIMER; BRIERLEY; UNGLESS, 2008). Ademais, lesões de vias serotonérgicas impedem a expressão de efeitos da punição (THIEBOT; HAMON; SOUBRIÉ, 1983). Estressores inescapáveis (choques elétricos na pata ou na cauda) induzem a expressão de c-Fos no DR, e entre todas as subdivisões do DR o DRC é a que mais manifesta imunorreatividade (GRAHN et al., 1999; GREENWOOD et al., 2003). Esta ativação neuronal no DRC é necessária para a manifestação do desamparo aprendido (MAIER; GRAHN; WATKINS, 1995). Estes dados experimentais fundamentam a teoria da oponência dopamina-5-HT na recompensa (DAW; KAKADE; DAYAN, 2002). Apoio pela teoria serotonérgica da punição foi obtido num estudo em que a depleção plasmática de triptófano em humanos saudáveis amplificou a previsão de punições, e não de recompensas (COOLS; ROBINSON; SAHAKIAN, 2008).

Dando continuidade aos estudos da representação subcortical de recompensas, Nakamura, Matsumoto e Hikosaka (2008) mostraram que neurônios do DR em primatas (com status serotonérgico não confirmado) respondem à demora na entrega de recompensas contingentes, e têm sua atividade tonicamente 
modificada de acordo com a magnitude da recompensa entregue. Diferente da LHb e do RMTg, o DR aparentemente não codifica erros na previsão de recompensas.

\subsection{Interações entre o complexo habenular lateral e o núcleo dorsal da rafe}

A maioria dos estudos eletrofisiológicos envolvendo a estimulação elétrica da LHb com registros de célula única no DR mostram que a estimulação da LHb silencia transitoriamente a atividade espontânea de neurônios do DR (PARK, 1987; STERN et al., 1981; WANG; AGHAJANIAN, 1977). Outros estudos (FERRARO et al., 1996; FERRARO et al., 1997) demonstraram um efeito ora excitatório, ora inibitório, a depender da subdivisão do DR registrada. A funcionalidade destes achados foi demonstrada através de técnicas de microdiálise que constataram modificações dos níveis teciduais de 5-HT no núcleo caudado, na SN e no próprio DR (REISINE et al., 1984) e no hipocampo (FERRARO et al., 1997) durante a estimulação elétrica da $\mathrm{LHb}$.

Por fim, lesões da LHb abortam a elevação de níveis de 5-HT no DR durante e após a exposição a estressores escapáveis e não-escapáveis (AMAT et al., 2001), impedindo a instalação do desamparo aprendido. 


\section{OBJETIVOS}

Devido aos fatos citados acima, o objetivo principal do presente projeto foi investigar em detalhe através de métodos de rastreamento neural e métodos de imunoistoquímica e hibridização in situ as projeções diretas e indiretas entre a LHb e o DR. Para esse propósito exploramos os seguintes objetivos específicos:

Investigar a organização das projeções RMTg-DR e LHb-DR através de uma revisão de casos arquivados em que foi injetado um traçador anterógrado no RMTg ou em diferentes divisões da LHb, e confirmar estas projeções através de injeções de um traçador retrógrado em diferentes distritos do DR.

Investigar, através de injeções de dois diferentes traçadores retrógrados no DR e na VTA, seguido por revelação dos traçadores com técnicas de dupla imunofluorescência, se existem neurônios no RMTg e na LHb que projetam para ambos os alvos.

Investigar, através de uma combinação metódica de injeção de um traçador retrógrado no DR com hibridação in situ para a glutamato descarboxilase (GAD), a enzima limitante na síntese do GABA, uma possível assinatura GABAérgica da projeção do RMTg para o DR.

Investigar, no DR, através de técnicas de dupla imunofluorescência para o traçador anterógrado e 5-HT ou o transportador vesicular do tipo 3 do glutamato, o fenótipo neuroquímico dos neurônios nas divisões alvo das projeções da $\mathrm{LHb}$ e do RMTg. 


\section{MATERIAL E MÉTODOS}

\subsection{Animais e intervenções cirúrgicas}

Os experimentos foram realizados em ratos albinos (Rattus norvegicus, linhagem Wistar), adultos, criados no Biotério do Instituto de Ciências Biomédicas I USP, mantidos sob temperatura constante $\left(21 \pm 2{ }^{\circ} \mathrm{C}\right)$, iluminação em ciclo de 12 horas e água e ração ad libitum. Somente ratos machos foram utilizados nos experimentos. Todos os procedimentos seguiram o protocolo aprovado pela Comissão de Ética em Experimentação Animal (CEEA) do ICB - USP (Protocolo no 061/04) e os princípios adotados pelo Colégio Brasileiro de Experimentação Animal e pelo "Guia de Uso de Animais em Pesquisas" do National Institutes of Health (NIH publicação No. 80-23, revisão 1996). Desde o início do presente estudo, 14 animais foram utilizados, sendo o restante do material já presente em nossos arquivos.

Os ratos foram anestesiados via subcutânea com um coquetel anestésico cetamina (Syntec, Hortolândia, Brasil; $5 \mathrm{mg} / 100 \mathrm{~g}$ peso corporal), acepromazina (Univet, São Paulo, Brasil) 0.04 mg/100 g pc) and xilazina (Syntec; 1 mg/100 g pc). Diluídos em água destilada. Foram posicionados num aparelho estereotáxico (Kopf), os crânios expostos e pequenas trepanações realizadas com uma broca odontológica para permitir o acesso a estruturas cerebrais com pipetas de vidro.

O primeiro grupo de ratos recebeu injeções unilaterais de CTb em diferentes distritos do DR. Um segundo grupo de ratos recebeu injeções unilaterais do PHA-L ou no RMTg ou na LHb. Outro grupo recebeu injeções do FG no DR e do CTb na VTA. As injeções na VTA foram direcionadas à porção rostral do subnúcleo parabraquial pigmentado (PBP). Os traçadores foram injetados por meio de uma corrente elétrica positiva pulsada (10 segundos "on"/10 segundos "off") de $4 \mu \mathrm{A}$ (no caso de PHAL e FG) e $5 \mu \mathrm{A}$ (no caso de CTb). As coordenadas estereotáxicas para as injeções foram inicialmente adquiridas do atlas de Paxinos e Watson (1998) e refinadas empiricamente. Após a injeção, a micropipeta (diâmetro interno da ponta de 20 a $30 \mu \mathrm{m}$ ) foi mantida em posição por pelo menos 3 minutos, e uma corrente 
negativa de $2 \mu \mathrm{A}$ foi aplicada para minimizar fluxo retrógrado do traçador pelo rastro da pipeta.

De uma biblioteca de 101 casos injetados com traçadores no DR, na VTA, no RMTg e na LHb, selecionamos para análise os casos listados na Tabela 1 abaixo. Três casos em que as injeções não foram bem sucedidas (casos 76, 79 e 93) foram processados pela técnica de dupla imunofluorescência para 5-HT e VGLUT3.

Tabela 1 - Grupos experimentais

\begin{tabular}{lll}
$\begin{array}{l}\text { Traçadores injetados e sítios } \\
\text { de injeção }\end{array}$ & $\begin{array}{l}\text { Total } \\
\mathbf{n}=\mathbf{2 1}\end{array}$ & Casos analisados \\
\hline PHA-L - LHb & 6 & ${ }^{*} \mathrm{R} 71,{ }^{*} \mathrm{R} 77,{ }^{*} \mathrm{R} 81,{ }^{*} \mathrm{R} 82, \mathrm{R} 113, \mathrm{R} 114$ \\
PHA-L - RMTg & 3 & $\mathrm{R} 85, \mathrm{R} 86, \mathrm{R} 87$ \\
CTb - DR & 9 & $\mathrm{R} 51, \mathrm{R} 66, \mathrm{R} 90, \mathrm{R} 95, \mathrm{R} 96, \mathrm{R} 97, \mathrm{R} 114$, \\
FG - DR & $\mathrm{RL} 13, \mathrm{RL} 23$ \\
CTb - RMTg & 3 & ${ }^{*} \mathrm{R} 63,{ }^{*} \mathrm{R} 64,{ }^{*} \mathrm{R} 65$ \\
\hline
\end{tabular}

* Asteriscos indicam os casos que foram preparados para um estudo anterior (GONÇALVES; SEGO; METZGER, 2012).

\subsection{Perfusão e microtomia}

Após uma sobrevida de 10 dias no caso das injeções de PHA-L e 7 dias no caso das injeções de CTb e FG, os ratos foram profundamente anestesiados e perfundidos transcardiacamente com $90 \mathrm{ml}$ de solução de salina a 0,9\%, seguida de uma solução de $500 \mathrm{ml}$ de formaldeído a 4\% (adquirido a partir de paraformaldeídeo aquecido a 60-65 ${ }^{\circ} \mathrm{C}$ ) em tampão fosfato de sódio (PB) a $4{ }^{\circ} \mathrm{C}$. Os cérebros, removidos dos seus envoltórios, foram pós-fixados por 4 horas, crioprotegidos em solução de sacarose a $20 \%$ em PB a $4{ }^{\circ} \mathrm{C}$. Na manhã seguinte, os encéfalos foram 
seccionados no plano coronal em micrótomo de congelamento, em $40 \mu \mathrm{m}$, e coletados em quatro séries em PB.

\subsection{Anticorpos}

Todos os anticorpos primários que foram usados no presente projeto (ver Tabela 2) já foram extensivamente utilizados em estudos prévios e suas especificidades reveladas no cérebro de rato por análise por Western Blot, e em experimentos de pré-incubação com seu imunógeno. Todos os anticorpos primários e secundários (ver Tabela 3), também já foram testados em nosso laboratório e suas diluições ótimas já foram determinadas.

Tabela 2 - Relação de anticorpos primários utilizados.

\begin{tabular}{lllll}
\hline \multirow{2}{*}{ Antígeno } & Animal & Fabricante & \multicolumn{2}{c}{ Diluições } \\
\cline { 4 - 5 } & & & IP & IF \\
\hline VGLUT3 & Porco de índia & Millipore, Temecula, CA & $1: 1.500$ \\
5-HT & coelho & ImmunoStar, Hudson, WI & $1: 80.000$ & $1: 40.000$ \\
PHA-L & coelho & DAKO, Carpinteira, CA & $1: 5.000$ & $1: 2.500$ \\
CTb & cabra & List & $1: 10.000$ & $1: 10.000$ \\
FG & coelho & Chemicon & $1: 5.000$ & $1: 2.500$ \\
\hline
\end{tabular}


Tabela 3 - Relação de anticorpos secundários utilizados, as respectivas espécies de origem, e as diluições determinadas.

\begin{tabular}{|c|c|c|c|c|}
\hline \multirow{2}{*}{ Anticorpo } & \multirow{2}{*}{ Animal } & \multirow{2}{*}{ Fabricante } & \multicolumn{2}{|c|}{ Diluições } \\
\hline & & & IP & IF \\
\hline $\begin{array}{l}\text { IgG anti-Coelho conjugado a } \\
\text { DyLight } 488\end{array}$ & Burro & $\begin{array}{l}\text { Jackson } \\
\text { Immunoresearch, West } \\
\text { Grove, PA }\end{array}$ & & $1: 200$ \\
\hline $\begin{array}{l}\text { IgG anti-Cabra conjugado a DyLight } \\
594\end{array}$ & Burro & Jackson & & $1: 200$ \\
\hline $\begin{array}{l}\text { IgG anti-Camundongo conjugado a } \\
\text { DyLight } 488\end{array}$ & Burro & Jackson & & $1: 200$ \\
\hline IgG anti-Coelho biotinilado & Cabra & Vector & $1: 200$ & \\
\hline IgG anti-Camundongo biotinilado & Cavalo & Vector & $1: 200$ & \\
\hline IgG anti-Cabra biotinilado & Burro & Jackson & $1: 4.000$ & \\
\hline $\begin{array}{l}\text { IgG anti-Porco da índia } \\
\text { conjugado a CY3 }\end{array}$ & Burro & Jackson & & $1: 400$ \\
\hline
\end{tabular}

\subsection{Marcações de imunoperoxidase}

As etapas de lavagem e incubação foram realizadas em cortes imersos em solução a temperatura ambiente; divergências são mencionadas. No caso de cortes destinados para incubação com anticorpos contra o traçador FG, estes foram prétratados com 1\% boroidreto de sódio (Sigma, Deisenhofen, Alemanha) em PB (10 minutos), seguido de lavagem em PB e pré-incubação em 1\% H2O2 em PB contendo $10 \%$ metanol (10 - 15 minutos). Os cortes foram lavados novamente várias vezes em PB e depois pré-incubados durante 30 minutos em PB contendo soro normal a $2 \%$ (Jackson) proveniente da espécie em que foi gerado o anticorpo secundário. Os cortes foram então incubados durante 72 horas a $4{ }^{\circ} \mathrm{C}$ com soluções dos respectivos anticorpos primários em PB contendo soro normal a 1\% proveniente da espécie em que foi gerado o anticorpo secundário e Triton X-100 a 0,3\%. Os 
cortes foram lavados novamente em PB e depois incubados durante 2 horas nos respectivos anticorpos secundários biotinilados (Veja Tabela 3 acima). Após várias lavagens em $\mathrm{PB}$, os cortes foram incubados por duas horas num kit $A B C$ ( $A B C$ Elite Kit, Vector Laboratories, Burlingame, CA). Após lavagem exaustiva em PB, o produto da reação de peroxidase foi visibilizado pelo procedimento de glicose oxidase (ITOH et al., 1979) e o 3,3'-diamenobenzidine (DAB) tetra-hidrocloreto sem metal como cromógeno (para demais detalhes, veja SHAMMAH- LAGNADO et al., 1999). Após uma ultima lavagem em $\mathrm{PB}$, os cortes foram montados em lâminas previamente submersas numa solução de gelatina alúmen-cromo. Para intensificação da marcação, as lâminas foram finalmente mergulhadas em uma solução de tetróxido de ósmio a 0,05\% por um período de 15 a 20 segundos e depois desidratadas em concentrações crescentes de etanol, transferidos para xilene e cobertas com DPX (Sigma). Tanto CTb (LUPPI et al., 1990) quanto PHA-L (GERFEN; SAWCHENKO, 1984) foram processados pelos métodos de imunoperoxidase como descrito acima. Somente os passos de préincubação no boreto de sódio e no $\mathrm{H} 2 \mathrm{O} 2$ foram omitidos. No caso do PHA-L, a solução bloqueadora com soro normal a $2 \%$ foi omitida e os cortes foram incubados diretamente na solução do anticorpo primário em PB, contendo leite desnatado a 10\% (Nestlé) e Triton X-100 a 0,3\%.

\subsection{Dupla-marcação de Imunofluorescência}

Os cortes destinados para ensaios de imunofluorescência (IF) foram prétratados como descrito acima e incubados durante 72 horas a 4 num "cocktail" de dois anticorpos primários em PB contendo $1 \%$ soro normal de burro (NDS) e 0,3\% Triton X-100. Usamos as seguintes combinações de anticorpos primários: antiFG/anti-CTb e anti-5-HT/anti VGLUT3. As respectivas diluições são mostradas na Tabela 2. Os cortes foram em seguida lavados em PB e incubados durante 2 horas num segundo "cocktail" contendo dois anticorpos secundários. Usamos as combinações de anticoelho DyLight488/anti-cabra DyLight594 e anti-coelho DyLight488/anti-porco da índia CY3, todas diluídas em PB contendo 1\% soro normal de burro (NDS). Após lavagens finais exaustivas em 0,05M Tris-HCL, os cortes foram 
montados em lâminas microscópicas submersas previamente em uma solução de gelatina alumén-cromo, cobertas com lamínulas usando uma solução "slowfade" (Molecular Probes) e finalmente seladas com esmalte de unha. Vários conjuntos de controles foram realizados, inclusive a omissão de um ou ambos os anticorpos primários, a omissão de um dos anticorpos secundários e a troca dos fluoróforos em relação aos diferentes marcadores.

\subsection{Hibridizações in situ com sonda ${ }^{35}$ S-GAD-67 combinadas com detecção imunoistoquímica de CTb}

Os procedimentos de anestesia e perfusão dos ratos cujo tecido era destinado para experimentos de hibridação in situ (HIS) foram idênticos aos dos outros grupos com a exceção da solução fixadora. Estes animais foram perfundidos com solução de salina a 0,9\%, seguido de formaldeído a $4 \%$ (obtido a partir de paraformaldeídeo aquecido a 60-65 ${ }^{\circ}$ ) em tampão borato (pH 9,5 a $4{ }^{\circ} \mathrm{C}, \pm 900 \mathrm{ml}$ durante 25 minutos). Os cérebros foram retirados dos seus envoltórios, pós-fixados na mesma solução fixadora durante 1 hora e crioprotegidos pernoite a $4{ }^{\circ} \mathrm{C}$ em $0,1 \mathrm{M} \mathrm{PB}, \mathrm{pH} 7,4$, contendo $20 \%$ sacarose preparado com água tratada com dietil pirocarbonato (DEPC). Foram em seguida cortados em plano frontal em micrótomo de congelamento a $40 \mu \mathrm{m}$. 4 séries de cortes foram coletadas em solução anticongelante (glicerol a 20\% e etilenoglicol a 30\% em DEPC-PB) e armazenadas a $-20{ }^{\circ} \mathrm{C}$. Todos os procedimentos de HIS a partir da $\mathrm{m}$ icrotomia foram realizados em ambientes, equipamentos e soluções livres de RNAse.

Cortes de encéfalos de ratos que receberam injeções de CTb no DR foram lavados com PBS tratado com DEPC, pH 7,0 durante uma hora e em boroidreto de sódio (Sigma) a 0,1\% (em DEPC-PBS durante 15 minutos. Os cortes foram então incubados durante 10 minutos em anidrido acético (Merck, Darmstadt, Alemanha) em trietanolamina a 0,1M. A ribossonda da AD- $67{ }^{35}$ S-marcada foi gerada a partir de templados de cDNA como descrita por Elias et al. (2001). Os plasmídios GAD-67 foram gentilmente cedidos por Drs. N. Tillakaratne and J. C. Bittencourt (Universidade de California, Los Angeles, CA, EUA, and Universidade de São Paulo, 
São Paulo, Brasil). Sondas cRNA foram diluidas a $10^{6} \mathrm{cpm} / \mathrm{ml}$ em tampão de hibridização e aplicadas aos cortes. A solução foi constituida de formamida a $50 \%$, Tris-HCl a 10 mM (Fisher Scientific, Fair Lawn, NY), DNA de esperma de salmão (Sigma), tRNA de levedura (Sigma) a 0,01\%, ditiotretiol a $10 \mathrm{mM}$ (Amresco, Solon, $\mathrm{OH})$, sulfato de dextran a $10 \%, \mathrm{NaCl}$ a $0,3 \mathrm{M}$, EDTA a $1 \mathrm{mM}(\mathrm{pH} 8,0)$ e a solução de Denhardt a $1 \times$ (Amresco). Os cortes foram hibridizados por uma noite a $50{ }^{\circ} \mathrm{C}$. No dia seguinte, os tecidos foram lavados 4 vezes em cloreto de sódio/citrato de sódio (4XSSC) e foam incubados em RNAse A (Roche Diagnostics, Mannheim, Germany) diluida em $\mathrm{NaCl}$ a $0,5 \mathrm{M}$, Tris- $\mathrm{HCl}$ a $10 \mathrm{mM}$, pH8,0 e EDTA a $1 \mathrm{mM}$ durante 30 minutos a $37^{\circ} \mathrm{C}$. Os cortes foram transferidos para banhos de astringência em 0,1 XSSC durante 60 minutos a $55^{\circ} \mathrm{C}$. Em seguida, os cortes foram incubados durante 48 horas em anticorpos anti-CTb (1:5.000) e processados pelo método de imunoperoxidase como decrito acima, usando DAB como cromógeno.

Os cortes foram montados em laminas SuperFrost (Fisher Scientific) e desidratados em concentrações crescentes de etanol. Após secar, as laminas foram colocadas em caixas de filmes radiograficos com filme BMR-2 (Kodak, Rochester, NY) durante 2 dias. As laminas foram então imersas em emulsão fotografica NTB2 (Kodak), secas e guardadas em caixas de lâmina com dessecante e embrulhadas em papel alumínio a $4^{\circ} \mathrm{C}$ durante 16 dias. As lamina s foram reveladas com revelador D-19 (Kodak), desidratadas em concentrações crescentes de etanol, clareadas em xilenos e cobertas com lamínulas usando o meio de montagem DPX (Sigma-Aldrich).

\subsection{Análise e registro dos dados}

\subsubsection{Aquisição e processamento de imagens}

Os cortes marcados pelas técnicas de IP e IP/HIS foram examinados ao microscópio óptico de campo claro e escuro com microscópio Zeiss Axioimager A1 (Zeiss, Muenchen, Alemanha) enquanto os cortes marcados pela técnica de IF foram examinados com o mesmo microscópio sob iluminação de epifluorescência. Fotomicrografias digitais foram adquiridas com uma câmera digital AxioCam HRc 
(Zeiss) e analisadas com uso do software Axiovision (Zeiss), que permite a aquisição de imagens de canais de fluorescência separados e uma superposição subseqüente destas imagens.

O processamento das imagens foi realizado com o software Adobe Photoshop (Versão 7.0; Adobe Systems Inc., Mountain View, CA). Baseamos a nomenclatura usada neste estudo no atlas de Paxinos e Watson (2007) com poucas exceções. Adotamos adicionalmente nomenclatura e abreviações já tradicionalmente aceitas e inseridas na literatura internacional sobre o assunto, como o termo RMTg como definido por JHOU et al (2009a, b) e a nomenclatura dos sub-núcleos da LHb é adotada de VEH e colaboradores (ANDRES et al., 1999; GEISLER; ANDRES; VEH, 2003). Finalmente, a subdivisão do DR como proposta por Hioki et al. (2010) foi adotada com o importante acréscimo da DRD central (DRDCe).

\subsubsection{Contagens e medidas na LHb e no DR}

A quantificação de neurônios retrógradamente marcados resultantes de injeções de traçador retrógrado na DR foi realizada em imagens com objetivo 10x no caso de cortes processados pela técnica de imunoperoxidase. Somente corpos celulares nitidamente em foco foram considerados para análise. Para a LHb, selecionamos três casos com injeções de CTb em diferentes distritos do DR. Em cada caso, selecionamos três cortes através do eixo rostro-caudal do representativos de níveis rostral, intermediário e caudal foram selecionados para esta análise. Desenhamos os cortes histológicos ilustrando a distribuição de neurônios retrogradamente marcados em cada subnúcleo, à direita e à esquerda, encima de microfotografias com a ajuda do software Canvas (ACD Systems, Victoria, Canada). As contagens de neurônios em cada caso foram realizadas a partir destes desenhos, somando o número total em cada subnúcleo entre os três níveis. Os dados foram tabelados com a ajuda do software Microsoft Excel (Versão 2010, Microsoft Corporation) e os gráficos desenhados com o mesmo software.

Em três animais foram quantificados e medidos neurônios serotonérgicos e glutamatérgicos em cortes imunomarcados para 5-HT e para VGLUT3 
respetivamente, através da técnica de dupla imunofluorescência. Entre todas as isoformas de transportadores vesiculares de glutamato o VGLUT3 é o mais comum expresso no DR (COMMONS, 2009; HIOKI et al., 2010). Em cada caso, foram analisados dois cortes coronais num nível rostrocaudal intermediário do DR localizado entre 7,80 mm e 8,04 mm posterior ao bregma, $160 \mu \mathrm{m}$ distantes entre si. A quantificação e as medidas de neurônios simples ou duplamente marcados foram realizadas em imagens num formato de 1388 x 1040 pixels, adquiridas com objetiva 20x, com a ajuda do software Axiovision (Zeiss). Somente corpos celulares nitidamente em foco foram considerados para análise e classificados como simples ou duplamente marcados. Os dados foram tabelados com a ajuda do software Microsoft Excel. Foram então somadas as contagens de corpos celulares em cada subnúcleo do DR nos dois níveis do DR entre os três casos. Calculamos a frequência relativa de neurônios de cada fenótipo neuroquímico em cada distrito do DR, dividindo o número de neurônios de cada fenótipo pelo total de neurônios VGLUT3+/5-HT+, VGLUT3+/5-HT- e VGLUT3-/5-HT+ contados naquele distrito. Os dados foram ilustrados em forma de um gráfico de barras divididas.

Para as medidas do diâmetro dos corpos celulares, foram considerados adequados somente aqueles neurônios cujos núcleos e corpos celulares eram nitidamente visíveis e em foco. Após a classificação dos neurônios como simples ou duplamente marcados, selecionamos aqueles que eram adequados para a medida do corpo celular. Com a ajuda do software Axiovision (Zeiss), foi medido o diâmetro maior e menor em cada célula. O tamanho médio do corpo celular foi obtido pelo cálculo da média entre o diâmetro maior e menor para cada neurônio. Os dados foram tabelados separadamente para cada fenótipo neuroquímico em cada subnúcleo do DR, com a ajuda do software Microsoft Excel. Depois, juntamos os cálculos do tamanho médio de corpo celular entre os dois níveis selecionados e entre os três casos. Medidas resumo (média, desvio padrão, quartis e range) para cada distrito foram calculadas e apresentadas em forma de tabelas. A partir destas tabelas foram desenhados dois gráficos: um box plot mostrando as medidas de dispersão para cada grupo, e um gráfico de barras mostrando as médias dos diversos grupos. 


\section{RESULTADOS}

Figura 2 - Fotomicrografias mostrando subdivisões do núcleo dorsal da rafe (DR) em um nível rostrocaudal intermediário.
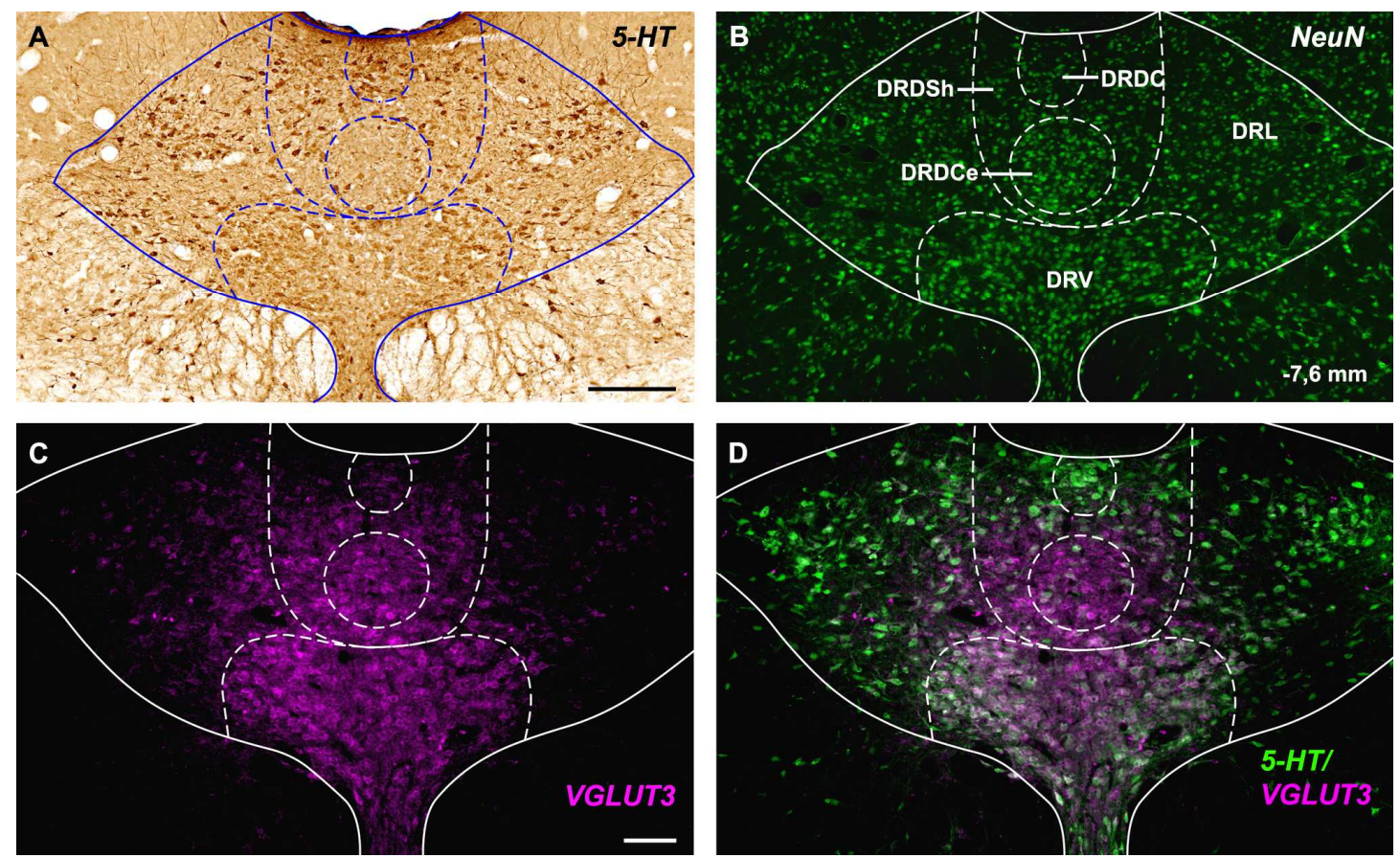

A, B: Cortes adjacentes marcados para serotonina (5-HT) e NeuN. C, D: Marcação por dupla-imunofluorescência para 5-HT (verde) e o transportador vesicular do tipo 3 do glutamato (VLGUT3; magenta) ilustrando o canal separado para 5-HT (verde) e VGLUT3 (magenta) e a imagem mesclada (D). Observe que uma subregião central da parte dorsal do DR (DRDCe) pode ser caracterizada como pobre em 5-HT e rica em neurônios nãoserotonérgicos que expressam VLGUT3. Para abreviaturas, veja lista. Barra $=200 \mu \mathrm{m}$ em A (também se aplica a B); $100 \mu \mathrm{m}$ em C (também se aplica a D). 


\subsection{Experimentos de rastreamento neuronal anterógrado: projeções da LHb para o DR}

Frente a evidências de que a LHb é composta por diversas subdivisões (ANDRES et al., 1999; GEISLER; ANDRES; VEH, 2003) que projetam de maneira topográfica para o tronco encefálico (GONÇALVES; SEGO; METZGER, 2012; KIM, 2009), injeções do traçador anterógrado PHA-L foram direcionadas para diferentes áreas ao longo do eixo médio-lateral da LHb. Todas as seis injeções analisadas neste estudo foram restritas à $\mathrm{LHb}$ e não envolveram a $\mathrm{MHb}$. A maioria destas injeções era semelhante, com um foco contendo um número variável de neurônios fortemente corados, circundado por marcação difusa de fundo. Dois casos foram selecionados como protótipos para ilustrar a marcação anterógrada no DR (Fig. 3). Caso 81 teve uma injeção pequena centrada na porção mais medial da LHbM (Fig. $3 A$ ), enquanto o caso 82 teve uma injeção maior que envolveu a maior parte da LHbL (Fig. 3B).

Em todos os casos, a marcação pelo PHA-L foi bilateral, com pouco menos fibras marcadas no hemisfério contralateral. A injeção no caso 81 envolvendo os subnúcleos marginal, parvocelular (LHbMPc) e central (LHbMC) da LHbM (CASO 81; Fig 3A), resultou em esparsa marcação anterógrada no DRR e moderada marcação em níveis intermediários pelo DR. Estas fibras foram espalhadas em todas as subregiões do DR (Fig. 4A). Muitas destas fibras exibiam pouca arborização e poucas varicosidades. No entanto, alguns axônios ricamente arborizados e varicosos com aparência de campos terminais foram observados no DRV e nas asas laterais. A densidade de axônios PHA-L+ aumentou gradualmente na região mediana do DR (Fig. 4B) até, entre cerca de $8,5 \mathrm{~mm}$ e $9,0 \mathrm{~mm}$ posterior ao bregma, um campo terminal proeminente (Figs. 4A', 4A") com vários axônios profusamente arborizados e numerosos varicosidades (Fig. $3 A^{\prime}$ ) foi observado no DRC. Ademais, diversos campos terminais pequenos e descontínuos foram observados no MnR (Fig. 3A').

Uma injeção de PHA-L com extensão maior no caso 82 (Fig. 3B), centrada no subnúcleo magnocelular da LHbL (LHbLMc) foi selecionada como representativa de injeções na LHbL. Neste caso, assim como em outros casos que não envolveram 
LHbM, os poucos axônios PHA-L-marcados observados em todas as subdivisões do DR foram dispersos e pouco ramificados e varicosos (Figs. 3B', 4B-B"). Extremamente raros no $D R R$, estes axônios ocorreram com mais frequência no $D R$ intermediário (Fig. 4B), diminuindo progressivamente em níveis caudais. Importantemente, ao contrário da injeção no caso 81, o DRC foi quase desprovido de marcação para PHA-L nos casos com injeções na LHbL (Fig. 4B") 
Figura 3 - Fotomicrografias mostrando injeções de PHA-L centradas da divisão medial (LHbM; caso 81; A) e no subnúcleo magnocelular (LHbLMc; caso 82; B) da divisão lateral ( $\mathrm{LHbL}$ ) da habenula lateral (LHb) e a marcação retrógrada resultante no DR.
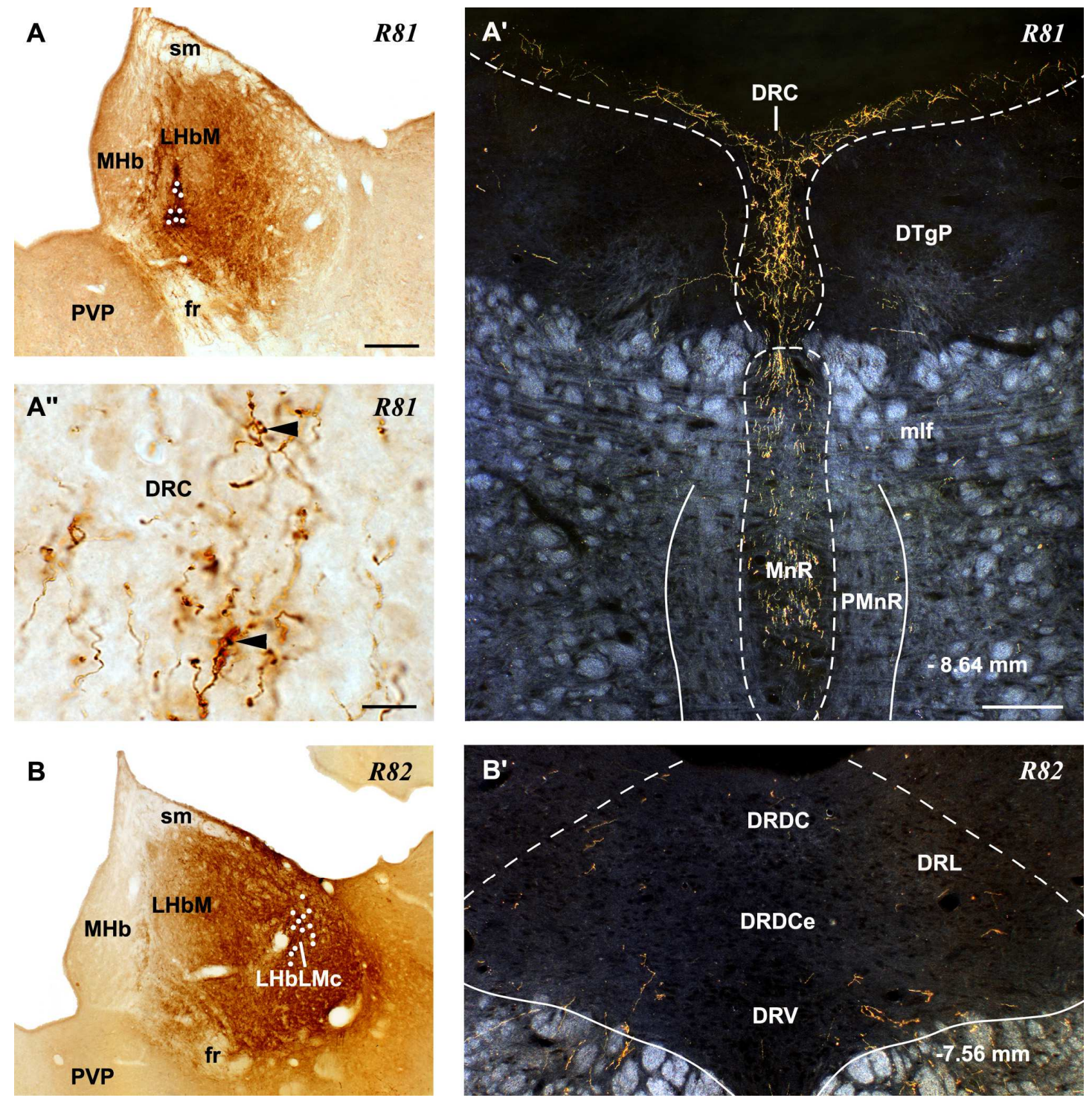

A', A": Fotomicrografia em baixo e maior aumento de marcação anterógrada na parte caudal do DR (DCR) resultante da injeção mostrada em A. Observa a marcação densa com característica de campo terminal no DRC, com muitos axônios marcados exibindo varicosidades e ramificações terminais (cabeças de seta em A"). B': marcação anterógrada esparsa num nível rostrocaudal intermediário pelo DR, resultante da injeção extensa mostrada em B. Pontos brancos indicam posições de neurônios impregnados pelo PHA-L que marcam o foco dos sítios de injeção. Para abreviaturas: veja lista. Barra $=200 \mu \mathrm{m}$ em $A$ (também aplica a B); $150 \mu \mathrm{m}$ em A' (também aplica a B'); 10 m em A". 
Figura 4 - A-B': Ilustrações semi-esquemáticas mostrando a distribuição de axônios anterógradamente marcados no DR e na área cinzenta periaquedutal após injeções de PHA-L na LHbM (A-A"; caso 81) e na LHbLMc (BB"; caso 82).
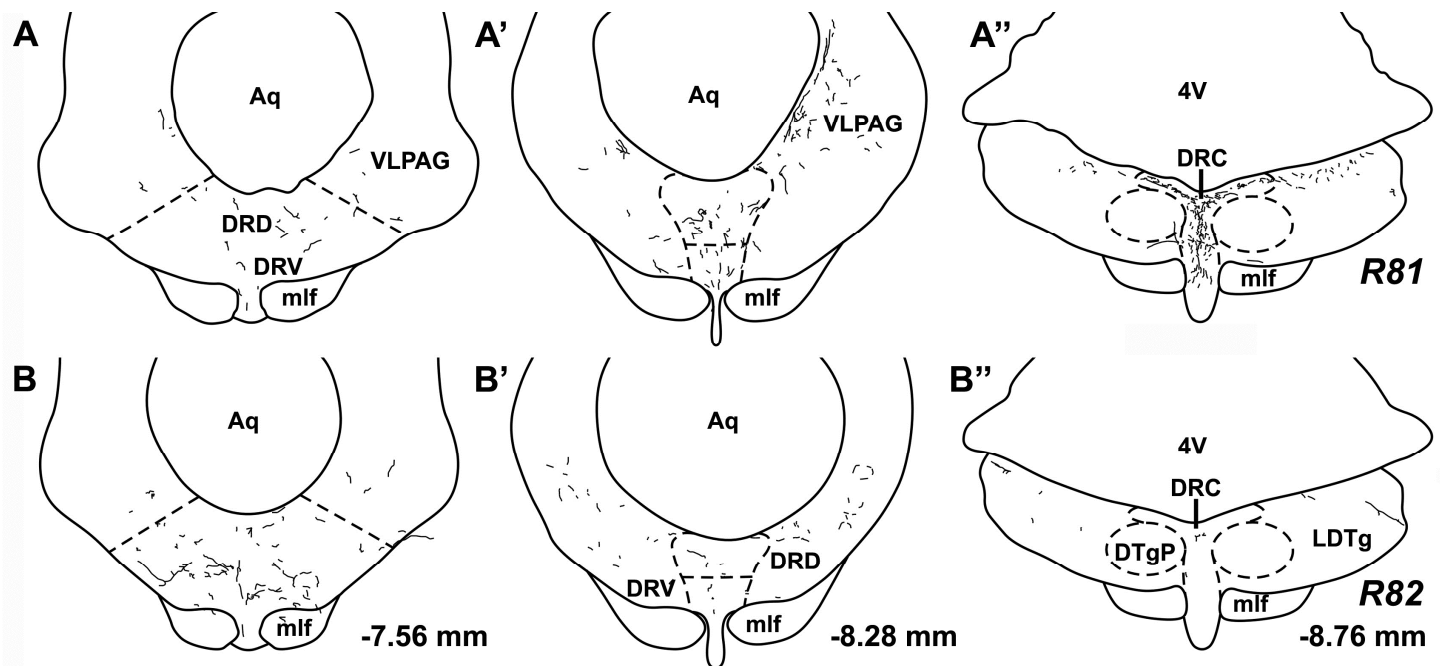

Cortes são apresentados numa sequencia rostrocaudal e os respectivos sítios de injeção são mostrados na Figura 2. Observe que o DRC foi densamente marcado após injeções de PHAL na LHbM mas não na LHbL. Para abreviaturas, veja lista. 


\subsection{Experimentos de rastreamento neuronal retrógrado: projeções da LHb para o DR}

Para confirmar que o DR recebe projeções topograficamente organizadas da $\mathrm{LHb}$, os traçadores retrógrados CTb ou FG foram depositados ao longo do eixo rostrocaudal do DR num outro grupo de ratos. Alguns animais receberam, além disso, uma injeção de traçador retrógrado no RMTg. No total de 18 injeções de CTb e 3 de FG no DR, 12 (9 CTb, 3 FG, veja Tabela 1) foram restritas ao DR e resultaram em marcações retrógrados robustas bilateralmente na LHb, sem nenhuma marcação na MHb. Injeções de CTb e FG no DR foram semelhantes, com um foco intensamente corado, circundado por um halo periférico restrito ao DR. Em alguns casos a periferia da injeção ligeiramente abarcou o VLPAG. Injeções comparáveis dos dois traçadores resultaram numa distribuição geral semelhante de marcação retrógrada na $\mathrm{LHb}$ e em outras estruturas no cérebro. As injeções de CTb foram melhor definidas do que as do FG, que no entanto produziram um numero total maior de neurônios retrógradamente marcados em regiões correspondentes.

Três casos (Casos 64, 65 e 95) foram selecionados para ilustrar nossos achados (Figs. 5, 6; Tabela 4). Caso 95 recebeu uma injeção de CTb centrada num nível dorsal do DRC. A marcação retrógrada no caso 95 foi quase inteiramente restrita à LHbM, e dentro da LHbM, a um agregado celular proeminente que ocupa as partes mais centrais dos subnúcleos LHbMPc e LHbMC, cujas populações neuronais se assemelham citoarquitetônicamente e neuroquímicamente. Sem coloração para TH e/ou o receptor tipo B do GABA, não foi possível delimitar os subnúcleos LHbMPc e LHbMC dos outros adjacentes (GEISLER; ANDRES; VEH, 2003). Para os propósitos do presente estudo, neurônios encontrados na parte central da região medial da LHb, e que respondem aos critérios citoarquitetônicos descritos por Geisler, Andres e Veh (2003) foram considerados integrantes de um complexo subnuclear LHbMPc/LHbMC. Do contrário, a LHbL inteira foi quase desprovida de neurônios retrógradamente marcados (Fig. 5', 6C'). Caso 64 teve uma injeção centrada num nível intermediário do $\mathrm{DR}$, envolvendo primariamente 0 DRDCe e o DRV (Fig. 5B). Como no caso 95, um agregado proeminente de 
neurônios FG-marcados foi encontrado no complexo subnuclear LHbMPc/LHbMC. No entanto, nos casos 64 e 65, encontramos um número considerável de neurônios retrógradamente marcados na LHbL, especificamente na LHbLMc e na margem externa da LHbL (Fig. 5B', 6A",B”). Tabela 4 mostra a proporção de neurônios CTbmarcados no complexo subnuclear LHbMPc-LHbMC em relação ao numero total observado na LHbM, e a proporção de neurônios observados na LHbM em relação ao numero total de neurônios observados na LHb.

Tabela 4 - Distribuição de neurônios retrógradamente marcados na LHb após a injeção do traçador CTb no DR em níveis rostrocaudais intermediários (Casos 64 e 65) e no DRC (Caso 95).

\begin{tabular}{|c|c|c|c|}
\hline Casos analisados & Caso 64 & Caso 65 & Caso 95 \\
\hline Complexo LHbMPc- & $81 \%$ & $84 \%$ & $78 \%$ \\
\hline \multicolumn{4}{|l|}{ LHbMC/LHbM } \\
\hline LHbM/LHb & $49 \%$ & $59 \%$ & $84 \%$ \\
\hline
\end{tabular}

O caso 64 e mais dois casos (casos 63 e 65, não mostrados) também receberam injeções de CTb no RMTg (Fig. 6C). Para verificar de neurônios individuais da LHb enviam projeções colaterais para o DR e o RMTg, analisamos cortes destes casos processados pela técnica de dupla-imunofluorescência para FG e CTb. No geral, estes casos vividamente ilustram que as projeções da LHb para o DR e o RMTg são topograficamente organizadas e essencialmente segregadas (Fig. $\left.6 C^{\prime}\right)$. Estes casos replicaram nossos achados num estudo prévio (GONÇALVES; SEGO; METZGER, 2012), em que mostramos que a maior parte das projeções da LHb para o RMTg emerge da LHbL. Em todos os casos, neurônios que projetam para ambos o DR e o RMTg foram poucos e dispersos. 
Figura 5 - A-C': Fotomicrografias representativas de sítios de injeção de CTb $(A, C)$ e FG (B) centrados no DRC (A; caso 95), DRDCe/DRV (B; caso 64) e no núcleo tegmental rostromedial ( $\mathrm{C}$; caso 64$)$, e a marcação retrógrada resultante na $\left.\mathrm{LHb} 9 \mathrm{~A}^{\prime}, \mathrm{B}^{\prime}, \mathrm{C}^{\prime}\right)$.
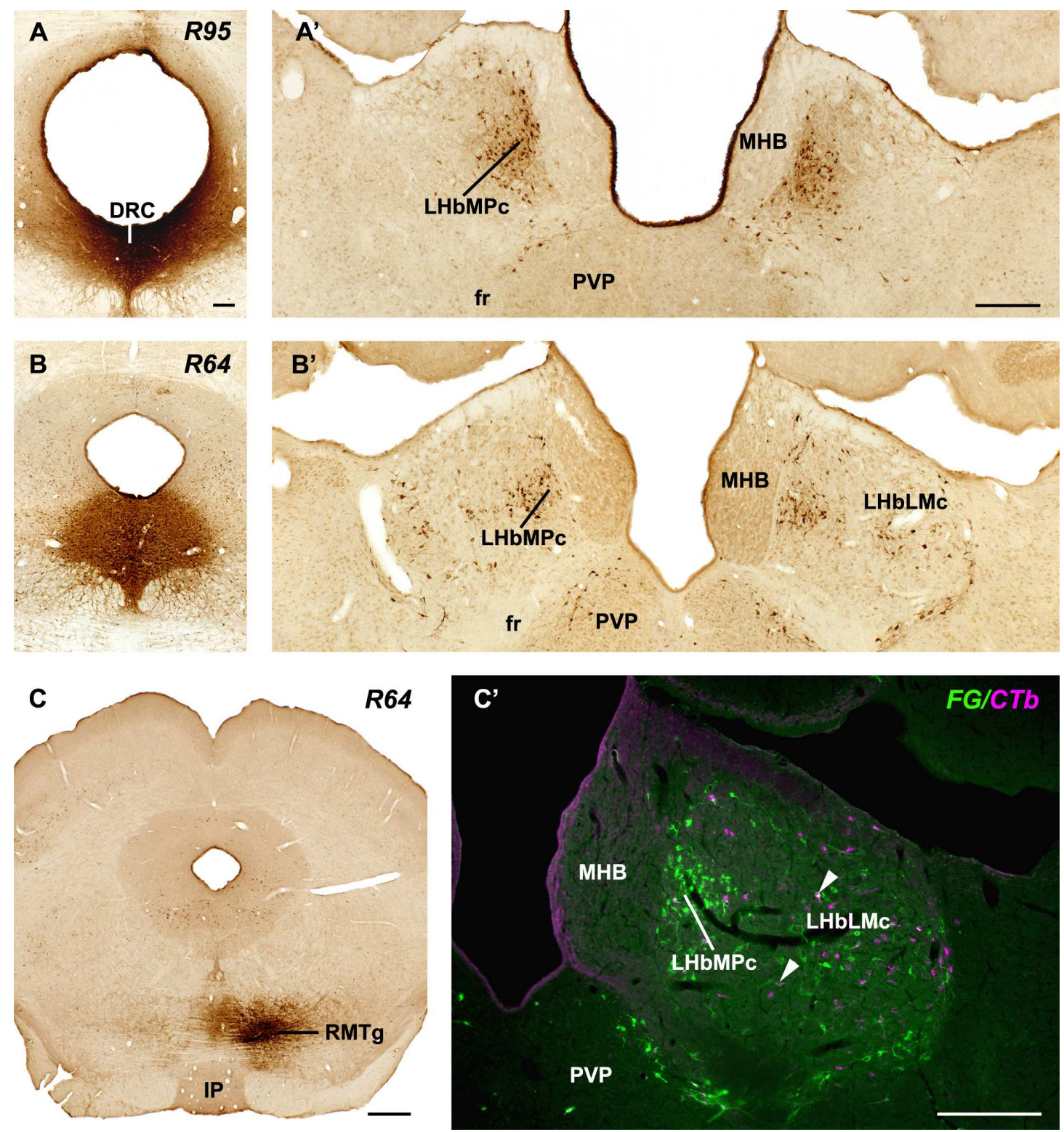

Observe em B' que após injeções no DRC a marcação retrógrada na LHb foi essencialmente restrita à LHbM. Observe também que caso 64 recebeu uma injeção adicional no RMTg (C), que resultou numa pequena quantidade de neurônios duplamente marcados na LHb (cabeças de seta em C'). Para abreviaturas, veja lista Barras $=150 \mu \mathrm{m}$ em A (também se aplica a B); $200 \mu \mathrm{m}$ em A' (também se aplica a B'); $500 \mu \mathrm{m}$ em C; $250 \mu \mathrm{m}$ em C'. 
Figura 6 - llustrações semi-esquemáticas mostrando a distribuição de neurônios retrógradamente marcados em três níveis rostrocaudais pela $\mathrm{LHb}$, resultantes das injeções no DR nos casos 64 (A'-A'”), 65 (B'-B'”) e 95 (C'C'”') mostradas em Figura 4.

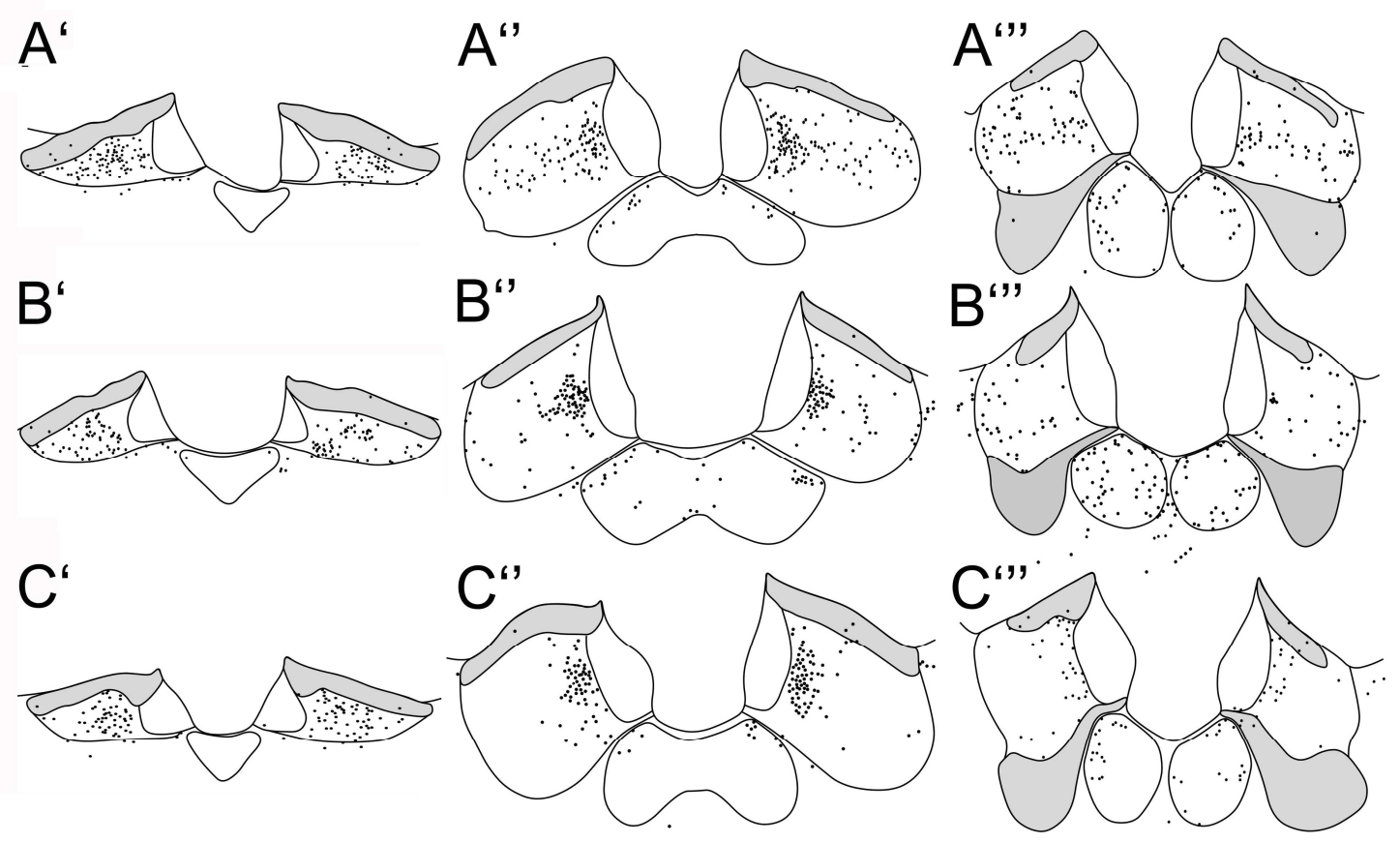

Cortes são apresentados em sequencia rostrocaudal e cada ponto representa um neurônio retrogradamente marcado Observe em B" e B'" que após injeções no DRC a marcação retrógrada na $\mathrm{LHb}$ foi essencialmente restrita à $\mathrm{LHbM}$. 


\subsection{Experimentos de rastreamento retrógrado: projeções do RMTg e outras estruturas pontomesencefálicas para o DR}

Cortes dos encéfalos dos ratos que receberam injeções de CTb no DR também foram analisados em relação á marcação retrógrada no tegmento mesopontino. Especificamente, pretendíamos verificar de os neurônios retrógradamente marcados preenchem o RMTg em toda sua extensão rostrocaudal, como descrevemos os neurônios do RMTg que projetam para a VTA (GONÇALVES; SEGO; METZGER, 2012). A figura 8 ilustra a distribuição da marcação retrógrada a partir de uma injeção representativa do CTb centrada no DRDCe, cerca de 7,4 mm posterior a bregma (caso 90; Fig. 8F). Esta injeção foi restrita ao DR e não envolveu DRR, DRC ou VLPAG. Marcação retrógrada bilateral foi observada no RMTg e diversas outras estruturas pontomesencefálicas, inclusive a VTA, SN (compacta e reticulata), o campo retrorubral (RRF), VLPAG, a formação ístmica reticular, PTg e o LDT. O RMTg foi preenchido em toda sua extensão rostrocaudal por neurônios CTbimunorreativos (Figs 7A', 7A"; 8A-F), entre cerca de $6,4 \mathrm{~mm}$ até $7,6 \mathrm{~mm}$ posterior a bregma, que foram em todos os níveis mergulhados nas fibra do xscp. No polo caudal do RMTg, neurônios CTb-marcados ficaram espaçados e progressivamente se mesclaram com neurônios retrógradamente marcados no PTg adjacente.

É importante notar que todas as injeções que não envolveram o DRDCe substancialmente resultaram num padrão de marcação retrógrada menos denso no RMTg. Tais injeções, como exemplificado por uma injeção no DRR (Fig. 7B, caso 51), tipicamente resultaram em marcação retrógrada no RMTg rostral (Fig. 7B'). No RMTg caudal, a marcação pelo CTb foi comparativamente menos proeminente (Fig. 7B") e frequentemente quase indistinguível de áreas adjacentes. 
Figura 7 - A-B": Fotomicrografias de sítios de injeção de CTb representativos centrados no DRDCe (A, caso 90) e na parte rostral do DR (DRR; $B$, caso 51 ), e da marcação retrógrada resultante em níveis rostral (A', B') e caudal (A", B') pelo RMTg.
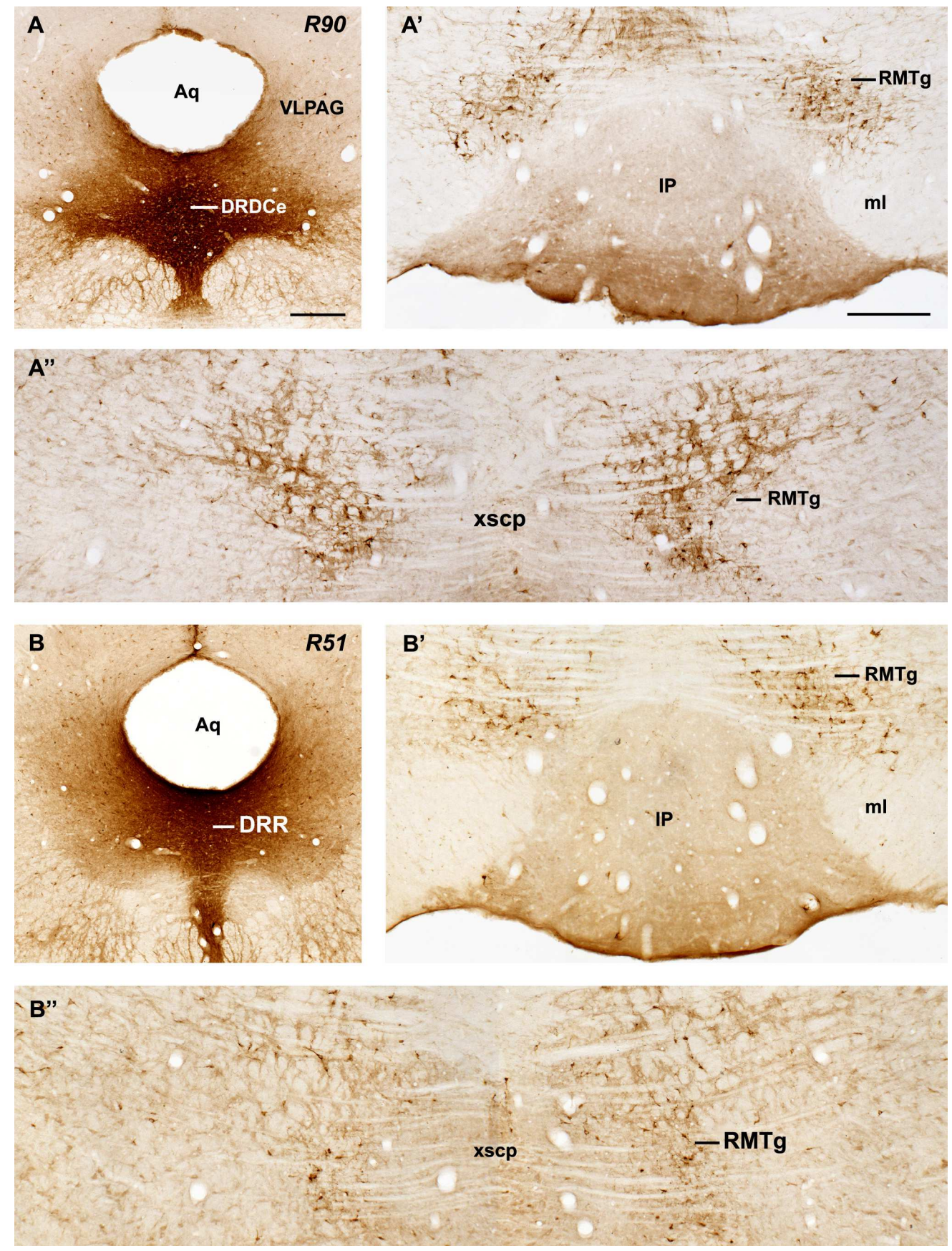

Barras $=300 \mu \mathrm{m}$ em A (também se aplica a B); $250 \mu \mathrm{m}$ em A' (também se aplica a A', B', B"). 
Figura 8 - A-H: llustrações semi-esquemáticas de um sítio de injeção de CTb centrado no DRDCe (caso 90) e a marcação retrógrada resultante em cortes frontais pelo mesencéfalo e ponte.
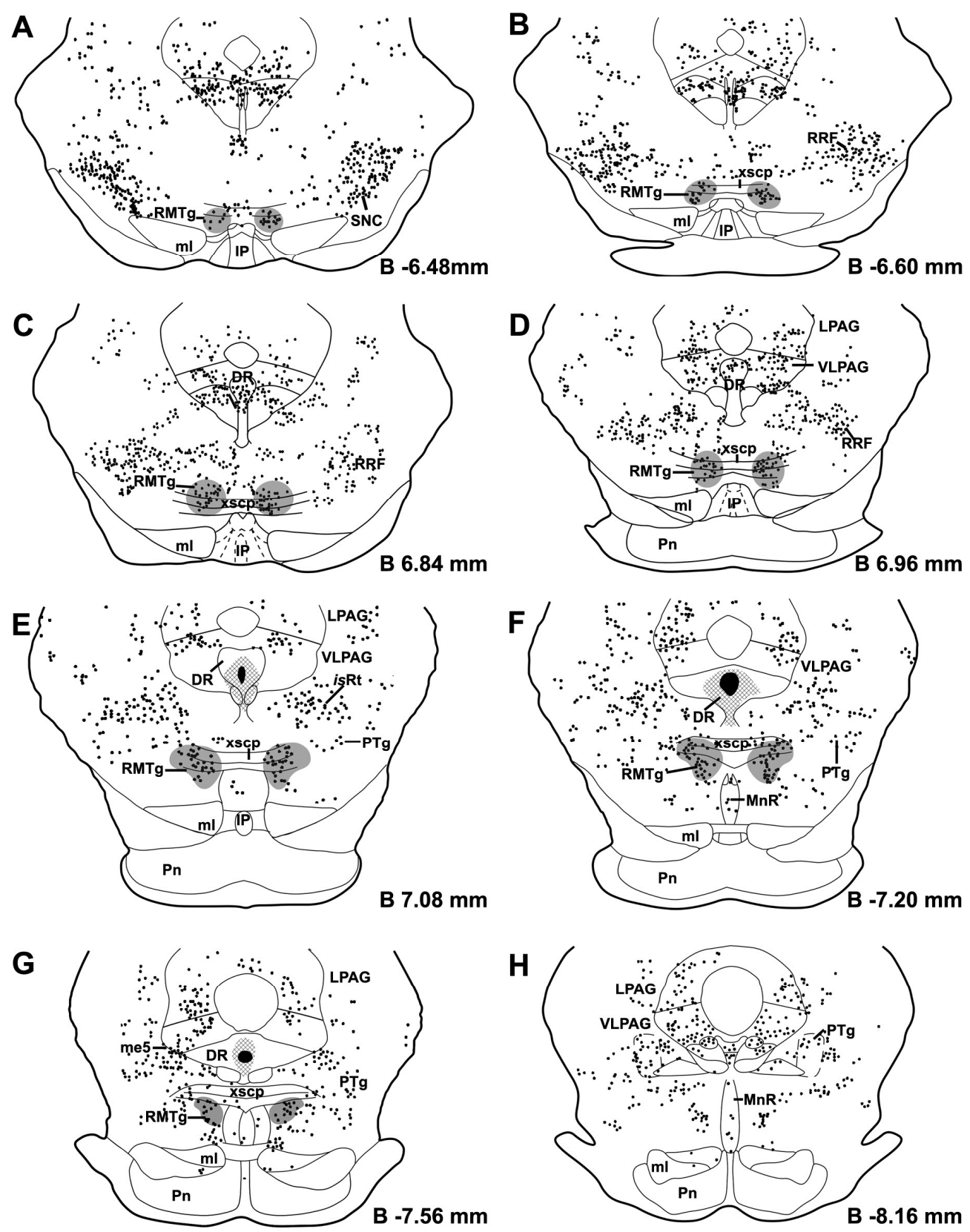

Cada ponto representa um neurônio retrogradamente marcado. O foco da injeção é indicado em preto e o halo ao volta por linhas diagonais. A área em cinzenta indica o core do RMTg. Para abreviaturas, veja lista. 


\subsection{Combinação de rastreamento retrógrado do DR com hibridização in situ para GAD-67}

Para verificar se as projeções do RMTg para o DR são predominantemente GABAérgicas como é o caso das projeções deste para a VTA (JHOU et al., 2009a; KAUFLING et al., 2009), analisamos cortes processados pela técnicas de imunoistoquímica para o traçador retrógrado CTb (injetado num nível rostrocaudal intermediário do DR) e hibridação in situ para mRNA de GAD-67 em dois ratos (Casos L13 e L23). Sob iluminação em campo escuro o RMTg se destacou bilateralmente como um agregado contendo o transcrito da GAD-67. Este agregado foi particularmente proeminente em níveis rostrais pelo RMTg, dorsolateral à parte caudal do IP (Fig. 9A). Em níveis mais caudais, se tornou progressivamente menos distintivo, pois muitos neurônios em estruturas adjacentes como o PTg também apresentavam o transcrito da GAD-67. A inspeção detalhada destes cortes sob iluminação em campo claro revelou que quase todos os neurônios CTb-marcados na região 'core' do RMTg contêm mRNA da GAD-67. Assim, no RMTg rostral (Fig. 9B) e caudal (Fig. 9C), células CTb-marcados tipicamente apresentam aglomerações de grão de prata indicativos de mRNA da GAD-67. 
Figura 9 - Fotomicrografias de cortes pelo RMTg duplamente marcados para o mRNA da descarboxilase 67 kDA do glutamato (GAD67) e CTb após uma injeção no DR.
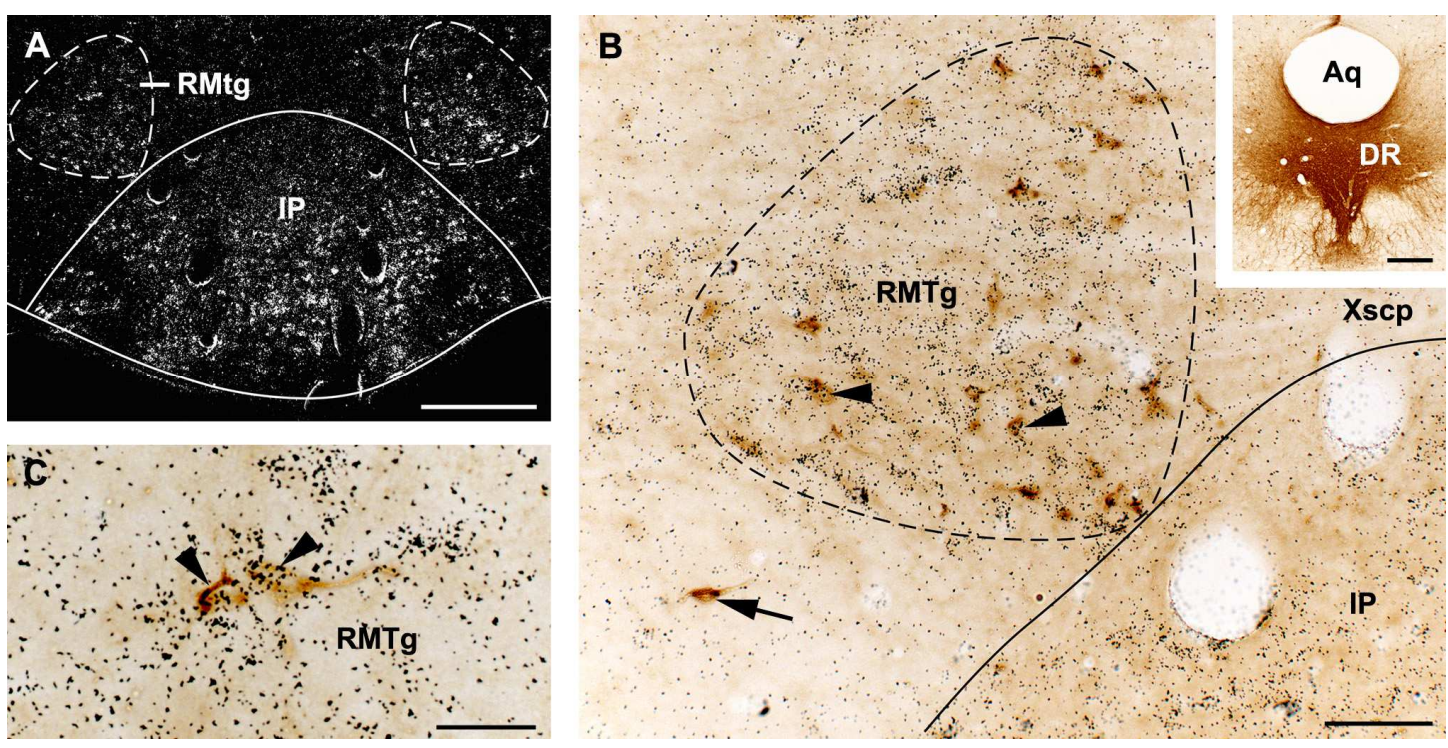

A: Fotomicrografia em campo escuro de transcrito GAD-67 num nível rostral pelo RMTg. Observe que o RMTg se destaca bilateralmente como um agregado densamente marcado situado dorsolateralmente à metade caudal do núcleo interpeduncular. B, C: Fotomicrografias em menor e maior aumento de marcação retrógrado e transcrito GAD-67 em níveis rostral (B) e caudal (C0 pelo RMTg. Células $C T b+$ resultaram da injeção mostrado em B. Observe que os agregados de grãos de prata se acumulam em quase todos os neurônios $\mathrm{CTb}+$ da região do core do RMTg. Cabeças de seta apontam para exemplos de neurônios do RMTg que expressam GAD-67 e a seta para um neurônios $C T b+$ sem o transcrito GAD-67. Para abreviaturas, veja lista. Barras $=250 \mu \mathrm{m}$ em A; $50 \mu \mathrm{m}$ em B; $300 \mu \mathrm{m}$ na imagem inserida; $20 \mu \mathrm{m}$ em $\mathrm{C}$. 


\subsection{Experimentos de rastreamento neuronal anterógrado: projeções do $\mathrm{RMTg}$ para o DR}

Para detalhar a exata topografia das projeções do RMTg para o DR, pequenas injeções de PHA-L foram realizadas no RMTg em 3 ratos (casos 85, 86, 87). Caso 86, que recebeu uma injeção de PHA-L centrada no RMTg rostral, cerca de 6,6 mm posterior ao bregma (Fig. 10A) mas também apresentou muitos neurônios PHAmarcados no RMTg caudal (Fig. 10B), foi selecionado como protótipo para ilustrar os resultados (Figs. 10,11). A distribuição da marcação anterógrada resultante no DR é ilustrada na Figura 11. Encontramos axônios PHA-L-imunomarcados em todas as subdivisões do DR e alguns no VLPAG adjacente. De forma geral, a marcação pelo PHA-L no DR foi mais densa em regiões medianas do que, por exemplo, nas asas laterais. No DRR, DRDSh, asas laterais e DRV, axônios pouco ramificados que seguiam longas distâncias com varicosidades ocasionais se mesclaram com alguns axônios ricamente ramificados e varicosos formando pequenos campos terminais. Um campo terminal proeminente com numero elevado de axônios exibindo varicosidades e ramificações terminais (Fig.10C-E) ocupou o DRDCe. Este campo terminal característico no DRDCe se estendeu de cerca de 7,4 a 7,8mm posterior ao bregma. Marcação proeminente com características de um campo terminal foi observada dorsalmente no DRDC. Em níveis mais caudais pelo DR, os axônios PHAL-imunomarcados ficaram mais esparsos e somente poucos axônios, a maioria sem varicosidades, foram observados no DRC (Fig. 11D).

Outras estruturas pontomesencefálicas que apresentaram marcação robusta pelo PHA-L são: o complexo VTA/SN, RRF (Fig. 10A, B), o LDT (Fig. 11D) e o PTg. Em níveis mais caudais, muito poucos axônios PHA-L-marcados foram detectados na área pré-coeruleus, enquanto o LC e o complexo sub-coeruleus foram quase desprovidos de axônios. Os dois casos restantes tiveram injeções menores no RMTg que envolveram a parte mais lateral do RMTg caudal. Em geral, a marcação anterógrada resultante no DR foi semelhante ao caso 86 embora, provavelmente devido ao tamanho menor das injeções, menos expressiva. 
Figura 10 - A-F: Fotomicrografias em dois níveis rostrocaudais das mesma injeção de PHA-L no RMTg (caso 86, A, B) e a marcação anterógrada resultante em diferentes níveis pelo DR.
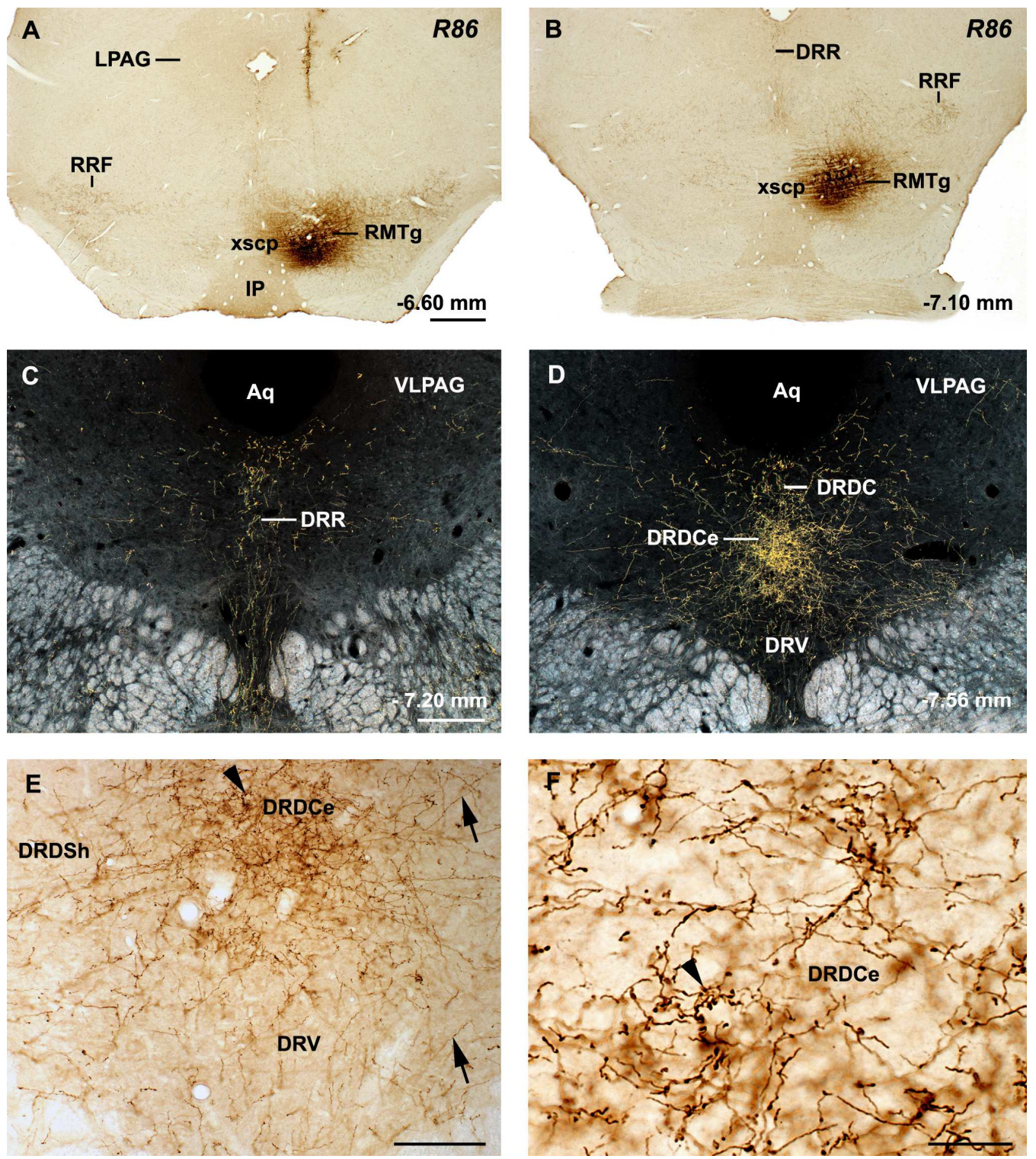

C, D: Fotomicrografias em campo escuro de marcação anterógrada em níveis rostral (C) e intermediário (D) pelo DR. Observe em D o campo terminal focal no DRDCe. E, F: Fotomicrografias em maior aumento do campo terminal no DRDCe. Observe que axônios $\mathrm{PHA}-\mathrm{L}+$ no DRDCe apresentam muitas varicosidades e ramificações terminais, enquanto axônios em subdivisões adjacentes são menos ramificadas (setas). A cabeça de seta indica o mesmo axônio terminal em menor (E) e maior $(F)$ aumento. Para abreviaturas, veja lista. Barras: $500 \mu \mathrm{m}$ em A (também se aplica a B); $250 \mu \mathrm{m}$ em C (também se aplica a D); $100 \mu \mathrm{m}$ em E; $20 \mu \mathrm{m}$ em D. 
Figura 11 - A-D: Ilustrações semi-esquemáticas mostrando a distribuição de axônios anterógradamente marcados após uma injeção de PHA-L no RMTg (caso 86, Fig. 11A, B).
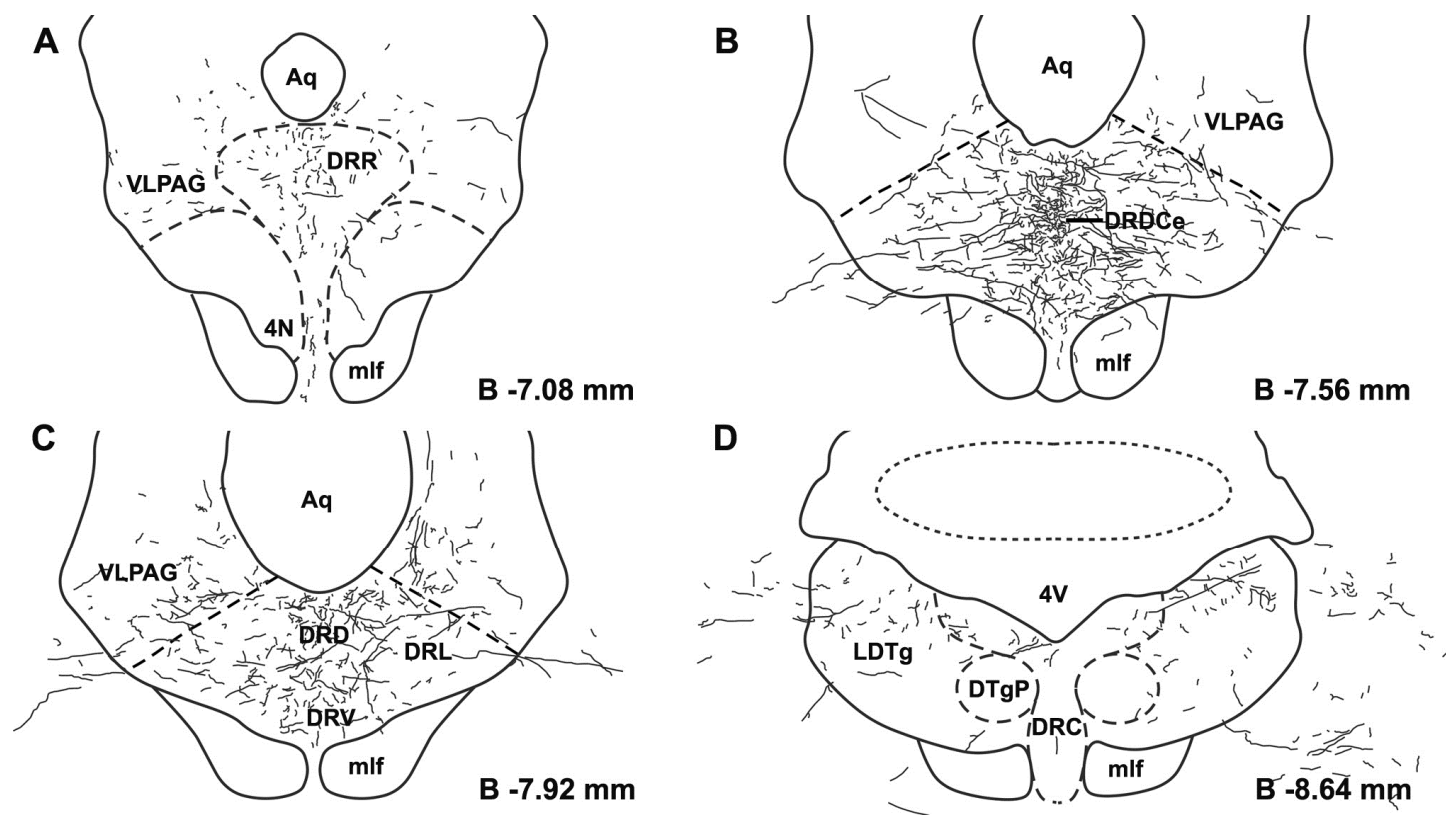

Os cortes são apresentados em sequência rostrocaudal. Observe a marcação anterógrada dispersa no DRC. Para abreviaturas, veja lista. 


\subsection{Marcação por dupla-imunofluorecencia para PHA-L e 5-HT ou VGLUT3}

Atualmente há evidências de que além dos neurotransmissores clássicos 5HT, GABA e dopamina, o DR possui grandes populações de neurônios com fenótipo serotonérgico/glutamatérgico ou puramente glutamatérgico, e que todos estes neurônios diferentes são misturados em proporções diferentes nas subdivisões do DR (FU et al., 2010; HIOKI et al., 2010; SHIKANAI et al., 2012). Um possível fenótipo glutamatérgico dos neurônios do DR é evidenciado pela expressão de VGLUT3 (GRAS et al., 2002; HIOKI et al., 2010). Para especificar se a marcação proeminente com características de um campo terminal se localiza na subdivisão DRDCe, e o fenótipo dos neurônios alvo dos axônios da LHb e do RMTg, processamos os cortes do caso 86 pela técnica de dupla-imunofluorescência para PHA-L e 5-HT ou VGLUT3.

Ao analisar os cortes marcados para PHA-L ou 5-HT ou VGLUT3, encontramos uma rede densa de axônios, a maioria varicosa, alguns direcionados para e formando aposições com neurônios 5-HT+ (Fig. 12A-A'). Ao contrário, o campo terminal proeminente formado por axônios do RMTg alvejou o DRDCe, que é quase desprovido de neurônios 5-HT+ (Fig. 12B-B"'). O DRDSh adjacente possui uma quantidade considerável de neurônios $5-\mathrm{HT}+$ porém somente poucos axônios PHA-L-marcados (Fig. 12B, B'). Analisamos em seguida a distribuição de neurônios VGLUT3+ em cortes do DR marcados para VGLUT3 e PHA-L. A imunorreatividade para VGLUT3 foi presente em pericários e axônios de todo o $\mathrm{DR}$, porém com distribuições diferenciais. O DRDCe possui neurônios VGLUT3+ pequenos, a maioria arredondada, e densamente empacotados (Fig. 13A). No entanto, neurônios VGLUT3+ são frequentes nas áreas medianas de outras subdivisões como DRR, DRV e DRC. Em contraste, as asas laterais e o DRDC possuem menos neurônios VGLUT3+ que são tipicamente mais fracamente marcados. Em imagens adquiridas com o auxílio de microscopia confocal, observamos axônios PHA-L+ do RMTg no DRDCe entremeados com neurônios VGLUT3+ e formando aposições com os mesmos (Fig. 13B, C). 
Figura 12 - A-B"”: Imagens em canal separado e mesclado de marcação por duplaimunofluorescência para 5-HT (verde) e PHA-L (magenta) no DRC (A-A") e em um nível rostrocaudal intermediário pelo DR $(B-B$ ').
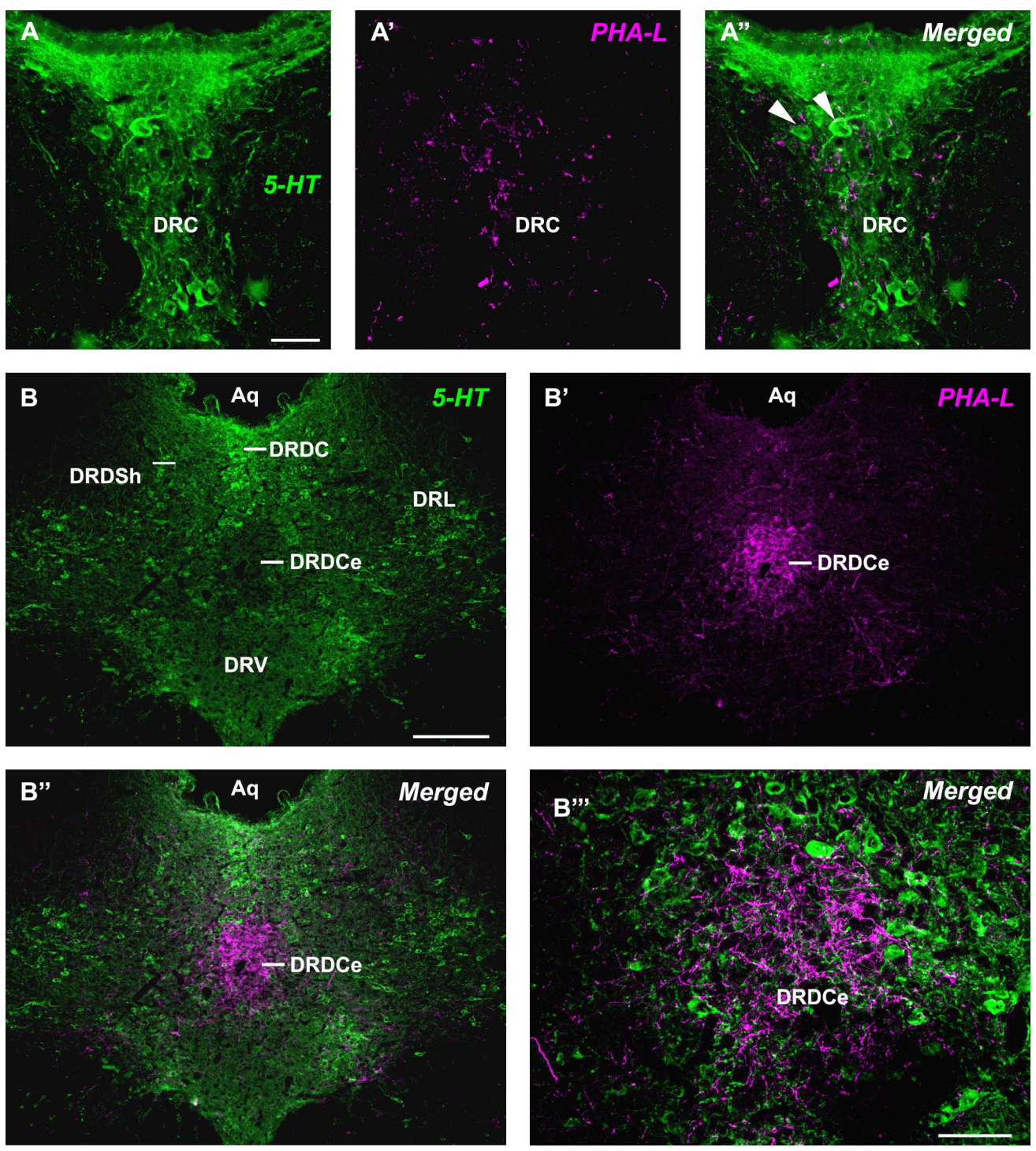

A marcação no DRC resultou de uma injeção de PHA-L na LHbM (caso 81, Fig. 4A) e a marcação no DR intermediário resultou de uma injeção de PHA-L no RMTg (caso 86, Figs. $11 \mathrm{~A}, \mathrm{~B}$ ). Observe que no DRC, axônios da LHbM são direcionados para neurônios 5-HT+ (cabeças de seta). Em contraste, no DR intermediário axônios do RMTg são direcionados para o DRDCe, que é quase desprovido de neurônios 5-HT. Barras: $50 \mu \mathrm{m}$ em A (também se aplica a A', A"); $250 \mu \mathrm{m}$ em B (também se aplica a B', B'); $40 \mu \mathrm{m}$ em B". 
Figura 13. A-C: Marcação por imunofluorescência para VGLUT3 (magenta, A) e dupla-imunofluorescência para VGLUT3 e PHA-L (verde, B, C) no DR em níveis rostrocaudais intermediários.
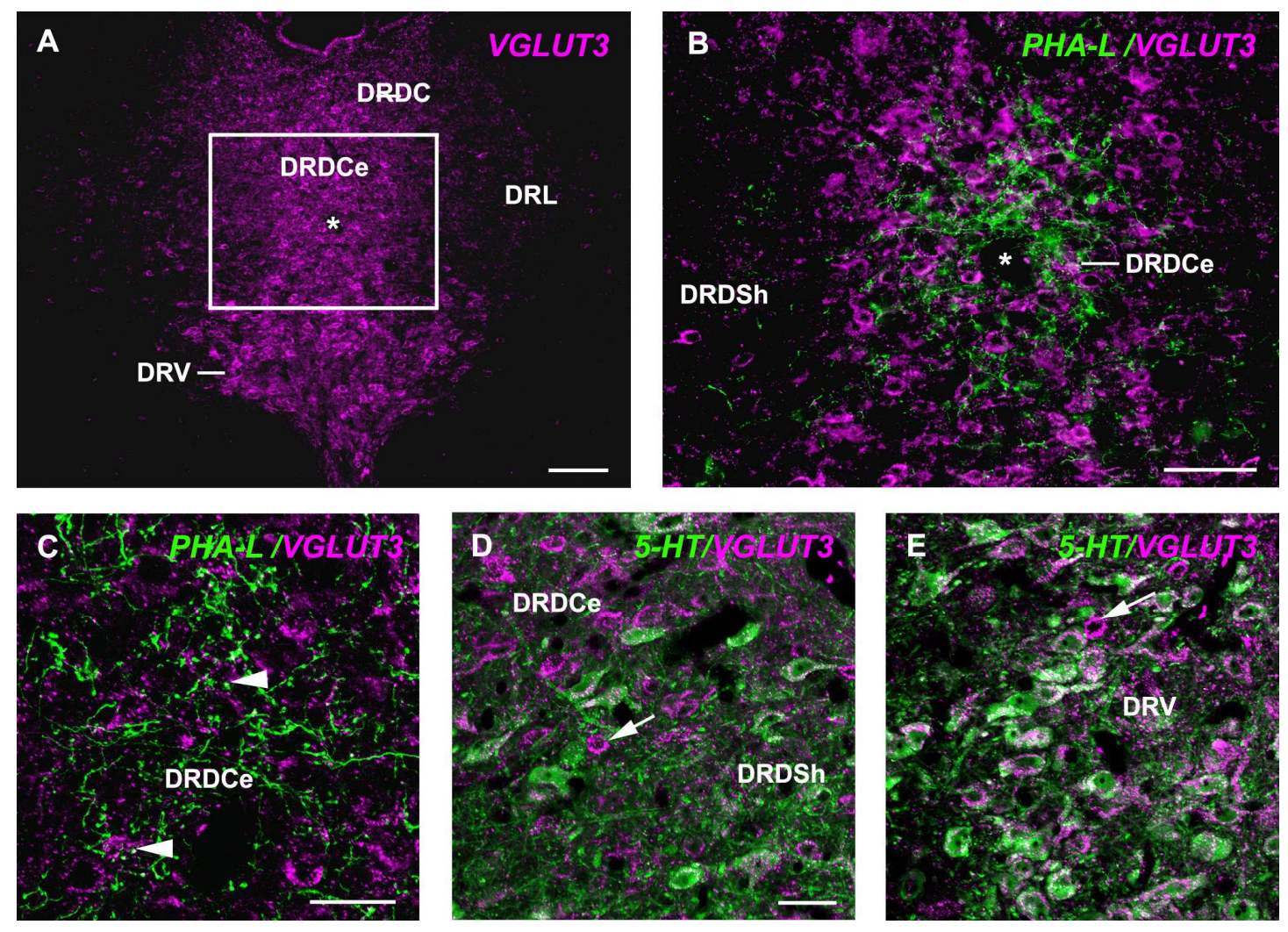

A marcação pelo PHA-L resultou de uma injeção no RMTg (caso 86). Observe que axônios do RMTg com varicosidades são encontrados principalmente no DRDCe, onde formam muitas aposições com corpos celulares VGLUT3+ (cabeças de seta). D, E: Marcação por dupla-imunofluorescência para VGLUT3 (magenta) e 5-HT (verde) no DRDCe e DRDSh (D) e no DRV (E). Observe que neurônios VGLUT3+/5-HT- são muito mais comuns no DRDCe em comparação com o DRDSh e DRV. Observe também o número elevado de neurônios duplamente marcados no DRV (fluorescência branca). Para abreviaturas, veja lista. Barras: $100 \mu \mathrm{m}$ em A; $40 \mu \mathrm{m}$ em B; $25 \mu \mathrm{m}$ em C; 20 m em D (também se aplica a E). 
Em cortes marcados para 5-HT e VGLUT3, realizamos uma análise semiquantitativa de neurônios marcados para somente 5-HT+ (VGLUT3-/5HT+), somente VGLUT3 (VGLUT3+/5HT-) e ambos (VGLUT3+/5HT+) nas diferentes subdivisões do DR. A frequência relativa de neurônios de cada fenótipo em subdivisões do DR é apresentada na Tabela 5 e ilustrada na Figura 15. O DRDCe se destacou entre todas as subdivisões analisadas por possuir a maior frequência relativa de neurônios VGLUT3+/5-HT- $(68.2 \% \pm 0.02 \%)$, bem como a menor frequência de neurônios VGLUT3-/5-HT+ (6.2\% \pm 0.07\%) e VGLUT3+/5-HT+ (25.6\% \pm 0.05\%). Ao contrário, a maior frequência de neurônios VGLUT3+/5-HT+ foi encontrada no DRC $(60.8 \% \pm$ $0.06 \%)$ e no DRV (51 \pm 0.03\%; Fig. 13E, 14). Em todas as regiões analisadas, neurônios VGLUT3-/5-HT+ formaram uma pequena minoria, com maior frequência encontrada no DRDSh $(11.8 \% \pm 0.08 \%)$ e DRV $(10.6 \% \pm 0.03 \%)$

Tabela 5 - Composição de populações neuronais marcados VGLUT3+/5-HT+, VGLUT3+/5-HT- ou VGLUT3-/5-HT+ nas respectivas subdivisões do DR.

\begin{tabular}{|c|c|c|c|c|c|c|c|}
\hline & $\begin{array}{c}\text { Fenótipo } \\
\text { neuroquímico }\end{array}$ & DRDC & DRDSh & DRDCe & DRV & $\begin{array}{l}\text { DRL/ } \\
\text { PDR }\end{array}$ & DRC \\
\hline \multirow{3}{*}{$\begin{array}{l}\text { Frequência } \\
\text { relativa de } \\
\text { neurônios } \\
\text { marcados }\end{array}$} & $\begin{array}{c}\text { VGLUT3+/ } \\
5-\mathrm{HT}+\end{array}$ & $\begin{array}{l}55,9 \% \\
(n=105)\end{array}$ & $\begin{array}{c}43,5 \% \\
(n=143)\end{array}$ & $\begin{array}{c}25,6 \% \\
(n=117)\end{array}$ & $\begin{array}{c}51,0 \% \\
(n=526)\end{array}$ & $\begin{array}{c}45,3 \% \\
(n=309)\end{array}$ & $\begin{array}{l}60,8 \% \\
(n=479)\end{array}$ \\
\hline & $\begin{array}{c}\text { VGLUT3+/ } \\
\text { 5-HT- }\end{array}$ & $\begin{array}{l}35,4 \% \\
(n=67)\end{array}$ & $\begin{array}{c}44,8 \% \\
(n=152)\end{array}$ & $\begin{array}{c}68,2 \% \\
(n=297)\end{array}$ & $\begin{array}{l}38,4 \% \\
(n=393)\end{array}$ & $\begin{array}{l}39,6 \% \\
(n=270)\end{array}$ & $\begin{array}{l}32,1 \% \\
(n=256)\end{array}$ \\
\hline & $\begin{array}{l}\text { VGLUT3-/ } \\
5-\mathrm{HT}+\end{array}$ & $\begin{array}{l}8,7 \% \\
(n=17)\end{array}$ & $\begin{array}{l}11,8 \% \\
(n=34)\end{array}$ & $\begin{array}{l}6,2 \% \\
(n=20)\end{array}$ & $\begin{array}{c}10,6 \% \\
(n=104)\end{array}$ & $\begin{array}{c}15,1 \% \\
(n=103)\end{array}$ & $\begin{array}{c}7,2 \% \\
(n=57)\end{array}$ \\
\hline
\end{tabular}


Figura 14 - Gráfico de barras divididas mostrando a frequência relativa de neurônios VGLUT3-/5-HT+, VGLUT3+/5HT- e VGLUT3+/5HT+ nas subdivisões do DR.

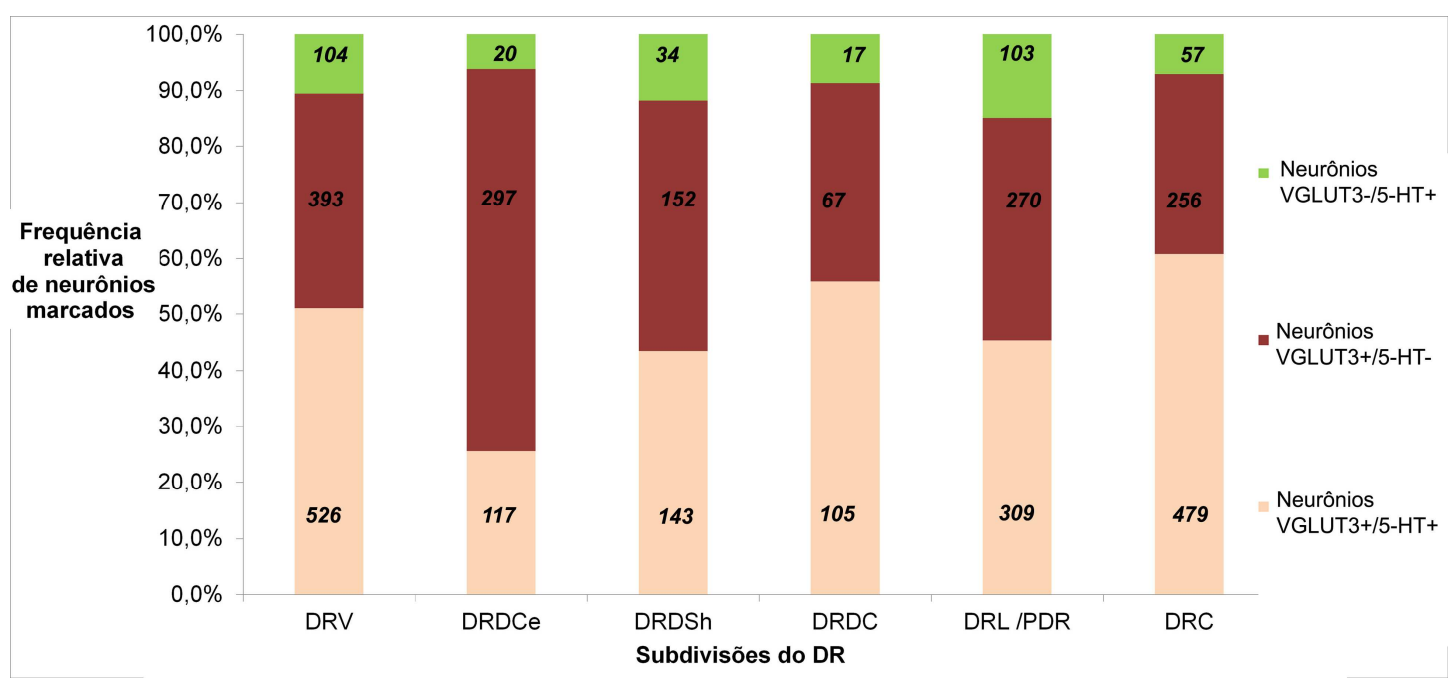

Para abreviaturas, veja lista. 
Os neurônios VGLUT3+ se distinguiram pelo tamanho pequeno dos corpos celulares, e pela forma arredondada ou triangular. Em imagens de cortes processados pela técnica de dupla-imunofluorescência para 5-HT e VGLUT3, realizamos medidas dos diâmetros maior e menor de neurônios VGLUT3+/5HT- e VGLUT3+/5HT+ nas subdivisões do DR, e a partir destes calculamos os diâmetros médio de cada neurônio medido, e em seguida a média dos diâmetros médio dos neurônios de cada fenótipo nas respectivas subdivisões do DR. Como o intuito desta análise foi somente descritiva, aplicamos métodos de estatística descritiva. As medidas de dispersão são apresentadas na Tabela 6 e ilustradas na Figura 16. Observamos que o diâmetro médio da maioria dos neurônios VGLUT3+/5HT+ (12,15 $-16,82 \mu \mathrm{m}$ ) em todas as subdivisões do DR analisadas se encontram numa faixa de valores maior do que a maioria dos neurônios VGLUT3+/5HT- (10,93 - 13,83 $\mu \mathrm{m})$. Portanto, os neurônios VGLUT3+/5-HT- aparentam ser uma população neuroquímica- e citoarquitetônicamente à parte em todas as subdivisões analisadas do DR (Fig. 16).

Tabela 6 - Medidas-resumo de posição e dispersão dos diâmetros médio dos neurônios marcados VGLUT3+/5-HT+ e VGLUT3+/5-HT- nas subdivisões DRDC, DRDSh, DRDCe e DRV do DR.

\begin{tabular}{|c|c|c|c|c|c|c|c|c|}
\hline & \multicolumn{2}{|c|}{ DRDC } & \multicolumn{2}{|c|}{ DRDSh } & \multicolumn{2}{|c|}{ DRDCe } & \multicolumn{2}{|c|}{ DRV } \\
\hline & VGLUT3+ & $\begin{array}{c}\text { VGLUT3+/ } \\
5 \mathrm{HT}+\end{array}$ & VGLUT3+ & $\begin{array}{l}\text { VGLUT3+/ } \\
\text { 5HT+ }\end{array}$ & VGLUT3+ & $\begin{array}{l}\text { VGLUT3+/ } \\
5 \mathrm{HT}_{+}\end{array}$ & VGLUT3+ & $\begin{array}{l}\text { VGLUT3+/ } \\
5 \mathrm{HT}_{+}\end{array}$ \\
\hline $\begin{array}{c}\text { Médio } \pm \\
\operatorname{SEM}(\mu \mathrm{m})\end{array}$ & & $14,22 \pm 2,23$ & $11,80 \pm 1,38$ & $13,77 \pm 2,03$ & $12,472 \pm 2,05$ & $14,52 \pm 1,84$ & $12,49 \pm 2,34$ & $15,45 \pm 1,87$ \\
\hline $\begin{array}{l}\text { Domínio de } \\
\text { variação } \\
(\mu \mathrm{m})\end{array}$ & $\begin{array}{c}\text { NÃO } \\
\text { ANALISA } \\
\text { DO }\end{array}$ & $11,20-19,78$ & $8,79-14,36$ & $10,31-19,25$ & $8,08-19,95$ & $10,26-18,96$ & $8,31-18,42$ & $12,03-19,44$ \\
\hline $\begin{array}{l}\text { intervalo } \\
\text { interquartil } \\
\text { (dq) }\end{array}$ & & $12,31-15,02$ & $11,31-13,08$ & $12,15-15,30$ & $11,29-13,55$ & $13,71-15,77$ & $10,93-13,83$ & $13,98-16,82$ \\
\hline
\end{tabular}


Figura 15 - Box plot mostrando medidas de posição e dispersão do diâmetro médio dos corpos celulares VGLUT3+/5HT- e VGLUT3+/5HT+ em subdivisões do DR em níveis rostrocaudais intermediários.

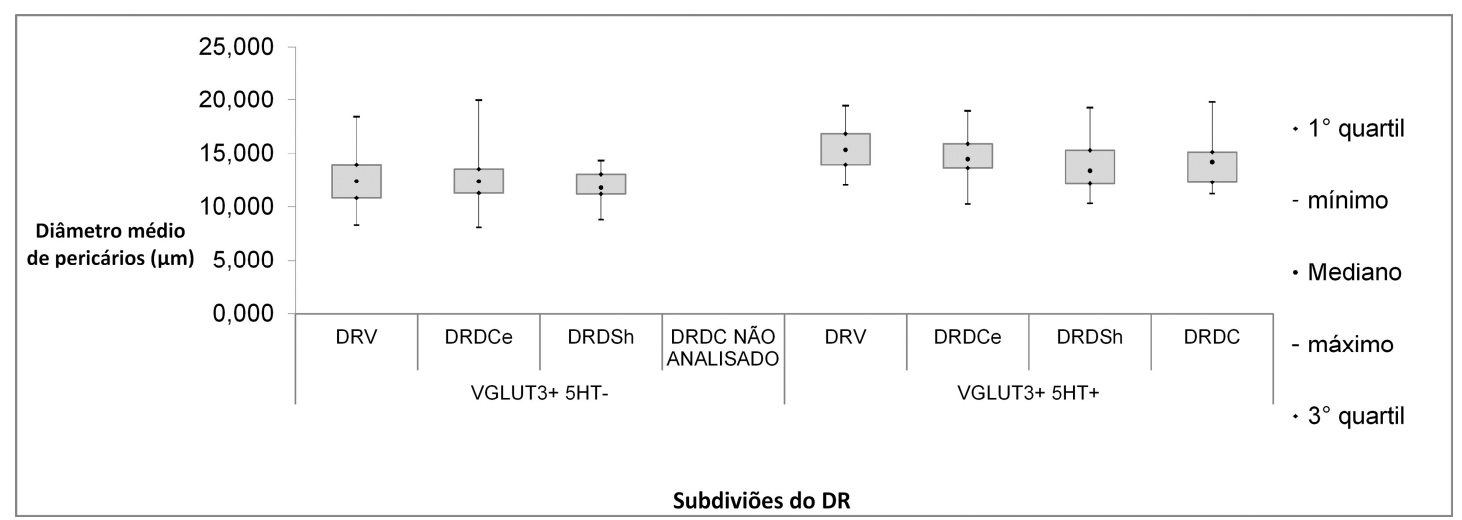


Figura 16 - llustração esquemática resumindo os principais achados do atual estudo.

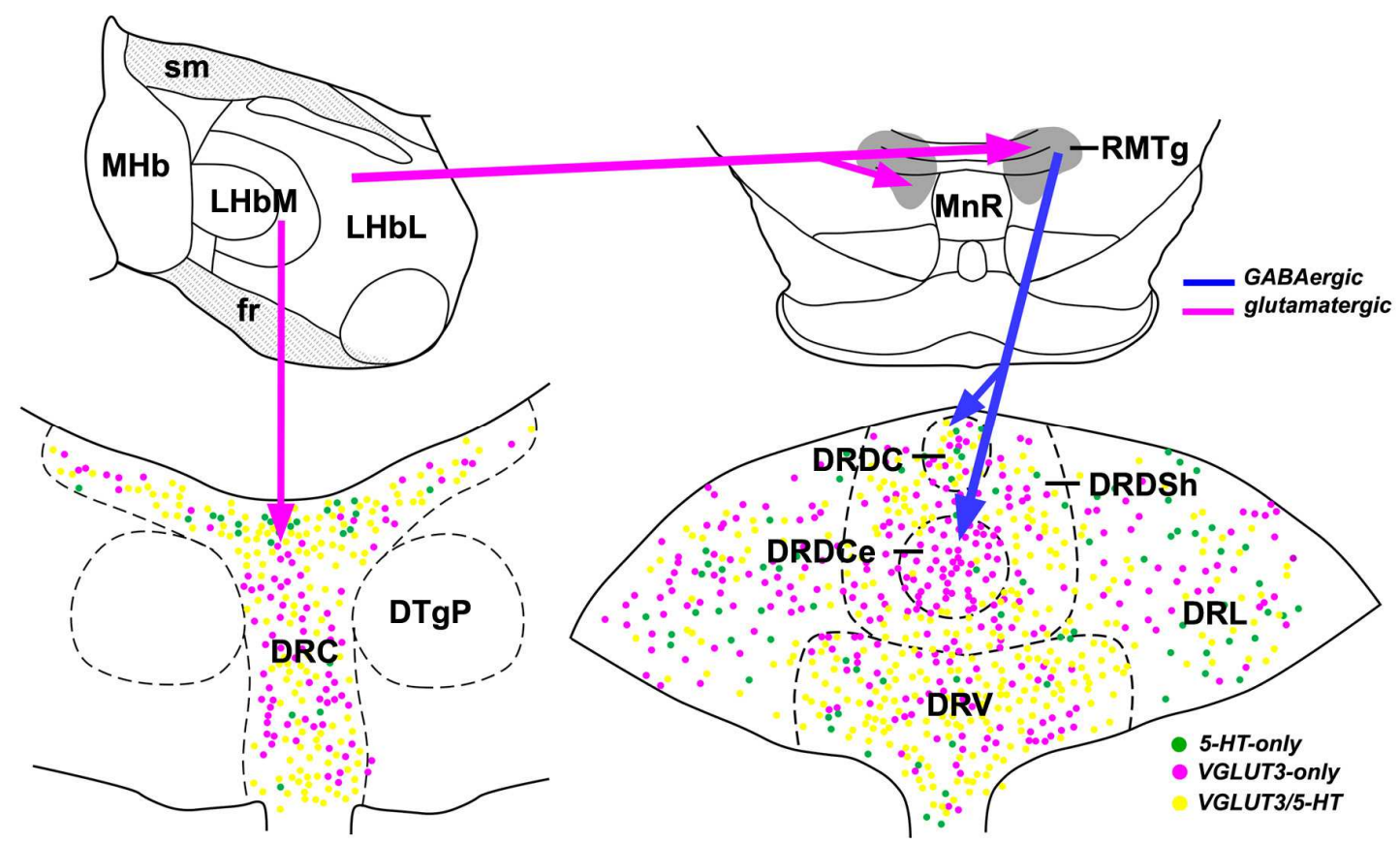

Observe que projeções diretas de caráter moderado emergem da LHbM e são direcionadas principalmente para o DRC, que contem cerca de dois terços de neurônios de fenótipo VGLUT3+/5-HT+ ou VGLUT3-/5-HT+. Em contraste, a maior parte das projeções indiretas da LHb emergem da LHbL, que projeta robustamente para o RMTg (GONÇALVES; SEGO; METZGER, 2012). O RMTg então envia projeções GABAérgicas densas para o DR, focalmente direcionadas para o DRDCe, onde a maior parte da população neuronal é VGLUT3+/5-HT-. 


\section{DISCUSSÃO}

No presente estudo investigamos sistematicamente através de técnicas de rastreamento neuronal retrógrado e anterógrado a organização das projeções diretas e indiretas (via o RMTg) da LHb para o DR. Examinamos ainda um possível fenótipo GABAérgico ne neurônios do RMTg que projetam para o DR, através de uma combinação metódica de rastreamento retrógrado á partir do DR com hibridização in situ para GAD-67. Investigamos ainda o fenótipo neuroquímico de neurônios do DR nas respectivas regiões alvo da $\mathrm{LHb}$ e RMTg pela técnica de dupla imunofluorescência para PHA-L e 5-HT ou VGLUT3. Desenhos esquemáticos em Fig. 12 resumem os achados deste estudo. Os principais achados são: 1) As projeções diretas da LHb para o DR são moderadas, se originam predominantemente da LHbM e são direcionadas principalmente para o DRC; 2) As projeções do RMTg para o DR são muito mais densas, emergem de neurônios que expressam mRNA da GAD-67 e são focadas numa subdivisão central do DRD caracterizada por poucos neurônios 5-HT+ e muitos VGLUT3+, e que denominamos DRDCe.

Nossos resultados serão discutidos em relação a estudos hodológicos anteriores e ao papel funcional do RMTg como interface entre a LHb e o DR.

\subsection{Considerações metodológicas}

Uma limitação inerente à interpretação de resultados de rastreamento neuronal é a possível incorporação e transporte de traçadores retrógrados e anterógrados por fibras que transitam pelo local de injeção e são danificadas durante a intervenção (CHEN; ASTON-JONES, 1995; CLIFFER; GIESLER, 1988; DADO et al., 1990). Necrose extensa no local da injeção foi considerada a principal causa de incorporação de traçadores por fibras danificadas (DADO et al., 1990; LUPPI et al., 1995). Portanto, neste estudo PHA-L, FG e CTb foram injetados iontoforéticamente por correntes descontínuas para minimizar a elevação de temperatura e 0 consequente dano tecidual junto à ponta da pipeta (LUPPI et al., 1990; 
GROENEWEGEN; WOUTERLOOD, 1990). Em geral, há poucas evidências de que a incorporação de traçadores por fibras de passagem possa ter afetado significativamente os principais resultados do atual estudo. Nossos dados de rastreamento anterógrado das projeções da $\mathrm{LHb}$ para o DR refletem estudos anterógrados anteriores (ARAKI et al., 1988; HERKENHAM; NAUTA, 1979; KIM, 2009) e são de forma geral sustentados pelo padrão de marcação retrógrada na LHb após a injeção de CTb ou FG no DR. Contudo, não podemos excluir alguma incorporação dos traçadores por fibras de passagem.

Outra limitação metodológica óbvia é a localização acurada das injeções de PHA-L em distintos subnúcleos da LHb. Nenhuma das injeções de PHA-L locadas na LHb foi pequena o suficiente para se restringir a um dos 10 subnúcleos descritos em duas publicações do grupo de Veh (ANDRES et al. 1999; GEISLER; ANDRES; VEH, 2003). Assim, foi impossível determinar se somente um ou mais subnúcleos contribuíram para a marcação anterógrada no tronco encefálico. Da mesma forma, consideramos imprecisa a nossa tentativa de localizar os neurônios retrogradamente marcados após a injeção de traçadores no RMTg ou no DR em diferentes subnúcleos da LHb, sem contracolorações para conhecidos marcadores com especificidade subnuclear. Todavia, consideramos que esta abordagem tenha gerado informações valiosas ao respeito de quais subnúcleos da LHb contribuem as principais aferências para o DR e RMTg, e validado os dados de rastreamento anterógrado.

\subsection{Topografia das projeções da LHb para o DR}

O DR sabidamente recebe entradas diretamente da LHb (AGHAJANIAN; WANG, 1977; ARAKI; MCGEER; KIMURA., 1988; BERNARD; VEH, 2012; HERKENHAM; NAUTA, 1979; JHOU et al., 2009b; KIM, 2009; PASQUIER et al., 1977; PEYRON et al., 1998; POLLER et al., 2011). Embora inicialmente fosse assumido um caráter GABAérgica para estas projeções (WANG; AGHAJANIAN, 1977), hoje há amplas evidências para um fenótipo predominantemente glutamatérgico dos neurônios da LHb (AIZAWA et al., 2012), inclusive os que 
projetam para o DR e a VTA (BRINSCHWITZ et al., 2010; KALÉN et al., 1985). Devido à enorme importância funcional sobressaliente das interações LHb-DR, examinamos em detalhe as projeções da LHb para o DR através de técnicas de rastreamento neuronal anterógrado e retrógrado. Em geral, nossos achados sustentam os estudos acima citados e acrescentam detalhes importantes. $O$ principais achados novos incluem uma descrição da topografia das projeções diretas da LHb para o DR, e de uma projeção densa e focada da LHbM para o DRC.

Em relação à origem subnuclear das projeções LHb-DR, nossos achados concordam com um estudo recente de rastreamento retrógrado (BERNARD; VEH, 2012). Conforme descrito neste estudo, encontramos que três subnúcleos da LHb, o complexo LHbMPc/LHbMC da LHbM e o LHbLMc da LHbL apresentam maior contribuição para as projeções LHb-DR. Nossos achados de rastreamento anterógrado ainda especificaram que o complexo LHbMPc/LHbMC dá origem a uma densa projeção focal para o DRC. Por outro lado, os dados anterógrados mostram que projeções moderadas emergem tanto da LHbM quanto da LHbL para outras subdivisões do DR. Este achado por parecer discrepante dos nossos próprios dados retrógrados, particularmente a densa marcação retrograda na LHb após a injeção de traçadores em níveis rostral e intermediário do DR. No entanto, isto pode ser devido a limitações técnicas. Há relatos de que FG e CTb são traçadores extremamente sensíveis, incorporados e transportados com tamanha avidez que limita a capacidade dos investigadores de distinguir entre projeções maiores e menores (para uma discussão detalhada, veja BROG et al., 1993). Além disso, nossas observações de uma inervação moderada do DR rostral e intermediário são sustentadas por resultados de estudos prévios de rastreamento anterógrado à partir da LHb (ARAKI; MCGEER; KIMURA, 1988; HERKENHAM; NAUTA, 1979; KIM, 2009). Por exemplo, Kim (2009) ilustrou uma marcação anterógrada densa no DRC após a injeção de aminas dextran biotiniladas no terço medial da LHb. Por outro lado, o mesmo estudo ilustra marcação anterógrada esparsa no DR após a injeção do traçador nos terços central e lateral (veja Figuras 7, 8, 9 em KIM, 2009).

Nos casos em que locamos injeções de dois traçadores retrógrados no DR e no RMTg, confirmamos a topografia marcante das projeções da LHb para a região 
ponto-mesensecálica descrita em estudos anterógrados anteriores (GONÇALVES; SEGO; METZGER, 2012; HERKENHAM; NAUTA, 1979; KIM, 2009). Assim, ao passo que injeções medianas no $\mathrm{DR}$ resultaram em marcação retrógrada restrita à LHbM, injeções no RMTg resultaram em marcação retrograda principalmente na LHbL. É notável que a pequena quantidade de neurônios duplamente marcados na LHb, resultantes destas injeções duplas, implica numa segregação quase total das projeções para o RMTg e o DR. Da mesma forma, as quantificações de BERNARD; VEH (2012) mostram poucos neurônios duplamente marcados após injeções duplas na VTA e DR ou MnR e VTA.

\subsection{Projeções do RMTg e outras estruturas mesopontinas para o DR}

Atualmente, há evidências de que o RMTg projeta maciçamente para o complexo VTA-SNC, assim como envia projeções significantes para o DR (JHOU et al., 2009b; LAVEZZI; PARSLEY; ZAHM, 2012). Além disso, através de uma combinação metódica de rastreamento neuronal retrógrado com imunoistoquímica para GAD-67, Gervasoni et al. (2000) ilustrou alguns neurônios GAD-67imunorreativos que projetam para o $\mathrm{DR}$ em uma posição que pode corresponder ao RMTg (veja Fig. 8 em GERVASONI et al., 2000). No entanto, a exata distribuição de axônios do RMTg no DR não foi investigada em detalhe. Ainda se deve esclarecer se as projeções do RMTg para o DR são predominantemente GABAérgicas, como foi constatado nas projeções do RMTg para a VTA (BALCITA-PEDICINO et al., 2011; JHOU et al., 2009B; KAUFLING et al., 2010). Assim, reexaminamos as projeções RMTg-DR através de rastreamento anterógrado e retrógrado e investigamos um possível fenótipo GABAérgico dos neurônios de projeção RMTg-DR através da combinação de rastreamento retrogrado do DR com hibridização in situ para GAD67.

Em geral, nossos achados confirmam a existência de uma projeção robusta do RMTg para o DR, conforme foi descrito em estudos anteriores (JHOU et al., 2009b; LAVEZZI; PARSLEY; ZAHM, 2012). Importantemente, eles especificam que a projeção RMTg-DR emerge de neurônios enriquecidos em mRNA do GAD-67. 
Ademais, mostramos pela primeira vez que, embora os axônios do RMTg se direcionem para todas as subdivisões do DR, há uma entrada densa e focal direcionada para uma subdivisão central, aqui denominada DRDCe. Este achado sustenta de maneira importante os nossos dados de rastreamento retrógrado que demonstram que a marcação retrógrada no RMTg foi mais intensa nos casos em que injeções de traçadores no DR envolveram integralmente o DRDCe. Assim como os neurônios do RMTg que projetam para a VTA (GONÇALVES; SEGO; METZGER, 2012) , os neurônios do RMTg que projetam para o DR nestes casos virtualmente delinearam a parte compacta do RMTg em toda sua extensão rostrocaudal. Além disso, sua posição corresponde indubitavelmente à posição de grande concentração de neurônios Fos-marcados ativados pela administração de psicoestimulantes observada em estudos anteriores (GEISLER et al., 2008; JHOU et al., 2009b; KAUFLING et al., 2009a, b). Interessantemente, Lavezzi, Parsley e Zahm (2012) mostraram que cerca de 10\% nos neurônios desta região dita 'core' do RMTg enviam colaterais para DR e VTA, e cerca de $5 \%$ de neurônios na mesma região enviam colaterais para DR e a parte dissipada do PTg. Nossos achados anterógrados confirmam projeções significantes do RMTg para o PTg e LDT (JHOU et al., 2009a; LAVEZZI; PARSLEY; ZAHM, 2012), porém questionam a existência de uma projeção robusta do RMTg para o complexo LC/SC descrita por Jhou et al. (2009a).

Nossos dados de rastreamento neuronal retrógrado a partir do DR confirmam e estendem estudos prévios que descrevem ou ilustram entradas do PTg, LDT, SNC, RRF, VTA e VLPAG para o DR (GERVASONI et al., 2000; KIROUAC et al., 2004; PEYRON et al., 1995, 1996; STEININGER et al., 1992; ZAHM et al., 2011). É notável que todas estas estruturas recebam entradas do RMTg (presentes achados, FERREIRA et al., 2008; JHOU et al., 2009a; LAVEZZI; PARSLEY; ZAHM, 2012) e que a maioria é mutuamente interconectada (e.g. BRODERICK; PHELIX, 1997; BRAZ et al., 2009; DEUTCH et al., 1988; HONDA; SEMBA, 1994; LAVOIE; PARENT, 1994; LIMA; GONÇALVES; METZGER, 2012; OAKMAN et al., 1995; OMELCHENKO; SESACK, 2005, 2006, 2010; PASQUIER et al., 1977; SEMBA; FIBIGER, 1992; VAN BOSCKSTAELE et al., 1994; VERTES, 1991; ZAHM et al., 2011). No entanto, o fenótipo de neurotransmissores destas conexões recíprocas 
entre estruturas tradicionalmente consideradas dopaminérgicas (SNC, VTA, RRF), serotonérgicas (DR) ou colinérgicas (PTg, LDT) deve ser cuidadosamente avaliado. Por exemplo, as projeções do complexo VTA-SNC para o DR são predominantemente GABAérgicas (KIROUAC; MABROUK, 2004), enquanto a maioria das projeções do DR para a VTA aparentemente possui fenótipo glutamatérgico ou glutamatérgico/serotonérgico misto (LIMA; GONÇALVES; METZGER, 2012; WANG et al., 2012).

Embora a presença de neurônios de fenótipo não-GABAérgico no RMTg nunca tenha sido sistematicamente investigada, uma população neuronal predominantemente GABAérgica é assumida como distintivo anatômico do RMTg (BOURDY; BARROT, 2012; LAVEZZI; ZAHM, 2011). Neste sentido, o RMTg foi inicialmente identificado como um agregado de neurônios GABAérgicos no polo caudal da VTA que expressa variantes do gene fos após a administração de psicoestimulantes (PERROTTI et al., 2005). Nossa observação que quase todos os neurônios do RMTg que projetam para o DR possuem um fenótipo GABAérgico sustenta esta visão de que o RMTg representa uma população celular GABAérgica relativamente pura. No entanto, há de se realizar estudos quantitativos de hibridização in situ em combinação com imunoistoquímica para NeuN, ou algum outro marcador neurônio-específico. Importantemente, o fenótipo GABAérgico dos neurônios do RMTg que projetam para o DR aponta para o RMTg como importante centro de controle inibitório capaz de exercer potente modulação sobre a atividade neuronal no DR.

\subsection{Fenótipo de neurotransmissores de neurônios no DR nas respectivas regiões alvo da LHb e RMTg}

Achados iniciais da anatomia e função do DR sugeriram que o DR fosse uma estrutura predominantemente serotonérgica, homogênea e com um modus operandi global (veja JACOBS; FORNAL, 1991). Atualmente, por exemplo, há evidências de que a liberação de 5-HT no prosencéfalo ocorre de uma maneira região-específica (KIRBY; ALLEN; LUCKI, 1995), e que o DR é uma estrutura altamente heterogênea 
composta por várias sub-regiões contendo subpopulações neuronais distintas que se diferem quanto aos fenótipos dos neurotransmissores, as projeções e as propriedades eletrofisiológicas (ABRAMS et al., 2005; BANG et al., 2012; CALIZO et al., 2011; COMMONS; CONNOLLEY; VALENTINO, 2003; CRAWFORD et al., 2011; DAY et al., 2004; FU et al., 2010; HALE; LOWRY, 2011; HALE; SHEKHAR; LOWRY, 2012; HIOKI et al., 2010; SHIKANAI et al., 2012; SOIZA-REILLY; COMMONS, 2011; VASUDEVA et al., 2011; WASELUS; VALENTINO; VAN BOCKSTAELE, 2011). Nossos achados demonstrando que a LHb e o RMTg preferencialmente inervam diferentes sub-regiões do DR fornecem evidências adicionais de que diferentes subdistritos do DR recebem aferências diferencialmente distribuídas (GONÇALVES et al., 2009; HALE et al., 2011; LEE et al., 2003; 2007; PEYRON et al., 1998). Especificamente, estes achados demonstram que as entradas do RMTg são direcionadas para uma subdivisão neuroquímicamente peculiar do DR aqui denominado DRDCe, caracterizada pela pobreza em 5-HT e a abundância de neurônios que expressam VGLUT3.

Estudos recentes realizados com técnicas de hibridação in situ e imunoistoquimica (COMMONS, 2009; FREMEAU et al., 2002; GRAS et al., 2002; HIOKI et al., 2010) revelaram uma expressão abundante de VGLUT3 em neurônios do DR e MnR. Ademais, Hioki et al. (2010) detectaram um alto grau de colocalização dos sinais de mRNA do VGLUT3 e da TPH no DR e MnR. Seus achados mostram que na maioria das subdivisões do DR, neurônios que expressam somente a 5-HT são minoria. Nossos dados detalhando as respectivas proporções de neurônios 5-HT+, VGLUT3+ e 5-HT+/VGLUT3+ em subdivisões selecionadas do DR não são diretamente comparáveis com os dados de Hioki et al. (2010), porque estes autores incluíram neurônios GABAérgicos e dopaminérgicos em sua análise. Contudo, muitos dos principais resultados mostram boa concordância. Assim, como descrito por Hioki et al. (2010), encontramos que em todas as subdivisões do DR analisadas neurônios 5-HT+ são somente uma pequena minoria (cerca de 10\%) e que entre todas as subdivisões analisadas, o DRC e DRV apresentam os maiores índices de co-localização entre VGLUT3 e 5-HT. É notável que nos dados de Hioki et al. (2010) o DRDSh se destaca como a subdivisão contendo maior proporção de 
neurônios VGLUT3+. No atual estudo, distinguimos o DRDCe como uma subdivisão separada do DR localizada dentro do DRDSh e revelamos que o DRDCe possui uma proporção ainda maior de neurônios VGLUT3+ em comparação com o DRDSh (68\% comparada com 49\%, respectivamente). Outros argumentos a favor de designar o DRDCe como uma subdivisão separada do DRD são: 1) uma projeção densa e focada do RMTg; 2) uma proporção extremamente baixa de neurônios 5-HT+; e 3) uma população de neurônios mais densamente empacotados em comparação com o DRDSh. Por outro lado, o DRC aqui identificado como principal recipiente de projeções da LHb possui cerca de $68 \%$ de neurônios de fenótipo VGLUT3+/5-HT+ ou $5-\mathrm{HT}+$, ou seja, cerca de dois terços de seus neurônios usam 5-HT como neurotransmissor.

Importantemente, neurônios VGLUT3+ e/ou VGLUT3/5-HT no DRD foram identificados como a fonte de projeções específicas para alvos como o complexo VTS-SNc, LPO, septo medial e região CA1 do hipocampo (GEISLER et al., 2007; HIOKI et al., 2010; JACKSON; BLAND; ANTLE, 2009). Entretanto, em regiões como o neocórtex e estriado, VGLUT3 é expresso principalmente em interneurônios GABAérgicos (FREMEAU et al., 2002; HIOKI et al., 2010) ou colinérgicos (GRAS et al., 2002, 2008). VGLUT3 é criticamente envolvido na transmissão glutamatérgica rápida no sistema auditivo (RUEL et al., 2008; SEAL et al., 2008), e nas projeções do DR para a VTA (WANG et al., 2012). A ausência do VGLUT3 predispõe a comportamentos do tipo ansioso, a uma dessensibilização de receptores $5-\mathrm{HT}_{1 \mathrm{~A}}$ e a um aumento da transmissão serotonérgica no hipocampo e córtex cerebral (AMILHON et al., 2010). Em conclusão, estes achados sublinham um papel chave para a transmissão glutamatérgica no funcionamento normal do DR.

\subsection{Considerações funcionais gerais}

Atualmente, há amplas evidências de que o RMTg seja uma estrutura intermediaria entre a LHb e neurônios dopaminérgicos do mesencéfalo (BALCITAPEDICINO et al., 2011; GONÇALVES; SEGO; METZGER, 2012; JHOU et al., 2009a,b) e que ambos a VTA e o RMTg sejam estruturas chave de um circuito anti- 
recompensa que codifica a omissão de reforçadores e a expectativa de eventos adversos. Assim, neurônios da LHb (MATSUMOTO; HIKOSAKA, 2008, 2009) e RMTg (HONG et al., 2011; JHOU et al., 2009b; LECCA et al., 2011) respondem ao valor negativo de um estímulo. É importante notar que este padrão de atividade da LHb e do RMTg é o inverso de neurônios da VTA, que respondem primariamente a estímulos novos, reforçadores e preditores de reforçadores com excitações fásicas (BROMBERG-MARTIN; HIKOSAKA, 2010, 2011; SCHULTZ, 1998, 2007).

Nossos achados anatômicos fortemente indicam o RMTg como um importante centro de controle GABAérgico não somente para o complexo VTA/SNC, como também um importante intermediário entre LHb e DR. Uma comparação da organização das projeções da LHb para a VTA e o DR revela semelhanças entre projeções diretas para ambos, bem como importantes diferenças na projeção do RMTg para os mesmos. Assim, tanto a VTA (BRINSCHWITZ et al., 2010; GONÇALVES; SEGO; MTEZGER, 2012; OMELCHENKO; BELL; SESACK, 2009) quanto o DR (atuais achados; ARAKI; MCGEER; KIMURA, 1988; HERKENHAM; NAUTA, 1979; KIM, 2009) recebem projeções menores diretamente da LHb, que por sinal emergem em de populações neuronais separadas na LHbM (BERNARD; VEH, 2012; achados atuais). Comparando projeções do RMTg para a VTA e DR, observam-se diferenças importantes. O RMTg inerva densamente de uma maneira homogênea todo o complexo VTA-SNC, inclusive o RRF (achados atuais; FERREIRA et al., 2008; JHOU et al., 2009a). Além disso, estudos ultra-estruturais revelaram que a maioria das sinapses formados por axônios do RMTg na VTA e SNC são apostos em dendritos imunorreativos para a TH (BALCITA-PEDICINO et al., 2011; BARROT et al., 2012), sugerindo fortemente que a influência inibitória do RMTg seja mediada diretamente em neurônios dopaminérgicos. Em contraste, mostramos aqui que as projeções do RMTg para o DR não são homogêneas, a maioria sendo focalmente direcionada para o DRDCe, onde a maioria dos neurônios possui fenótipo glutamatérgico. Devido à novidade de nossos achados, podemos apenas especular sobre a função desta densa projeção RMTg-DRDCe.

Tanto o DRC quanto o DRD (sem distinguir entre suas subdivisões) foram identificados como componentes importantes de circuitos relacionados a estresse e 
ansiedade (para revisões, veja LOWRY et al., 2008; HALE; LOWRY, 2011; HALE; SHEKHAR; LOWRY, 2012). Consistente com esta visão, ambas são especificamente interconectados com estruturas chave envolvidas na regulação de comportamentos emotivas, a saber, o PFC, BNST, amígdala, áreas pré-opticas medial e lateral, LH e VLPAG (GONÇALVES et al., 2009; LEE et al., 2007; PEYRON et al., 1998). A maioria destas projeções é recíproca (por exemplo, COMMONS, CONNOLLEY e VALENTINO, 2003; VERTES, 1991). O DRC possui conexões semelhantes, porém mais restritas, com as mesmas estruturas, recebe projeções focais do LHbM (nossos achados) e envia projeções maciças para o septo lateral (VERTES, 1991; WASELUS et al., 2006) e o sistema ventricular (MIKKELSEN; HAY-SCHMIDT; LARSEN, 1997). Interessantemente, uma série de estudos mostrou que o DRC e a LHb são juntamente envolvidos na resposta neuroquímica e comportamental ao estresse inescapável (AMAT et al., 2001; GRAHN et al., 1999; MASWOOD et al., 1998). Dado que a LHbM é preferencialmente ativada por diferentes formas de estresse (BROWN; SHEPARD, 2013; CHASTRETTE; PFAFF; GIBBS, 1991; WIRTSHAFTER; ASIN; PITZER, 1994) e que neurônios da LHb são predominantemente glutamatérgicos (AIZAWA et al., 2012; BRINSCHWITZ et al., 2010), é altamente sugestivo que as projeções diretas da LHbM para o DRC sejam responsáveis por estes efeitos, através de uma excitação monosináptica (por exemplo, FERRARO et al., 1997).

Por outro lado, foi demonstrado por diferentes grupos que a estimulação elétrica da LHb suprime profundamente a atividade espontânea de neurônios do DR (FERRARO et al., 1996; PARK, 1987; STERN, 1979, 1981; WANG; AGHAJANIAN, 1977). É tentadora especular que tal inibição seja mediada pelo RMTg. No entanto, dado que grande parte das eferências do RMTg seja direcionada para neurônios VGLUT3+ do DRDCe, a forma pela qual este efeito sobre a transmissão serotonérgica é efetuada permanece um enigma. Uma possibilidade é que os neurônios VGLUT3+ do DRDCe possam influenciar neurônios serotonérgicos em outras sub-regiões através de colaterais axonais. Neste sentido, foi demonstrado que axônios VGLUT3+ são frequentemente apostos a neurônios serotonérgicos do DR (SOIZA-REILLY e COMMONS, 2011) e que a maioria das projeções intrínsecas possa ter origem em neurônios VGLUT3+ do DRD que expressam a neurocinina 1, 0 
receptor da substancia P (COMMONS, 2009; VALENTINO et al., 2003; veja também LACOSTE et al., 2009). Outra possibilidade é que as projeções moderadas do RMTg para outras subdivisões do DR aqui demonstradas sejam suficientes para promover esta influência inibitória.

Evidências obtidas em ratos submetidos à depleção de neurônios serotonérgicos indicam que muitos neurônios VGLUT3+ no DRD são neurônios de projeção que inervam alvos como a área pré-óptica, o hipotálamo anterior, a VTA e o SNC (HALBERSTADT; BALABAN, 2008; HIOKI et al., 2010). Nossos achados de rastreamento retrógrado indicam que neurônios VGLUT3+ e VGLUT3+/5-HT+ no DRDCe contribuem substancialmente para as projeções do DR para a VTA (LIMA; GONÇALVES; METZGER, 2012) e enviam uma projeção robusta para a SNC (nossos achados não publicados). Assim, dado que o DRD é fortemente interconectado com estruturas envolvidas na regulação de comportamentos emotivos, o DRDCe pode ser um importante elo modulatório entre estas e o complexo VTA/SNC.

Uma teoria unificada da função da LHb propõe que seu sinal indica uma ação com consequências aversivas e que deve ser suprimida (HIKOSAKA, 2010). Foi recentemente demonstrado que a ativação optogenética de terminais da $\mathrm{LHb}$ no RMTg promove esquiva ativa, passiva e condicionada (STAMATAKIS; STUBER, 2012). Nossos achados, junto com dados anteriores (LAVEZZI; PARSLEY; ZAHM, 2012) sugerem que o circuito LHb-RMTg seja importante no controle de neurônios do complexo VTA/SNC, bem como do DR. Um papel para a LHb como acoplador funcional dos sistemas dopaminérgicos e serotonérgicos é fortemente sugerido por um estudo recente de neuroimagem funcional realizada em ratos com lesões unilaterais da SN (SOURANI et al., 2012). Quando estes animais foram sujeitos a estressores específicos, houve uma diminuição da conectividade funcional entre núcleos da rafe e a LHb. O acoplamento funcional dos sistemas dopaminérgicos e serotonérgicos pelo RMTg e outros circuitos aqui discutidos pode ajudar a explicar os distúrbios da transmissão dopaminérgica responsáveis pelos sintomas psicomotores da depressão maior (BUYUKDURA; MCCLINTOCK; CROARKIN, 2011; SOBIN; 
SACKHEIM, 1997), bem como da transmissão serotonérgica nos sintomas afetivos do mal de Parkinson (LINDGREN; DUNNETT, 2012; TAN et al., 2011). 


\section{REFERÊNCIAS*}

ABRAMS, J. K. et al. Anatomic and functional topography of the dorsal raphe nucleus. Ann. N. Y. Acad. Sci., v. 1018, p. 46-57, 2004.

AGHAJANIAN, G. K.; WANG, R. Y. Habenular and other midbrain raphe afferents demonstrated by a modified retrograde tracing technique. Brain Res., v. 122, n. 2, p. 229-242, 1977.

AIZAWA, H. et al. Molecular characterization of the subnuclei in rat habenula. J. Comp. Neurol., v. 520, n. 18, p. 4051-4066, 2012.

AMAT, J. et al. The role of the habenular complex in the elevation of dorsal raphe nucleus serotonin and the changes in the behavioral responses produced by uncontrollable stress. Brain Res.., v. 917, n. 1, p. 118-126, 2001.

ANDRES, K. H.; VON DURING, M.; VEH, R. W. Subnuclear organization of the rat habenular complexes. J. Comp. Neurol., v. 407, n. 1, p. 130-150, 1999.

ARAKI, M.; MCGEER, P. L.; KIMURA, H. The efferent projections of the rat lateral habenular nucleus revealed by the PHA-L anterograde tracing method. Brain Res.., v. 441, n. 1-2, p. 319-330, 1988.

BAKER, K. G. et al. Cytoarchitecture of serotonin-synthesizing neurons in the pontine tegmentum of the human brain. Synapse, v. 7, n. 4, p. 301-320, Apr 1991.

BALCITA-PEDICINO, J. J. et al. The inhibitory influence of the lateral habenula on midbrain dopamine cells: ultrastructural evidence for indirect mediation via the rostromedial mesopontine tegmental nucleus. J. Comp. Neurol., v. 519, n. 6, p. 1143-1164, 2011.

BANG, S. J. et al. Projections and interconnections of genetically defined serotonin neurons in mice. Eur. J. Neurosci., v. 35, n. 1, p. 85-96, 2012.

BEHZADI, G. et al. Afferents to the median raphe nucleus of the rat: retrograde cholera toxin and wheat germ conjugated horseradish peroxidase tracing, and selective D-[3H]aspartate labelling of possible excitatory amino acid inputs. Neuroscience, v. 37, n. 1, p. 77-100, 1990.

\footnotetext{
* De acordo com: ASSOCIAÇÃO BRASILEIRA DE NORMAS TÉCNICAS. NBR 6023: informação e documentação: referências: elaboração. Rio de Janeiro, 2002.
} 
BERNARD, R.; VEH, R. W. Individual neurons in the rat lateral habenular complex project mostly to the dopaminergic ventral tegmental area or to the serotonergic raphe nuclei. J. Comp. Neurol., v. 520, n. 11, p. 2545-2558, 2012.

BOURDY, R.; BARROT, M. A new control center for dopaminergic systems: pulling the VTA by the tail. Trends Neurosci., v. 35, n. 11, p. 681-690, 2012.

BRAZ, J. M.; ENQUIST, L. W.; BASBAUM, A. I. Inputs to serotonergic neurons revealed by conditional viral transneuronal tracing. J. Comp. Neurol., v. 514, n. 2, p. 145-160, 2009.

BRINSCHWITZ, K. et al. Glutamatergic axons from the lateral habenula mainly terminate on GABAergic neurons of the ventral midbrain. Neuroscience, v. 168, n. 2, p. 463-476, 2010.

BRODERICK, P. A.; PHELIX, C. F. I. Serotonin (5-HT) within dopamine reward circuits signals open-field behavior. II. Basis for 5-HT--DA interaction in cocaine dysfunctional behavior. Neurosci. Biobehav. Rev., v. 21, n. 3, p. 227-260, 1997.

BROG, J. S. et al. The patterns of afferent innervation of the core and shell in the "accumbens" part of the rat ventral striatum: immunohistochemical detection of retrogradely transported fluoro-gold. J. Comp. Neurol., v. 338, n. 2, p. 255-278, 1993.

BROMBERG-MARTIN, E. S.; HIKOSAKA, O. Lateral habenula neurons signal errors in the prediction of reward information. Nat. Neurosci., v. 14, n. 9, p. 1209-1216, 2011.

BROMBERG-MARTIN, E. S.; MATSUMOTO, M.; HIKOSAKA, O. Distinct tonic and phasic anticipatory activity in lateral habenula and dopamine neurons. Neuron, v. 67, n. 1, p. 144-155, 2010.

CALIZO, L. $\mathrm{H}$. et al. Raphe serotonin neurons are not homogenous: electrophysiological, morphological and neurochemical evidence. Neuropharmacology, v. 61, n. 3, p. 524-543, 2011.

CHARARA, A.; PARENT, A. Chemoarchitecture of the primate dorsal raphe nucleus. J. Chem. Neuroanat., v. 15, n. 2, p. 111-127, 1998.

CHASTRETTE, N.; PFAFF, D. W.; GIBBS, R. B. Effects of daytime and nighttime stress on Fos-like immunoreactivity in the paraventricular nucleus of the hypothalamus, the habenula, and the posterior paraventricular nucleus of the thalamus. Brain Res., v. 563, n. 1-2, p. 339-344, 1991.

CHEN, S.; ASTON-JONES, G. Evidence that cholera toxin B subunit (CTb) can be avidly taken up and transported by fibers of passage. Brain Res., v. 674, n. 1, p. 107$111,1995$. 
CLIFFER, K. D.; GIESLER, G. J., JR. PHA-L can be transported anterogradely through fibers of passage. Brain Res., v. 458, n. 1, p. 185-191, 1988.

COMMONS, K. G. Locally collateralizing glutamate neurons in the dorsal raphe nucleus responsive to substance $P$ contain vesicular glutamate transporter 3 (VGLUT3). J. Chem. Neuroanat., v. 38, n. 4, p. 273-281, 2009.

COMMONS, K. G.; CONNOLLEY, K. R.; VALENTINO, R. J. A neurochemically distinct dorsal raphe-limbic circuit with a potential role in affective disorders. Neuropsychopharmacology, v. 28, n. 2, p. 206-215, 2003.

CONCHA, M. L.; WILSON, S. W. Asymmetry in the epithalamus of vertebrates. J. Anat., v. 199, n. Pt 1-2, p. 63-84, 2001.

COOLS, R.; ROBINSON, O. J.; SAHAKIAN, B. Acute tryptophan depletion in healthy volunteers enhances punishment prediction but does not affect reward prediction. Neuropsychopharmacology, v. 33, n. 9, p. 2291-2299, 2008.

CORNWALL, J.; COOPER, J. D.; PHILLIPSON, O. T. Afferent and efferent connections of the laterodorsal tegmental nucleus in the rat. Brain Res. Bull, v. 25, n. 2, p. 271-284,1990.

CRAWFORD, L. K.; CRAIGE, C. P.; BECK, S. G. Glutamatergic input is selectively increased in dorsal raphe subfield 5-HT neurons: role of morphology, topography and selective innervation. Eur. J. of Neurosci., v. 34, n. 11, p. 1794-1806, Dec 2011.

DADO, R. J. et al. Evidence that Fluoro-Gold can be transported avidly through fibers of passage. Brain Res., v. 533, n. 2, p. 329-333, 1990.

DAHLSTROEM, A.; FUXE, K. Evidence for the existence of monoamine-containing neurons in the central nervous system. i. demonstration of monoamines in the cell bodies of brain stem neurons. Acta Physiol. Scand. Suppl., v. 232, p. 1-55, 1964.

DAW, N. D.; KAKADE, S.; DAYAN, P. Opponent interactions between serotonin and dopamine. Neural Netw., v. 15, n. 4-6, p. 603-616, 2002.

DAY, H. E. W. et al. Differential expression of $5 \mathrm{HT}-1 \mathrm{~A}$, alpha(1b) adrenergic, CRF$\mathrm{R} 1$, and CRF-R2 receptor mRNA in serotonergic, gamma-aminobutyric acidergic, and catecholaminergic cells of the rat dorsal raphe nucleus. J. Comp. Neurol., v. 474, n. 3, p. 364-378, 2004.

DESCARRIES, L. et al. The serotonin neurons in nucleus raphe dorsalis of adult rat: a light and electron microscope radioautographic study. J. Comp. Neurol., v. 207, n. 3, p. 239-254, 1982.

$\mathrm{DEUTCH}, \mathrm{A}$. Y. et al. Telencephalic projections of the A8 dopamine cell group. Ann. 
N. Y. Acad. Sci., v. 537, p. 27-50, 1988.

FERREIRA, J. G. et al. Organization of ventral tegmental area projections to the ventral tegmental area-nigral complex in the rat. Neuroscience, v. 153, n. 1, p. 196213, 2008.

FREMEAU, R. T., JR. et al. The expression of vesicular glutamate transporters defines two classes of excitatory synapse. Neuron, v. 31, n. 2, p. 247-60, 2001.

al. Chemical neuroanatomy of the dorsal raphe nucleus and adjacent structures of the mouse brain. J. Comp. Neurol., v. 518, n. 17, p. 3464-94, 2010.

GAHR, M. How should brain nuclei be delineated? Consequences for developmental mechanisms and for correlations of area size, neuron numbers and functions of brain nuclei. Trends Neurosci, v. 20, n. 2, p. 58-62, 1997.

GAO, D. M.; HOFFMAN, D.; BENABID, A. L. Simultaneous recording of spontaneous activities and nociceptive responses from neurons in the pars compacta of substantia nigra and in the lateral habenula. Eur. J. Neurosci., v. 8, n. 7, p. 1474-8, Jul 1996.

GEISLER, S.; ANDRES, K. H.; VEH, R. W. Morphologic and cytochemical criteria for the identification and delineation of individual subnuclei within the lateral habenular complex of the rat. J. Comp. Neurol., v. 458, n. 1, p. 78-97, 2003.

GERFEN, C. R.; SAWCHENKO, P. E. An anterograde neuroanatomical tracing method that shows the detailed morphology of neurons, their axons and terminals immunohistochemical localization of an axonally transported plant lectin, phaseolusvulgaris leukoagglutinin (Pha-L). Brain Research, v. 290, n. 2, p. 219-238, 1984.

GERVASONI, D. et al. Role and origin of the GABAergic innervation of dorsal raphe serotonergic neurons. J Neurosci, v. 20, n. 11, p. 4217-4225, 2000.

GONCALVES, L. et al. Prefrontal afferents to the dorsal raphe nucleus in the rat. Brain Res. Bull, v. 78, n. 4-5, p. 240-247, Mar 162009.

GONCALVES, L.; SEGO, C.; METZGER, M. Differential projections from the lateral habenula to the rostromedial tegmental nucleus and ventral tegmental area in the rat. J. Comp. Neurol., v. 520, n. 6, p. 1278-300, 2012.

GOTTESFELD, Z. Origin and distribution of noradrenergic innervation in the habenula: a neurochemical study. Brain Res., v. 275, n. 2, p. 299-304, 1983.

GRAHN, R. E. et al. Activation of serotonin-immunoreactive cells in the dorsal raphe nucleus in rats exposed to an uncontrollable stressor. Brain Res., v. 826, n. 1, p. 3543, 1999. 
GREATREX, R. M.; PHILLIPSON, O. T. Demonstration of synaptic input from prefrontal cortex to the habenula i the rat. Brain Res., v. 238, n. 1, p. 192-197, 1982.

GREENWOOD, B. N. et al. Freewheel running prevents learned helplessness/behavioral depression: role of dorsal raphe serotonergic neurons. J. Neurosci., v. 23, n. 7, p. 2889-2898, 2003.

GROENEWEGEN, H. J.; WOUTERLOOD, F. G. Light and electron microscopic tracing of neuronal connections with Phaseolus vulgaris-leucoagglutinin (PHA-L), and combinations with other anatomical techniques. In: BJÖRKLUND, A.; HÖKFELT, T. (Ed.). Analysis of neuronal microcircuits and synaptic interactions: handbook of chemical neuroanatomy. Amsterdam: Elsevier, 1990. v. 8.

HALE, M. W.; LOWRY, C. A. Functional topography of midbrain and pontine serotonergic systems: implications for synaptic regulation of serotonergic circuits. Psychopharmacology (Berl), v. 213, n. 2-3, p. 243-264, 2011.

HALE, M. W.; SHEKHAR, A.; LOWRY, C. A. Stress-related serotonergic systems: implications for symptomatology of anxiety and affective disorders. Cell. Mol. Neurobiol., v. 32, n. 5, p. 695-708, Jul 2012.

HERKENHAM, M.; NAUTA, W. J. Efferent connections of the habenular nuclei in the rat. J. Comp. Neurol., v. 187, n. 1, p. 19-47, Sep 1979.

HERKENHAM, M.; NAUTA, W. J. H. Afferent Connections of Habenular Nuclei in Rat - Horseradish-Peroxidase Study, with a Note on Fiber-of-Passage Problem. J. Comp. Neurol., v. 173, n. 1, p. 123-145, 1977.

HIKOSAKA, O. Basal ganglia mechanisms of reward-oriented eye movement. Ann. N. Y. Acad. Sci., v. 1104, p. 229-249, 2007.

HIKOSAKA, O. The habenula: from stress evasion to value-based decision-making. Nat. Rev. Neurosci., v. 11, n. 7, p. 503-513, 2010

HIKOSAKA, O. et al. Habenula: crossroad between the basal ganglia and the limbic system. J. Neurosci., v. 28, n. 46, p. 11825-11829, 2008.

$\mathrm{HIOKI}, \mathrm{H}$. et al. Vesicular glutamate transporter 3-expressing nonserotonergic projection neurons constitute a subregion in the rat midbrain raphe nuclei. J. Comp. Neurol., v. 518, n. 5, p. 668-686, 2010.

HONDA, T.; SEMBA, K. Serotonergic synaptic input to cholinergic neurons in the rat mesopontine tegmentum. Brain Res., v. 647, n. 2, p. 299-306, 1994.

HONG, S. et al. Negative Reward Signals from the Lateral Habenula to Dopamine Neurons Are Mediated by Rostromedial Tegmental Nucleus in Primates. Journal of Neurosci., v. 31, n. 32, p. 11457-11471, 2011. 
HORNUNG, J. P. The Neuroanatomy of the Serotonergic System. In: MULLER, P. M. J. (Ed.). Handbook of behavioral neurobiology of serotonin: Elsevier BV, 2010.

JACOBS, B. L.; FORNAL, C. A. Activity of brain serotonergic neurons in the behaving animal .5. Pharmacological Reviews, v. 43, n. 4, p. 563-578, 1991.

JALABERT, $M$. et al. Neuronal circuits underlying acute morphine action on dopamine neurons. Proc. Natl. Acad. Sci. U S A, v. 108, n. 39, p. 16446-16450, 2011

JHOU, T. Neural mechanisms of freezing and passive aversive behaviors. J. Comp. Neurol., v. 493, n. 1, p. 111-114, 2005

JHOU, T. C. et al. The rostromedial tegmental nucleus (RMTg), a GABAergic afferent to midbrain dopamine neurons, encodes aversive stimuli and inhibits motor responses. Neuron, v. 61, n. 5, p. 786-800, 2009.

JHOU, T. C. et al. The mesopontine rostromedial tegmental nucleus: A structure targeted by the lateral habenula that projects to the ventral tegmental area of Tsai and substantia nigra compacta. J. Comp. Neurol., v. 513, n. 6, p. 566-596, 2009.

KALEN, P.; KARLSON, M.; WIKLUND, L. Possible excitatory amino acid afferents to nucleus raphe dorsalis of the rat investigated with retrograde wheat germ agglutinin and D-[3H]aspartate tracing. Brain Res., v. 360, n. 1-2, p. 285-297, 1985

KAUFLING, J. et al. Afferents to the GABAergic tail of the ventral tegmental area in the rat. J. Comp. Neurol., v. 513, n. 6, p. 597-621, 2009.

KAUFLING, J. gamma-Aminobutyric acid cells with cocaine-induced DeltaFosB in the ventral tegmental area innervate mesolimbic neurons. Biol Psychiatry, v. 67, n. 1, p. 88-92, 2010.

$\mathrm{KIM}$, U. Topographic commissural and descending projections of the habenula in the rat. J. Comp. Neurol., v. 513, n. 2, p. 173-187, 2009.

KIRBY, L. G.; ALLEN, A. R.; LUCKI, I. Regional Differences in the Effects of Forced Swimming on Extracellular Levels of 5-Hydroxytryptamine and 5-Hydroxyindoleacetic Acid. Brain Res., v. 682, n. 1-2, p. 189-196, 1995.

KIROUAC, G. J.; LI, S.; MABROUK, G. GABAergic projection from the ventral tegmental area and substantia nigra to the periaqueductal gray region and the dorsal raphe nucleus. J. Comp. Neurol., v. 469, n. 2, p. 170-184, 2004.

LAVEZZI, H. N.; PARSLEY, K. P.; ZAHM, D. S. Mesopontine rostromedial tegmental nucleus neurons projecting to the dorsal raphe and pedunculopontine tegmental nucleus: psychostimulant-elicited Fos expression and collateralization. Brain Struct. 
Funct., v. 217, n. 3, p. 719-734, 2012

LAVEZZI, H. N.; ZAHM, D. S. The mesopontine rostromedial tegmental nucleus: an integrative modulator of the reward system. Basal Ganglia, v. 1, n. 4, p. 191-200, 2011.

LAVOIE, B.; PARENT, A. Pedunculopontine nucleus in the squirrel monkey: cholinergic and glutamatergic projections to the substantia nigra. J. Comp. Neurol., v. 344, n. 2, p. 232-241, 1994.

LECCA, S. et al. Effects of drugs of abuse on putative rostromedial tegmental neurons, inhibitory afferents to midbrain dopamine cells. Neuropsychopharmacology, v. 36, n. 3, p. 589-602, 2011.

LECCA, S. et al. Inhibitory inputs from rostromedial tegmental neurons regulate spontaneous activity of midbrain dopamine cells and their responses to drugs of abuse. Neuropsychopharmacology, v. 37, n. 5, p. 1164-1176, 2012.

LECOURTIER, L.; KELLY, P. H. Bilateral lesions of the habenula induce attentional disturbances in rats. Neuropsychopharmacology, v. 30, n. 3, p. 484-496, 2005.

LECOURTIER, L.; KELLY, P. H. A conductor hidden in the orchestra? Role of the habenular complex in monoamine transmission and cognition. Neurosci. Biobehav. Rev., v. 31, n. 5, p. 658-672, 2007.

LEE, H. S. et al. Glutamatergic afferent projections to the dorsal raphe nucleus of the rat. Brain Res., v. 963, n. 1-2, p. 57-71, 2003.

LIDOV, H. G.; MOLLIVER, M. E. An immunohistochemical study of serotonin neuron development in the rat: ascending pathways and terminal fields. Brain Res. Bull., v. 8, n. 4, p. 389-430, 1982.

LIMA, L. B. et al. Subnuclear origin and transmitter neurotype of dorsal raphe afferents to the ventral tegmental area in the rat. J. Neurosci. Abstracts, n. 38, p. 605-617, 2012.

LIU, Z. H.; IKEMOTO, S. The midbrain raphe nuclei mediate primary reinforcement via GABA(A) receptors. Eur. J. Neurosci., v. 25, n. 3, p. 735-743, 2007.

LUPPI, P. H. et al. Afferent-Projections to the Rat Locus-Coeruleus Demonstrated by Retrograde and Anterograde Tracing with Cholera-Toxin-B Subunit and PhaseolusVulgaris-Leukoagglutinin. Neuroscience, v. 65, n. 1, p. 119-160, 1995.

LUPPI, P. H.; FORT, P.; JOUVET, M. Iontophoretic Application of Unconjugated Cholera Toxin-B Subunit (Ctb) Combined with Immunohistochemistry of Neurochemical Substances - a Method for Transmitter Identification of Retrogradely Labeled Neurons. Brain Res., v. 534, n. 1-2, p. 209-224, 1990. 
MAIER, S. F.; GRAHN, R. E.; WATKINS, L. R. 8-OH-DPAT microinjected in the region of the dorsal raphe nucleus blocks and reverses the enhancement of fear conditioning and interference with escape produced by exposure to inescapable shock. Behav. Neurosci., v. 109, n. 3, p. 404-412, 1995

MAIER, S. F.; SELIGMAN, M. E. P. Learned Helplessness - Theory and Evidence. J. Exp. Psych.-General, v. 105, n. 1, p. 3-46, 1976.

MATSUMOTO, M.; HIKOSAKA, O. Negative motivational control of saccadic eye movement by the lateral habenula. Prog. Brain Res., v. 171, p. 399-402, 2008.

MENG, $H$. et al. Chronic deep brain stimulation of the lateral habenula nucleus in a rat model of depression. Brain Res., v. 1422, p. 32-38, 2011.

MICHELSEN, K. A.; SCHMITZ, C.; STEINBUSCH, H. W. The dorsal raphe nucleus-from silver stainings to a role in depression. Brain Res. Rev., v. 55, n. 2, p. 329-342, Oct 2007.

MORRIS, J. S. et al. Covariation of activity in habenula and dorsal raphe nuclei following tryptophan depletion. Neuroimage, v. 10, n. 2, p. 163-172, Aug 1999.

NAGAO, M. et al. Induction of c-Fos-like protein in the lateral habenular nucleus by persistent noxious peripheral stimulation. Neurosci. Lett., v. 151, n. 1, p. 37-40, Mar 51993.

NAKAMURA, K.; MATSUMOTO, M.; HIKOSAKA, O. Reward-dependent modulation of neuronal activity in the primate dorsal raphe nucleus. J. Neurosci., v. 28, n. 20, p. 5331-43, May 142008

NAUTA, W. J. Hippocampal projections and related neural pathways to the midbrain in the cat. Brain, v. 81, n. 3, p. 319-340, 1958.

OAKMAN, S. A. et al. Distribution of pontomesencephalic cholinergic neurons projecting to substantia nigra differs significantly from those projecting to ventral tegmental area. J Neurosci, v. 15, n. 9, p. 5859-5869, 1995

OMELCHENKO, N.; BELL, R.; SESACK, S. R. Lateral habenula projections to dopamine and GABA neurons in the rat ventral tegmental area. Eur. J. Neurosci., v. 30, n. 7, p. 1239-1250, 2009.

OMELCHENKO, N.; SESACK, S. R. Laterodorsal tegmental projections to identified cell populations in the rat ventral tegmental area. J. Comp. Neurol., v. 483, n. 2, p. 217-235, 2005.

OMELCHENKO, N.; SESACK, S. R.. Cholinergic axons in the rat ventral tegmental area synapse preferentially onto mesoaccumbens dopamine neurons. J. Comp. Neurol., v. 494, n. 6, p. 863-875, 2006. 
OMELCHENKO, N.; SESACK, S. R.. Periaqueductal gray afferents synapse onto dopamine and GABA neurons in the rat ventral tegmental area. Journal of Neurosci. Research, v. 88, n. 5, p. 981-991, 2010.

PARENT, A.; GRAVEL, S.; BOUCHER, R. The origin of forebrain afferents to the habenula in rat, cat and monkey. Brain Res. Bull, v. 6, n. 1, p. 23-38, 1981.

PARENT, A.; STERIADE, M. Afferents from the periaqueductal gray, medial hypothalamus and medial thalamus to the midbrain reticular core. Brain Res. Bull, v. 7, n. 4, p. 411-418, 1981

PARENT, M.; LEVESQUE, M.; PARENT, A. Two types of projection neurons in the internal pallidum of primates: single-axon tracing and three-dimensional reconstruction. J. Comp. Neurol., v. 439, n. 2, p. 162-175, 2001.

PASQUIER, D. A. et al. Dorsal raphe, substantia nigra and locus coeruleus: interconnections with each other and the neostriatum. Brain Res. Bull., v. 2, n. 5, p. 323-339, 1977

PAXINOS, G. W. C. The rat brain in stereotaxic coordinates. San Diego: Elsevier, 2007.

PERROTTI, L. I. et al. DeltaFosB accumulates in a GABAergic cell population in the posterior tail of the ventral tegmental area after psychostimulant treatment. Eur. J. Neurosci., v. 21, n. 10, p. 2817-2824, 2005.

PEYRON, C. et al. Lower brainstem catecholamine afferents to the rat dorsal raphe nucleus. J. Comp. Neurol., v. 364, n. 3, p. 402-413, 1996.

PEYRON, C. et al. Origin of the dopaminergic innervation of the rat dorsal raphe nucleus. Neuroreport, v. 6, n. 18, p. 2527-2531, 1995.

PEYRON, C. et al. Forebrain afferents to the rat dorsal raphe nucleus demonstrated by retrograde and anterograde tracing methods. Neurosci., v. 82 , n. 2, p. 443-468, 1998.

PHILLIPSON, O. T.; PYCOCK, C. J. Dopamine neurones of the ventral tegmentum project to both medial and lateral habenula. Some implications for habenular function. Exp. Brain Res., v. 45, n. 1-2, p. 89-94, 1982.

PINEYRO, G.; BLIER, P. Autoregulation of serotonin neurons: role in antidepressant drug action. Pharmacol. Rev., v. 51, n. 3, p. 533-591, 1999.

POLLER, W. C. et al. Lateral Habenular Neurons Projecting to Reward-Processing Monoaminergic Nuclei Express Hyperpolarization-Activated Cyclic Nucleotid-Gated Cation Channels. Neuroscience, v. 193, p. 205-216, 2011. 
PUJOL, J. F. et al. The serotonin connection: some evidence for a specific metabolic organization. Adv. Exp. Med. Biol., v. 133, p. 417-29, 1981.

SARTORIUS, A.; HENN, F. A. Deep brain stimulation of the lateral habenula in treatment resistant major depression. Med. Hypotheses, v. 69, n. 6, p. 1305-8, 2007

SCHAFER, M. K. et al. Molecular cloning and functional identification of mouse vesicular glutamate transporter 3 and its expression in subsets of novel excitatory neurons. J. Biol. Chem., v. 277, n. 52, p. 50734-50748, 2002.

SCHULTZ, W. Predictive reward signal of dopamine neurons. (vol 80, pg 1, 1998). J. Neurophys., v. 80, n. 6, p. U32-U32, 1998

SCHULTZ, W. Behavioral dopamine signals. Trends Neurosci., v. 30, n. 5, p. 20310, 2007.

SCHWEIMER, J. V.; UNGLESS, M. A. Phasic responses in dorsal raphe serotonin neurons to noxious stimuli. Neuroscience, v. 171, n. 4, p. 1209-1215, 2010.

SELIGMAN, M. E.; MAIER, S. F. Failure to escape traumatic shock. J. Exp. Psychol., v. 74, n. 1, p. 1-9, 1967.

SEMBA, K.; FIBIGER, H. C. Afferent connections of the laterodorsal and the pedunculopontine tegmental nuclei in the rat: a retro- and antero-grade transport and immunohistochemical study. J. Comp. Neurol., v. 323, n. 3, p. 387-410, 1992.

SHAMMAH-LAGNADO, S. J.; SANTIAGO, A. C. Projections of the amygdalopiriform transition area (APir) - A PHA-L study in the rat. Advancing from the Ventral Striatum to the Extended Amygdala, v. 877, p. 655-660, 1999.

SHEPARD, P. D.; HOLCOMB, H. H.; GOLD, J. M. Schizophrenia in translation: the presence of absence: habenular regulation of dopamine neurons and the encoding of negative outcomes. Schizophr. Bull., v. 32, n. 3, p. 417-421, 2006.

SHIKANAI, $H$. et al. Distinct neurochemical and functional properties of GAD67containing 5-HT neurons in the rat dorsal raphe nucleus. J. Neurosci., v. 32, n. 41, p. 14415-14426, 2012.

SHIN, R.; IKEMOTO, S. The GABAB receptor agonist baclofen administered into the median and dorsal raphe nuclei is rewarding as shown by intracranial selfadministration and conditioned place preference in rats. Psychopharmacology (Berl.), v. 208, n. 4, p. 545-554, 2010.

SHUMAKE, J.; EDWARDS, E.; GONZALEZ-LIMA, F. Opposite metabolic changes in the habenula and ventral tegmental area of a genetic model of helpless behavior. Brain Res., v. 963, n. 1-2, p. 274-281, 2003. 
SICA, A. L. et al. Chronic-intermittent hypoxia induces immediate early gene expression in the midline thalamus and epithalamus. Brain Res., v. 883, n. 2, p. 224228, 2000.

SINGEWALD, N.; SALCHNER, P.; SHARP, T. Induction of c-Fos expression in specific areas of the fear circuitry in rat forebrain by anxiogenic drugs. Biol. Psychiatry, v. 53, n. 4, p. 275-283, 2003.

SKAGERBERG, G.; LINDVALL, O.; BJORKLUND, A. Origin, course and termination of the mesohabenular dopamine pathway in the rat. Brain Res., v. 307, n. 1-2, p. 99108, 1984.

SMITH, K. A.; FAIRBURN, C. G.; COWEN, P. J. Relapse of depression after rapid depletion of tryptophan. Lancet, v. 349, n. 9056, p. 915-919, 1997.

SOIZA-REILLY, M.; COMMONS, K. G. Glutamatergic drive of the dorsal raphe nucleus. J. Chem. Neuroanat., v. 41, n. 4, p. 247-255, 2011.

STAMATAKIS, A. M.; STUBER, G. D. Activation of lateral habenula inputs to the ventral midbrain promotes behavioral avoidance. Nat. Neurosci., v. 15, n. 8, p. 1105, 2012.

STEINBUSCH, H. W. Distribution of serotonin-immunoreactivity in the central nervous system of the rat-cell bodies and terminals. Neuroscience, v. 6, n. 4, p. 557-618, 1981.

STEININGER, T. L.; RYE, D. B.; WAINER, B. H. Afferent-Projections to the Cholinergic Pedunculopontine Tegmental Nucleus and Adjacent Midbrain Extrapyramidal Area in the Albino-Rat .1. Retrograde Tracing Studies. J. Comp. Neurol., v. 321, n. 4, p. 515-543, 1992.

SUTHERLAND, R. J. The dorsal diencephalic conduction system: a review of the anatomy and functions of the habenular complex. Neurosci. Biobehav. Rev., v. 6, n. 1, p. 1-13, 1982.

THIEBOT, M. H.; HAMON, M.; SOUBRIE, P. The involvement of nigral serotonin innervation in the control of punishment-induced behavioral inhibition in rats. Pharmacol Biochem Behav, v. 19, n. 2, p. 225-229, 1983.

THORNTON, E. W.; EVANS, J. A.; HARRIS, C. Attenuated response to nomifensine in rats during a swim test following lesion of the habenula complex. Psychopharmacology (Berl), v. 87, n. 1, p. 81-85, 1985.

ULLSPERGER, M.; VON CRAMON, D. Y. Error monitoring using external feedback: specific roles of the habenular complex, the reward system, and the cingulate motor area revealed by functional magnetic resonance imaging. J. Neurosci., v. 23, n. 10, 
p. 4308-4314, 2003.

VAN BOCKSTAELE, E. J.; CESTARI, D. M.; PICKEL, V. M. Synaptic structure and connectivity of serotonin terminals in the ventral tegmental area: potential sites for modulation of mesolimbic dopamine neurons. Brain Res., v. 647, n. 2, p. 307-322, 1994.

VAROQUI, $\mathrm{H}$. et al. Identification of the differentiation-associated $\mathrm{Na}+\mathrm{PI}$ transporter as a novel vesicular glutamate transporter expressed in a distinct set of glutamatergic synapses. J. Neurosci., v. 22, n. 1, p. 142-155, 2002.

VASUDEVA, R. K. et al. Functional organization of the dorsal raphe efferent system with special consideration of nitrergic cell groups. J. Chem. Neuroanat., v. 41, n. 4, p. 281-293, 2011.

VERTES, R. P. A PHA-L analysis of ascending projections of the dorsal raphe nucleus in the rat. J. Comp. Neurol., v. 313, n. 4, p. 643-668, 1991.

VERTES, R. P.; KOCSIS, B. Projections of the dorsal raphe nucleus to the brainstem: PHA-L analysis in the rat. J. Comp. Neurol., v. 340, n. 1, p. 11-26, 1994.

WANG HL, et al. Dorsal raphe excitatory drive on VTA dopamine neurons. Soc. Neurosci. Abstracts, n. 38, p. 361-406, 2012.

WANG, R. Y.; AGHAJANIAN, G. K. Physiological evidence for habenula as major link between forebrain and midbrain raphe. Science, v. 197, n. 4298, p. 89-91, 1977.

YANG, L. M. et al. Lateral habenula lesions improve the behavioral response in depressed rats via increasing the serotonin level in dorsal raphe nucleus. Behav. Brain Res., v. 188, n. 1, p. 84-90, 2008.

ZAHM, D. S. et al. Inputs to the midbrain dopaminergic complex in the rat, with emphasis on extended amygdala-recipient sectors. J. Comp. Neurol., v. 519, n. 16, p. 3159-3188, 2011. 
The Journal of

Comparative Neurology

Fdt Acrount I Inthutions e forme I Log out I Get Holp vow

Hobotrch in Sfstoms whu ruscientre

SCHOLARONE

Manuscripts

Maln Nenu $\rightarrow$ Buthor Dashboard $\rightarrow$ Submisson Corlimaliun

You are logger in as Maitin Metzger

\title{
Submission
}

Confirmation

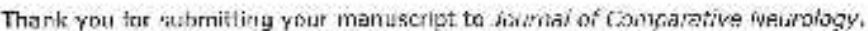

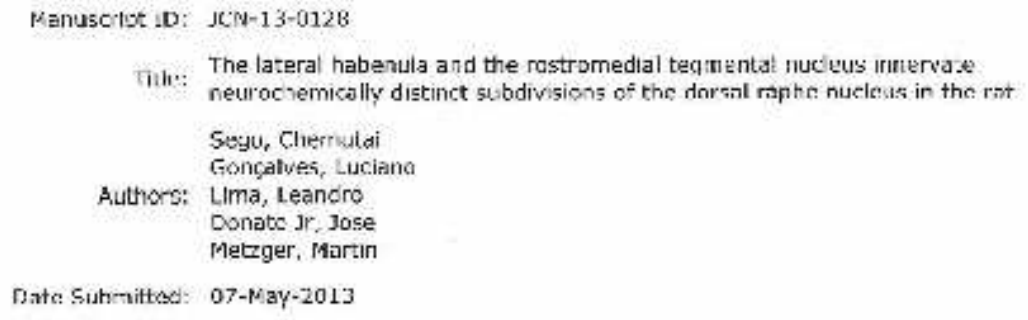

[2] Pnnt [2] Return to Dosinbourd

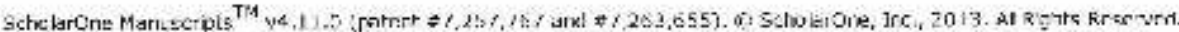

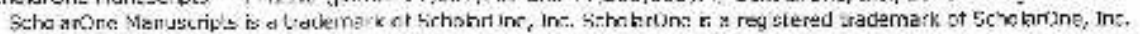

Foinw sronosion an I wilt:
\end{abstract}

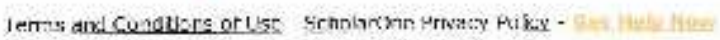

